José Vicente García Santamaría

$$
\text { Félix Pérez Bahón }
$$

(Universidad Carlos III de Madrid)

\title{
Los medios digitales españoles: procesos de cambio e innovación
}

Cuadernos Artesanos de Comunicación / 104

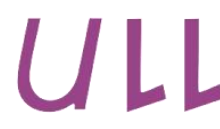

Universidad de La Laguna

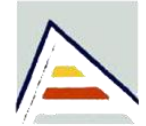

Universitat d'Alacant Universidad de Alicante
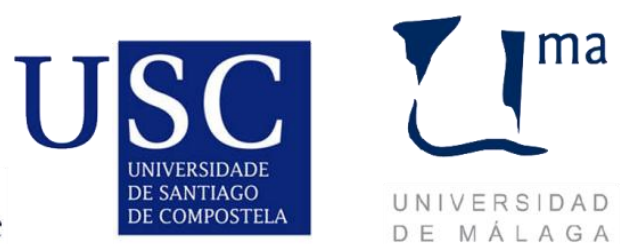

UNIVERSIDAD DE MÁLAGA

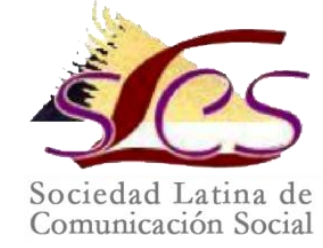




\section{Cuadernos Artesanos de Comunicación}

Coordinador editorial: José Manuel de Pablos [jpablos@ull.edu.es ]

Comité Científico

Presidencia: José Luis Piñuel Raigada (UCM)

Secretaría: Concha Mateos (URJC)

- Maricela López-Ornelas (Universidad Autónoma de Baja California, AUBC)

- Javier Marzal (Universidad Jaume I, UJI)

- José Antonio Meyer (Benemérita Universidad Autónoma de Puebla, BUAP)

- Ramón Reig (Universidad de Sevilla, US)

- Miquel Rodrigo Alsina (Universidad Pompeu Fabra, UPF)

- Xosé Soengas (Universidad de Santiago de Compostela, USC)

- José Luis Terrón (Universidad Autónoma de Barcelona, UAB)

- José Miguel Túñez (Universidad de Santiago, USC)

- Victoria Tur (Universidad de Alicante, UA)

- Miguel Vicente (Universidad de Valladolid, UVA)

- Ramón Zallo (Universidad del País Vasco, UPV-EHU)

- Núria Almiron (Universidad Pompeu Fabra, UPF)

- Francisco Campos Freire (Universidad de Santiago de Compostela, USC)

- José Cisneros (Benemérita Universidad Autónoma de Puebla, BUAP)

- Bernardo Díaz Nosty (Universidad de Málaga, UMA)

- Carlos Elías (Universidad Carlos III de Madrid, UC3M)

- Paulina B. Emanuelli (Universidad Nacional de Córdoba, UNC)

- José Luis González Esteban (Universitas Miguel Hernández de Elche, UMH)

- Marisa Humanes (Universidad Rey Juan Carlos, URJC)

- Juan José Igartua (Universidad de Salamanca, USAL)

-Octavio Islas (Universidad de los Hemisferios, Ecuador)

- Xosé López (Universalidad de Santiago de Compostela, USC)

* Queda expresamente autorizada la reproducción total o parcial de los textos publicados en este libro, en cualquier formato o soporte imaginables, salvo por explícita voluntad en contra del autor o autora o en caso de ediciones con ánimo de lucro. Las publicaciones donde se incluyan textos de esta publicación serán ediciones no comerciales y han de estar igualmente acogidas a Creative Commons. Harán constar esta licencia y el carácter no venal de la publicación.

\section{(ब) $(1 \otimes \Theta$} Atribución-No Comercial-Sin Derivadas 3.0 Unported. Puede ver una copia de esta licencia en http://creativecommons.org/licenses/by-nc-nd/3.0/ Esto significa que Ud. es libre de reproducir y distribuir esta obra, siempre que cite la autoría, que no se use con fines comerciales o lucrativos y que no haga ninguna obra derivada. Si quiere hacer alguna de las cosas que aparecen como no permitidas, contacte con los coordinadores del libro o con el autor del capítulo correspondiente. ${ }^{*}$ La responsabilidad de cada texto es de su autor o autora. 
José Vicente García Santamaría

Félix Pérez Bahón

(Coords.)

\section{Los medios digitales españoles: procesos de cambio e innovación}

Cuadernos Artesanos de Comunicación / 104

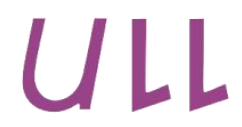

Universidad de La Laguna
Universitat d'Alacant Universidad de Alicante
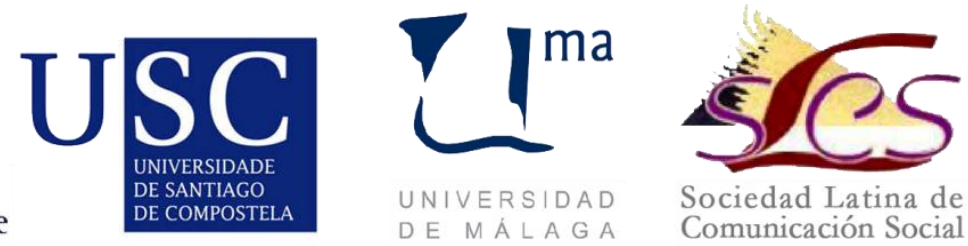
$104^{\circ}$ - Los medios digitales españoles: procesos de cambio e innovación José Vicente García Santamaría y Félix Pérez Bahón (Coords.)

Precio social: $7,95 € \mid$ Precio en librería: $10,35 € \mid$ Editores: Javier Herrero y Milena Trenta Diseño: F. Drago

Ilustración de portada: Fragmento del cuadro Mujer con bernegal, de Pedro de Guezala (1958).

Imprime y distribuye: F. Drago. Andocopias S. L. c/ La Hornera, 41. La Laguna. Tenerife.

Teléfono: 922250554 | fotocopiasdrago@telefonica.net

Edita: Sociedad Latina de Comunicación Social - edición no venal - La Laguna (Tenerife), 2016 - Creative Commons http://www.revistalatinacs.org/14SLCS/portada2014.html

Descargar en pdf:

http://www.cuadernosartesanos.org/\#104

Protocolo de envío de manuscritos http://www.cuadernosartesanos.org/protocolo.html

ISBN - 13: 978-84-16458-46-2

DL: TF-300-2016

DOI: $10.4185 / \mathrm{cac} 104$ 


\title{
Los medios digitales españoles: procesos de cambio e innovación
}

\author{
José Vicente García Santamaría y Félix Pérez Bahón \\ (Coords.) \\ Universidad Carlos III de Madrid (U3CM) \\ josevicente.garcia@hum.uc3m.es ; fpbahon@hum.uc3m \\ Publicado en abril de 2016
}

\begin{abstract}
Este cuaderno se sumerge, desde una perspectiva académica, en los procesos de innovación que están llevando a cabo los medios digitales españoles. El análisis lleva a observar cómo han cambiado los procesos de producción, distribución y recepción de la información. Con ellos se han transformado, casi de manera imperceptible, algunos paradigmas del oficio y, de manera muy notable, las bases del negocio periodístico. Los trabajos de campo se acercan a ejemplos prototípicos y proporcionan un amplio espectro sobre lo que está ocurriendo en este momento en el mercado digital y plantean la necesidad de una mayor investigación crítica del sector.
\end{abstract}

\section{Keywords}

Periodismo; ciberperiodismo; prensa digital; modelos de negocio periodísticos; ciberradio; transmedia, narrativas transmedia.

Forma de citar este libro

Nombre del autor o autora del capítulo (2016): “ $x x x$ ”. En García Santamaría, José Vicente, y Pérez Bahón, Félix (Coords.), (2016). Los medios digitales españoles: procesos de cambio e innovación. Col. Cuadernos Artesanos de Comunicación, 104. La Laguna (Tenerife): Latina. 


\section{Índice}

0. Introducción. ............................................

1. La crisis de la prensa escrita en España: algunas razones para su tardía transición digital.......................................11

2. El arranque de El Español o la dificultad de cumplir expectativas en el mercado mediático digital..........................................25

3 La Marea como modelo de negocio: nuevas formas de organización, financiación e innovación en el producto ........................55

4. Las revistas de nueva creación para tabletas impulsan el mercado editorial 'online' en España..........................................81

5. Publicidad digital: del retorno monetario de los soportes tradicionales al valor añadido de los medios sociales.................99

6. Innovación en radio y nuevo modelo de negocio. El caso de StreamRadio...............................................113

7. Los museos y el uso de las narrativas transmedia en las redes sociales................................................ 135

8. Las comunicaciones de marca digitales: hacia un modelo experiencial transmedia..................................... 153 


\section{0 \\ Introducción \\ José Vicente García Santamaría \\ Universidad Carlos III de Madrid \\ Félix Pérez Bahón \\ Universidad Carlos III de Madrid}

$\mathrm{E}$

STE Cuaderno se adentra, desde una perspectiva académica, en variados procesos de cambio e innovación que están llevando a cabo un buen número de medios digitales españoles, ya formen parte de grupos de comunicación o provengan de los denominados pure players o nativos digitales. Asimismo, el libro se ocupa de las transformaciones que han tenido lugar en el mercado de la publicidad digital; la radio corporativa; los museos y las comunicaciones de las marcas digitales con el uso de las narrativas transmedia.

En todos estos casos, la innovación ha sido sin duda un factor que ha recorrido los vértices de la financiación, la estructura y el propio producto, en un proceso convergente que ha dado como resultado no solamente nuevos modelos de negocio y financiación social de los media, sino también la utilización de nuevas estructuras narrativas.

El análisis lleva a observar también cómo han cambiado los procesos de producción, distribución y recepción de la información. Con ellos se han transformado, casi de manera imperceptible, algunos paradigmas del oficio y, de manera muy notable, las bases del negocio periodístico.

El Cuaderno comienza con un primer estudio de J. V. García Santamaría (Universidad Carlos III de Madrid), que pretende 
desentrañar las razones fundamentales por las que la prensa escrita en España $-\mathrm{y}$, fundamentalmente, los denominados diarios de referencia-, abordaron tardíamente su transición digital. $\mathrm{O}$, en otras palabras, por qué razón o razones unos diarios que, a finales del siglo XX, habían visto decaer su difusión no tomaron medidas al respecto cuando era evidente el agotamiento de este modelo de negocio y la necesidad de una urgente transformación digital.

Los capítulos siguientes, 2, 3 y 4 abordan interesantes case study o estudios de caso, como ejemplos en acción, sobre dos proyectos innovadores: El Español y La Marea, y el tercero, sobre las revistas de nueva creación para tablets.

Así, Félix Pérez Bahón (Universidad Carlos III), emprende un concienzudo análisis sobre el proyecto de El Español, el diario liderado por Pedro José Ramírez, y que ha constituido hasta el momento un éxito económico sin precedentes. La pormenorización de las diferentes etapas que abordó el diario antes de su lanzamiento y la propia gestación del proyecto serán un caso a seguir por venideros proyectos digitales.

Gema Alcolea (Universidad Rey Juan Carlos) y María José Pérez Serrano (Universidad Complutense) estudian el proyecto de La Marea desde la disciplina de la empresa informativa, y hacen gala de una profusión de datos. Como indican sus autoras, esta experiencia empresarial constituye un claro exponente de los nuevos modelos que emergen en la industria de la comunicación en la transición digital.

Juan Yunquera Nieto (Universidad Carlos III) aprovecha su larga experiencia y profundo conocimiento de los procesos de diseño periodístico para abordar el proceso de revistas de nueva creación para tablets como grandes impulsoras del mercado editorial on line en España.

Lidia Maestro Espínola (UNIR) desarrolla una pormenorizada explicación de la transformación operada en el sector publicitario, más necesitado de atención académica; sobre todo por los profundos 
cambios operados por la digitalización e Internet y el valor añadido aportado por las redes sociales.

Más centrados en otros territorios colindantes con las narrativas transmedia y la innovación radiofónica son los tres últimos capítulos de este volumen.

En primer lugar, se incluye una novedosa e interesante visión de la radio corporativa, con varios ejemplos de éxito, nacionales e internacionales. Se trata de las aportadas por Míriam Rodríguez Pallarés (Universidad Complutense), Dolores Rodríguez Barba (Universidad Complutense) y por Fernando Peinado Miguel (Universidad Complutense). StreamRadio, paradigma de la radio corporativa nacional, ofrece servicios de radio corporativa a empresas, organismos e instituciones, con la posibilidad de incorporar la creación de una plataforma de radio para dar a conocer sus productos y promociones, y en un contexto en el que la empresa radiofónica debe redefinir su actividad.

David Cordón Benito (UNIR) aporta su conocimiento de las instituciones museísticas para analizar las innovadoras iniciativas puestas en marcha desde hace unos años en la creación de narrativas específicas para redes sociales, sobre todo para twitter. Su autor escribe, por tanto, sobre el desarrollo de estas nuevas narrativas transmedia, cuyo objetivo inmediato es promover el conocimiento de estas instituciones y la participación ciudadana.

En el último capítulo del libro, María Galmés Cerezo (UNIR) traza una sugestiva visión sobre las innovaciones desarrolladas por muchas marcas al apelar a las experiencias de los consumidores mediante un modelo experiencial transmedia. La investigadora hace además un especial hincapié en el caso de los 'doodles', una apuesta innovadora de Google, que ha creado una atractiva propuesta de comunicación experiencial, tenida en cuenta por la autora del capítulo para desarrollar su investigación. 



\title{
La crisis de la prensa escrita en España: algunas razones para su tardía transición digital
}

\author{
José Vicente García Santamaría \\ Universidad Carlos III de Madrid
}

\begin{abstract}
Forma de citar este capítulo: García Santamaría, J.V (2016): "La crisis de la prensa escrita en España: algunas razones para su tardía transformación digital”, en García Santamaría, J.V. y Pérez Bahón, F. (coord.): Los medios digitales españoles: procesos de cambio e innovación. Cuadernos Artesanos de Comunicación, CAC104. La Laguna (Tenerife): Latina.
\end{abstract}

\section{Resumen}

Si bien los comienzos de la década de los noventa trajeron consigo un crecimiento considerable en la difusión de los diarios y, sobre todo, en los incrementos de la publicidad contratada, se observaron datos claros del estancamiento de las cifras de difusión a finales de esa misma década, e, incluso en el caso del diario Abc a partir de mediados de la misma década.

Parecía evidente que los diarios de referencia y sus grupos de comunicación deberían afrontar un azaroso tránsito digital. Sin embargo, y como los ingresos de la industria de los diarios siguió incrementándose hasta el comienzo de la crisis económica, una mayoría de los directivos de medios decidieron postergar procesos de desarrollos tecnológicos con procesos de digitalización pendientes. La consecuencia inmediata fue una tardía transición digital en la prensa española y un tardío ensayo de nuevos modelos de negocios en los que apoyarse para desarrollar otros proyectos editoriales.

Palabras clave: Periodismo, crisis de la prensa, prensa de referencia, medios digitales. 


\section{Introducción}

T OS orígenes de la crisis de la prensa se remontan a un período 1 muy anterior a la irrupción de Internet o a la recesión global de la economía mundial, con especial incidencia en España. Al menos desde la década de los años setenta del pasado siglo se han venido produciendo importantes movimientos que han devaluado el papel de la prensa. Primero fue la pérdida de la "calidad periodística", motivada por la formación de grandes conglomerados mediáticos que deseaban aprovechar las sinergias y economías de escala derivadas de estas concentraciones mediáticas. Al abaratamiento de costes le sucedió una maximización de los beneficios, pero a costa, en muchos casos, de despreocuparse del producto final y de los intereses de los lectores.

Una década más tarde, en los años ochenta, y como afirma Díaz Nosty (2011), la reconversión tecnológica de los medios impresos había propiciado una pérdida notable de puestos de trabajo que se cifraba en más de medio millón en todo el mundo. Los años noventa, que contemplaron la irrupción de Internet, fueron años de grandes cambios, si bien en España los grupos de comunicación con un fuerte anclaje regional y la casi totalidad de los diarios de referencia vivieron unos "años dorados", que les permitieron crecer en ingresos -incluso por encima de los dos dígitos anuales-, aunque a finales de la década la difusión -con datos de AEDE- parecía estancada.

No obstante, la urgente preocupación por los desarrollos tecnológicos; los profundos cambios introducidos por la llegada de Internet y, sobre todo, de la digitalización, y la búsqueda de modelos de negocio adaptados a la nueva situación, no parecieron una tarea urgente para una buena parte de los directivos de estos medios, que, fiados a la coyuntura de los resultados, hicieron caso omiso de las señalas de alarma de entonces. 


\section{Cuadro $\mathbf{N}^{\mathrm{o}} 1$}

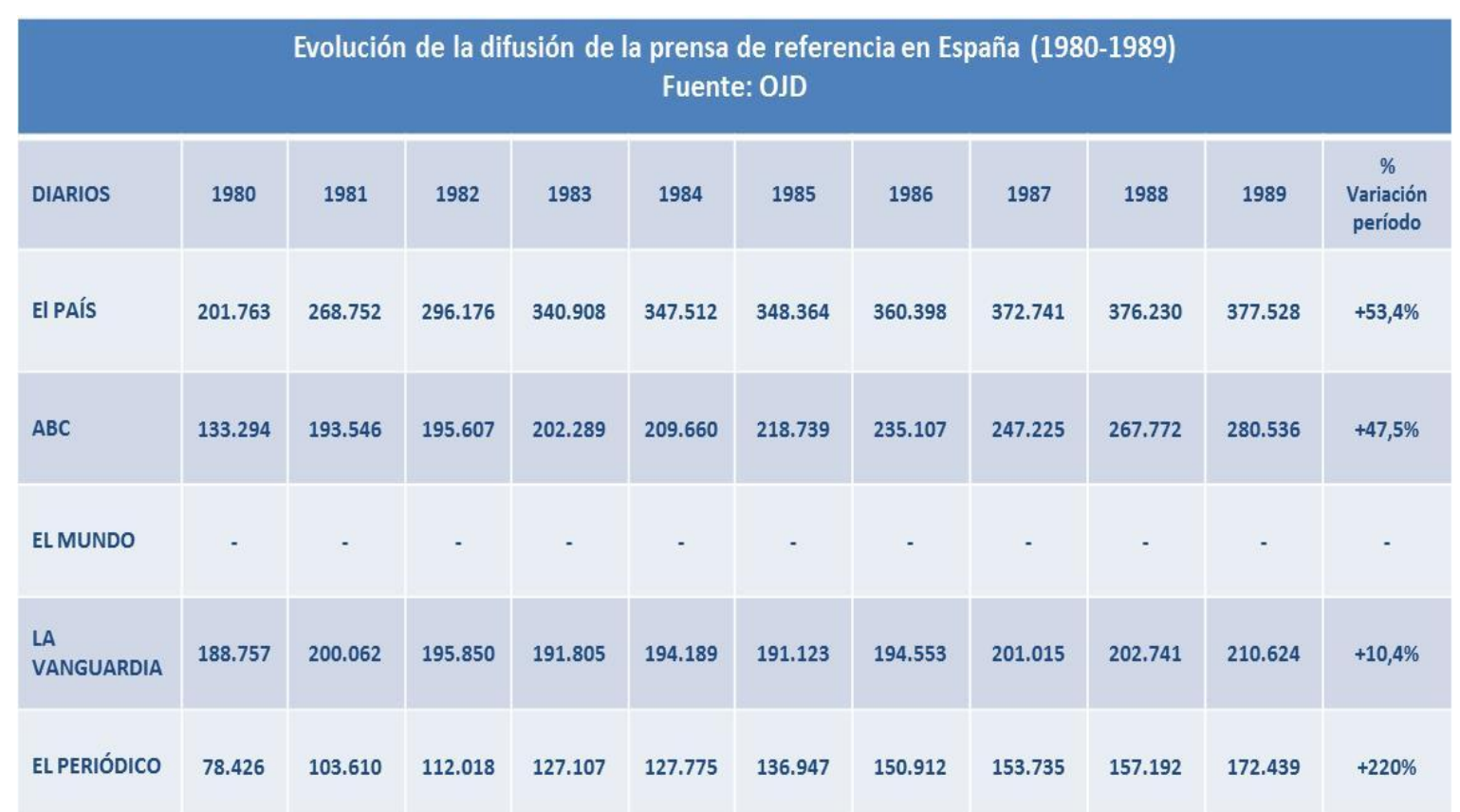

La crisis abarcó también los desarrollos económicos y tecnológicos, aunque en opinión de Larrañaga (2009), obedeció sobre todo a la confluencia de una crisis de modelo, surgido en las últimas décadas del siglo XX. Ramón Salaverría (2010) opinaba que los diarios adoptaron ante Internet una serie de políticas erráticas y no acertaron a encontrar en la red un modelo rentable. Bernard Poulet (2011) aludía también a la desestabilización completa de todos los medios de comunicación, y no solamente de la prensa, seguramente el primer y mayor damnificado.

La erosión de las bases del modelo tradicional sobre el que se asentaron los diarios llevó, sin duda, -como han descrito Casero y Domenech (2010) - al estancamiento, y consiguiente descenso, de la difusión de los diarios. Y el impacto de Internet, la carencia de una estrategia adecuada por parte de las empresas editoras y de los grupos de comunicación que los sustentaban y la desafección del público joven, que dejó de interesarse por la información que emanaba de sus ediciones, acabó por dibujar un panorama diferente. Por no mencionar otros componentes, como ha indicado el exdirector del diario Abc, José Antonio Zarzalejos (2015: 253), al referirse a "la 
promiscuidad entre el poder y los medios, sus editores y sus profesionales".

Pero también como ha señalado repetidamente Bernardo Díaz Nosty (2013: 15), esta crisis responde, en realidad, al "fruto de la inadaptación tecnológica de una industria vinculada a un soporte informativo y publicitario de altos rendimientos económicos que, después de una profunda reconversión tecnológica en los años setenta y ochenta del siglo XX, no supo liderar las oportunidades que abría Internet". Y podemos decir, que estas oportunidades que se le brindaban tenían relación tanto con las posibilidades de carácter tecnológico como de creación de contenidos o de periodismo en su modalidad más narrativa.

\section{La industria de los diarios en España}

Hasta que llegó la crisis económica la industria de los diarios de pago en España era una de las más importantes de Europa. A comienzos del siglo XXI, y según datos de la AEDE (2002), el volumen de negocio que generaba rondaba los 2.700 millones de euros, y se repartía casi de manera similar (datos del año 2002) entre la venta de ejemplares (48\%) y los ingresos netos (42,8\%), destacando muy especialmente el aumento de los ingresos de explotación, proporcionados por las promociones de pago de los periódicos (enciclopedias, DVD y gadgets varios); mientras que el beneficio neto suponía casi 170 millones de euros.

Dicho de otra manera, la conjunción entre las ventas de ejemplares, el éxito arrollador de algunas promociones y la contención de los gastos de explotación generaron un marco aparentemente muy "estable" para el sector de la prensa, que, sin embargo, no fue capaz de traspasar las fronteras de los años de la crisis (García Santamaría, 2014).

En cualquier caso, el dato positivo que hacía concebir esperanzas a algunos directivos y parecía contradecir una desestabilización completa del entramado periodístico, radicaba en el estado de las 
ventas anuales de diarios, que se mantenían a comienzos del siglo XXI por encima de los cuatro millones de ejemplares, con una difusión de 105 ejemplares por cada 1.000 habitantes (215 en la Unión Europea). Es más, como indicaba Consuelo Sánchez Vicente (2002), los años 1999 y 2000 fueron "años dorados", puesto que las cifras del sector fueron las mejores desde hacía años y el beneficio empresarial llegó a alcanzar 300 millones de euros. Ya en el año 1999, y con datos del Informe Anual de la Comunicación (1999-2000), la prensa diaria superaba los 2.400 millones de ingresos y en el año 2000 llegó hasta los 2.700 millones de euros, una vez que el precio de los ejemplares experimentase un incremento del 20 por ciento (García Santamaría, 2016).

\section{Cuadro $\mathbf{N}^{\circ} 2$}

\begin{tabular}{|c|c|c|c|c|c|c|c|c|c|c|c|}
\hline \multicolumn{12}{|c|}{$\begin{array}{l}\text { Evolución de la difusión de la prensa de referencia en España (1990-1999) } \\
\text { Fuente: OJD }\end{array}$} \\
\hline DIARIOS & 1990 & 1991 & 1992 & 1993 & 1994 & 1995 & 1996 & 1997 & 1998 & 1999 & $\begin{array}{l}\text { Variación } \% \\
\text { periodo }\end{array}$ \\
\hline EL PAís & 375.875 & 394.686 & 407.269 & 401.258 & 408.267 & 420.934 & 413.543 & 440.628 & 450.176 & 435.433 & $+13,7 \%$ \\
\hline$A B C$ & 290.517 & 292.631 & 304.098 & 334.317 & 321.571 & 321.573 & 303.019 & 301.054 & 302.013 & 293.013 & $+0.85 \%$ \\
\hline EL MUNDO & 104.001 & 131.626 & 173.766 & 209.992 & 268.748 & 307.618 & 260.616 & 284.519 & 272.299 & 285.303 & $+274,3 \%$ \\
\hline LA RAZÓN & - & - & - & - & - & - & - & - & - & 28.511 & - \\
\hline $\begin{array}{l}\text { LA } \\
\text { VANGUARDIA }\end{array}$ & s.d. & s.d. & 206.829 & 208.029 & 207.112 & 203.026 & 196.807 & 210.012 & 212.202 & 205.126 & $-0,80 \%$ \\
\hline EL PERIÓDICO & 171.439 & 171.995 & 180.992 & 185.517 & 193.576 & 215.581 & 210.793 & 207.772 & 208.070 & 209.123 & $+18,0 \%$ \\
\hline
\end{tabular}

Ahora bien, sin dejarnos por la euforia reinante entonces, y examinando a fondo las cuentas de los principales grupos mediáticos, llegaríamos a conclusiones muy diferentes. Por ejemplo, analizando la evolución del diario El País entre los años 1986 y 2014 (OJD, Noticias de la Comunicación, Fundación Telefónica) observaríamos como el diario comienza en 1986 con una difusión media de 360.398 ejemplares; alcanza la cota de los 400.000 (407.269) en el año 1992; llega en 1998 a 450.176, y a partir de este año su difusión media se estanca. Así, entre 1998 y 2003 se produce un descenso de la difusión para 
incrementarse en el año 2004 hasta los 469.1283 ejemplares, y, a continuación, el declive es pronunciado, bajando a los 391.816 ejemplares en el año 2009 y cerrando el año 2014 con 259.775 ejemplares.

Es decir, entre los años 1998 y 2014 el diario pierde nada menos que 190.041 ejemplares, un 42,2\%. El mismo caso se repite en otros diarios de referencia. $A b c$ conoce su mejor año en 1993 con 334.317 ejemplares y cierra el año 2014 con una difusión de 128.000 ejemplares; un descenso de más de doscientos mil ejemplares. Por su parte, El Mundo había alcanzado sus mejores registros en 1995 con 307.618 ejemplares, aunque llegase en el año 2005 a los 309.445 ejemplares. Y finalizó el año 2014 con 153.000 ejemplares, casi un $50 \%$ menos. Mientras que La Vanguardia, y al igual que El País, obtuvo sus mejores resultados en 1998 con 212.202 ejemplares, y llegó a los 140.000 en 2014 (-34\%). Y su colega barcelonés El Periódico llegó en 1995 a su máxima difusión con 307.618 ejemplares y cerró el año 2014 con 92.163 ejemplares, tres veces menos que en su mejor año.

\section{Cuadro $\mathbf{N}^{\circ} 3$}

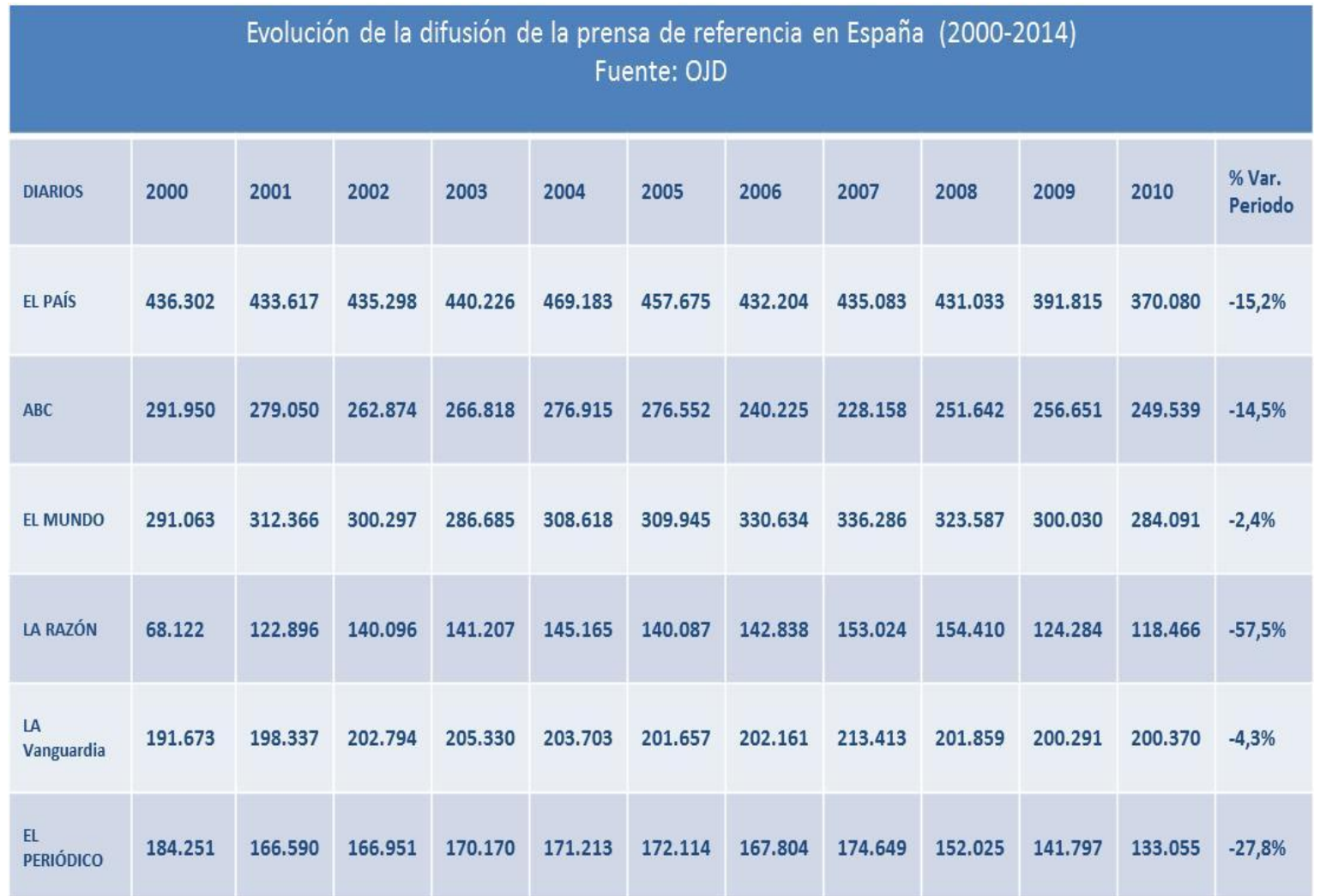


En general, y como destacaba PR Noticias, ${ }^{1}$ los tres grandes diarios madrileños (El País, El Mundo y Abc) habían perdido la mitad de su difusión en los años de la crisis (2007-2014), pasando de casi 1 millón a 538.000 ejemplares. Pero la crisis económica tal vez haya enmascarado una crisis que principió entre los años 1995-1998. Es decir, si estableciésemos una comparativa entre los años finales del siglo XX y el año 2014, las pérdidas en difusión serían mayores, con el agravante de que la prensa de referencia lleva más de quince años de crisis continua de difusión. ${ }^{2}$

\section{Cuadro $\mathrm{N}^{\mathrm{o}} 4$}

Evolución de la difusión de la prensa de referencia en España (2011-2014) Fuente: OJD

\begin{tabular}{|l|l|l|l|l|l|}
\hline DIARIOS & 2011 & 2012 & 2013 & 2014 & $\begin{array}{l}\text { Variación \% } \\
\text { periodo }\end{array}$ \\
\hline EL PAÍS & 365.117 & 324.814 & 292.227 & 259.775 & $-28,9 \%$ \\
\hline Abc & 221.351 & 171.969 & 140.049 & 128.660 & $-41,9 \%$ \\
\hline EL MUNDO & 252.770 & 206.007 & 172.427 & 149.684 & $-40,8 \%$ \\
\hline LA RAZÓN & 103.789 & 90.902 & 85.135 & 81.449 & $-21,5 \%$ \\
\hline $\begin{array}{l}\text { LA } \\
\text { VANGUARDIA }\end{array}$ & 190.033 & 172.263 & 152.320 & 140.176 & $-26,2 \%$ \\
\hline $\begin{array}{l}\text { EL } \\
\text { PERIÓDICO }\end{array}$ & 119.374 & 107.512 & 101.053 & 92.163 & $-22,8 \%$ \\
\hline
\end{tabular}

\footnotetext{
${ }^{1}$ PR Noticias, "El País, El Mundo y Abc pierden la mitad de su difusión (461.000 ejemplares) durante la crisis".

${ }^{2}$ Otra cosa son los resultados económicos, que, por mor de la continua subida del precio de los ejemplares, los incrementos publicitarios en los años de bonanza y el éxito de las promociones a comienzos del siglo XXI, arrojaron resultados positivos, y permitieron a muchos accionistas de estos medios mirar directamente para otro lado, sin preocuparse realmente por la gravedad de los hechos.
} 
Los niveles de difusión de la prensa de referencia son ya propios de la gran prensa regional. El hecho de que La Razón haya cerrado el año 2014 con 81.300 ejemplares le coloca por debajo de las mejores cifras de algunos diarios regionales. Y lo mismo sucedería con los 92.162 de El Periódico, los 129.000 ejemplares de $A b c$, e incluso los 140.000 de La Vanguardia.

El problema lo planteaba Gómez Calderón en Tendencias 06 (2006: 69), en el mismo título de su texto ("Bonanza económica frente a estancamiento de la difusión") al remarcar que, "aunque la alianza entre cuentas saneadas e inversión publicitaria in crescendo constituye un aval más que suficiente para desterrar cualquier atisbo de inquietud financiera, el producto en sí, el periódico, titubea, cuando no se atasca, sacudido por fenómenos imprevistos hace tan sólo unos años".

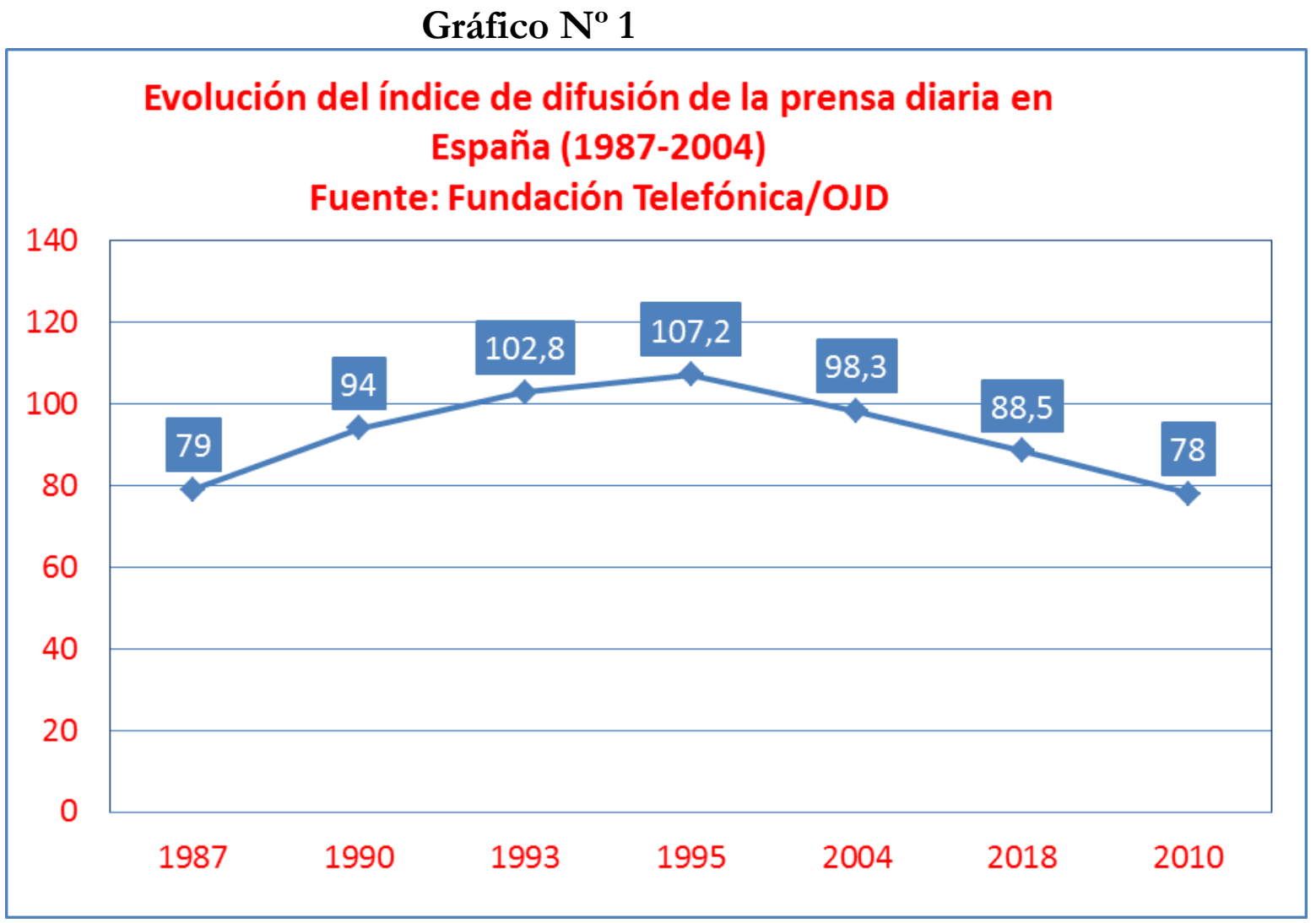

\footnotetext{
${ }^{3}$ Por ejemplo, La Voz de Galicia tenía una difusión de 107.850 ejemplares en el año 2000 y El Correo de 132.113 ese mismo año.
} 
Este mismo autor, destacaba que las empresas periodísticas españolas habían puesto en marcha procesos de concentración para formar un "oligopolio" que permitiese sanear sus cuentas y emprender una urgente renovación tecnológica y de recursos humanos. Así, cinco grupos de comunicación pasaron a concentrar el $60 \%$ del mercado ${ }^{4}$, con un total de 47 cabeceras, un tercio del total. Y fueron años de buenos resultados - como hemos apuntado- puesto que Vocento y Recoletos crecieron por encima de los dos dígitos en el año 2004 (10,2\% y 11,7\%, respectivamente), y Godó alcanzó el 15\% y Unedisa el $24 \%$.

\section{Gráfico $\mathbf{N}^{\mathrm{o}} 2$}

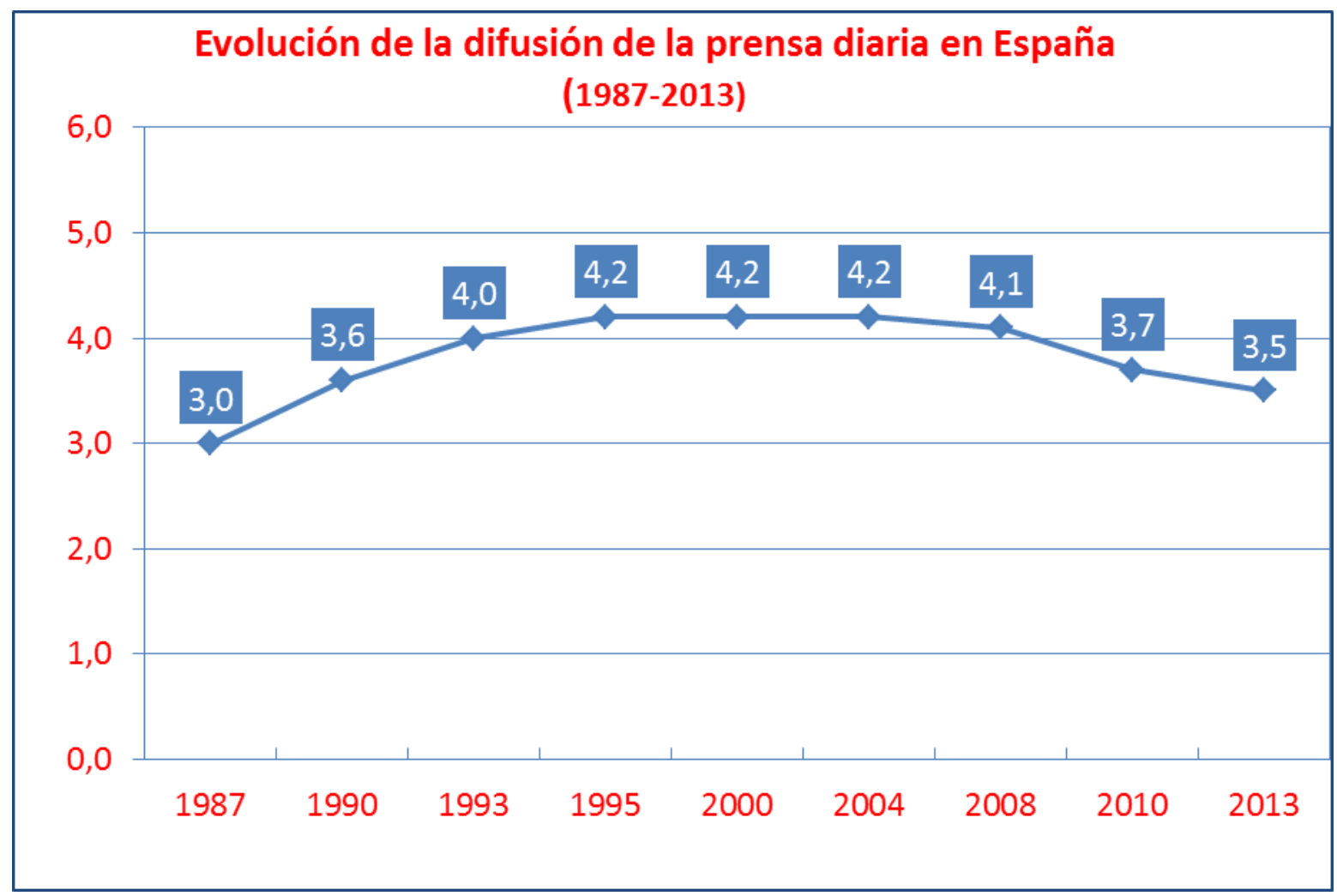

\footnotetext{
${ }^{4} \mathrm{Nada}$ escandaloso si tenemos realmente en cuenta que, en los años noventa tres canales generalistas concentraban más de dos tercios del mercado televisivo y que las tres primeras cadenas radiofónicas disponían de dos tercios del mercado publicitario y de las audiencias. La creación, por tanto, de "oligopolios imperfectos" ha sido algo consustancial al mundo de la comunicación desde la llegada de la democracia a España.
} 
Pese a ello, otros indicadores del negocio eran menos positivos. Como se apunta en la página 82 del Informe Tendencias 06, el Índice de difusión de la prensa en España en el año 2004 era de 98,3 copias por cada mil habitantes, pero de 476,9 en Suecia; 298 en Reino Unido y 131,1 en Francia. Es decir, no solo era uno de los más bajos de la Unión Europea, sino que había retrocedido hasta niveles de los primeros años noventa, como subrayaba Gómez Calderón, a pesar de que la circulación de la prensa había alcanzado en el año 2005 los 4.264.470 ejemplares diarios de media.

La evolución de la difusión de la prensa diaria en España confirma que si bien la velocidad de crucero fue buena entre los años 1980 y 1995 (véanse los cuadros adjuntos), al pasar de 3 a 4,2 millones de ejemplares; a partir de ese último año se estancó durante más de una década, para descender claramente en los años de la crisis, alcanzando los 3,7 millones en el año 2010, y situándose -aún sin cifras oficiales-, en el entorno de los 3 millones en el bienio 2013-2014; lo cual denota: a) que la prensa era un mercado "maduro" a finales del siglo $\mathrm{XX}, \mathrm{b})$ que estamos volviendo a cifras de comienzos de la década de los ochenta, en una clara regresión del sector.

A todo ello se le añade un constante incremento de la edad media del lector de la prensa de pago, que ronda ya los 48-50 años (AEDE, 2014); el hecho de que el sector más joven de la población no se incorpore como lector, y que la tasa de penetración de lectores en España -como ya había destacado Larrañaga (2010), con cifras por debajo del 35\%, se haya situado como el segundo más valor de la UE, cuya media era casi el doble que la española.

\section{La evolución de la "prensa de referencia"}

Si estudiamos también la evolución de la denominada "prensa de referencia", -tal y como puede comprobarse en los cuadros adjuntos que reflejan la evolución en la década de los ochenta, noventa y siglo XXI- podemos apreciar tres períodos de evolución diferentes: 
a) Década de los ochenta: una época de despegue, en la que todavía sigue existiendo la denominada "prensa del movimiento" hasta que se procede a su subasta en el año 1984. El sector de la prensa empieza a pensar -como ya se ha apuntado- en la conveniencia de aplicar economías de escala, que solo pueden producirse después de procesos concentradores.

b) Década de los noventa: es el auténtico momento del despegue del negocio periodístico. El índice de difusión se sitúa por encima de 100. La difusión de la prensa diaria comienza el año 1990 con 3,6 millones y acaba la década con 4,2 millones (aunque entre 1995 y el año 2000 dejase de crecer).

c) Siglo XXI: una etapa de estancamiento, en la que los beneficios siguen creciendo por la buena marcha de la economía, pero en el que desciende la difusión de la prensa. A título de ejemplo, El País comienza el año 2000 con 436.402 ejemplares; logra aumentarlos en el año 2004 hasta los 469.183 (su máximo histórico), y de ahí desciende en el año 2014 hasta los 259.775, un 55\% menos. El diario $A b c$ comienza el año 2000 con 291.950 ejemplares y finaliza 2014 con 128.660, con menos de la mitad de ese primer período. Y lo mismo sucede con el resto de diarios de referencia, aunque la secuencia no sea similar.

Obviamente, la cuenta de resultados de estos diarios no engaña, y es evidente que entran en pérdidas al principiar la crisis económica. Ninguno de ellos obtiene beneficios en el período que media entre 2011 y 2014, incluido el diario del grupo Prisa. Se cumplía así lo que expresaba Ramón Salaverría (2010), "los periódicos han adoptado ante Internet una serie de políticas erráticas y no han acertado todavía a encontrar un modelo de negocio rentable".

El Libro Blanco de la Prensa Diaria 2014 (AEDE, 2014), resumía tres datos esenciales del mercado español de prensa: la disminución del número de cabeceras, un fuerte descenso en el volumen de difusión y de la inversión publicitaria, y, sobre todo, un cambio evidente de hábito de lectura en el lector tradicional de prensa en papel, que estaba migrando hacia los soportes online y los distribuidores y 
agregadores de noticias. Y el Anuario ofrecía el dato de una disminución publicitaria del 24\% entre los años 2010 y 2012.

Es más, como subrayaba este informe, el año 2013 había sido el primero en el que el sector de la prensa había obtenido en su conjunto unos resultados operativos negativos, siendo los ingresos de explotación de tan solo 1.755 millones de euros, y la expectativa de que en el ejercicio de 2014 bajasen hasta los 1.500 millones de euros. Por otra parte, y en tan solo seis años, el sector había dejado de ingresar una cantidad superior a los 1.000 millones de euros, aunque el principal problema estribe en que los diarios parecen incapaces de recuperar las masivas audiencias del pasado y se sitúan a niveles del año 2008, pero con una clara tendencia a un descenso pronunciado de los lectores de la prensa en papel sin que los lectores digitales experimenten por el contrario un aumento que pueda compensar esta desafección.

\section{Gráfico $\mathrm{N}^{\circ} 3$}

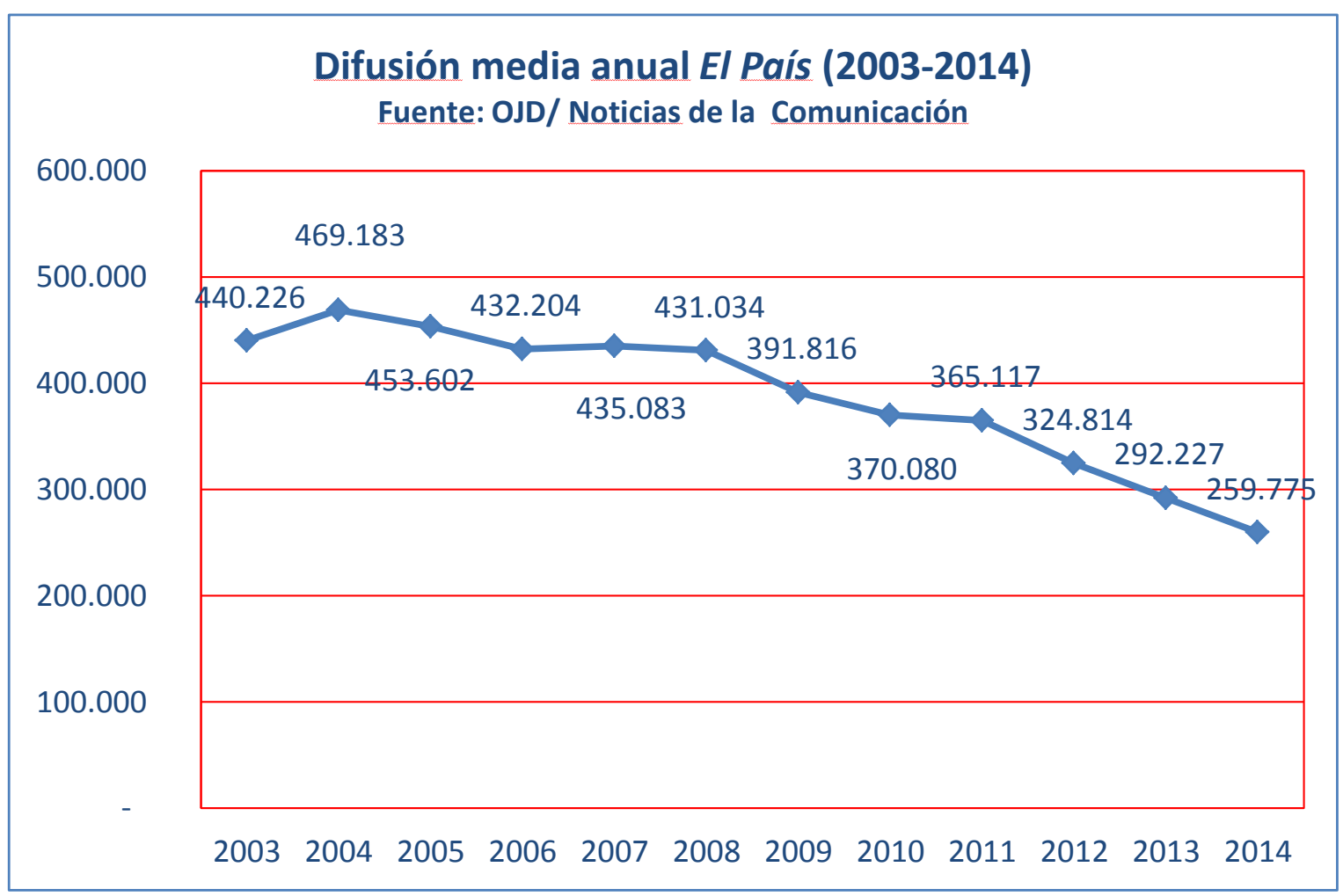

Así las cosas, parece claro que nos encontramos ante un negocio realmente "maduro", que no podrá soportar las mismas estructuras 
empresariales que en el pasado y que tenderá a realizar un profundo viraje estratégico en busca de nuevas audiencias, nuevos modelos de negocios -nucleados ahora en torno a los clubes de lectores, como ya apuntamos en nuestro estudio del año 2014 (García Santamaría, 2014) - y con un equipaje mucho más ligero que el que todavía está imperando hoy día, y en la senda trazada por algunos de los más importantes pure players (García Santamaría, Aboal y Clemente, 2014).

\section{Referencias bibliográficas}

AEDE (2003-2015): Libro Blanco de la Prensa Diaria. Madrid: AEDE. APM (2010-2015): Informe Anual de la profesión periodística. Madrid:

Ediciones APM.

Burgueño, J.M. (2011): "La metamorfosis de la prensa. Hacia un nuevo modelo periodístico". Telos, No 86, p. 87-97.

Casero, A. y Domenech, H. (2010): "La prensa escrita". En César Herrero, J. y Pérez-Ugena, A.: Materiales para la innovación en estructura de la comunicación. Madrid: Editorial Universitas, p. 637668.

Díaz Nosty, B. (2011): "La crisis en la industria de la prensa. Vida más allá del papel”. Telos, no 86, p. 52-65.

Díaz Nosty, B. (Coord.): Informe Anual de la Comunicación 1999-2000. Barcelona: Grupo Zeta

Díaz Nosty, B. (2013): La prensa en el nuevo ecosistema informativo. Que paren las rotativas;. Barcelona: Ariel/Fundación Telefónica.

Fundesco (1989): Comunicación Social 1999/Tendencias. Informes Anuales de Fundesco. Madrid: Fundesco.

Fundesco (1990): Comunicación Social 1990/Tendencias. Informes Anuales de Fundesco. Madrid: Fundesco.

Fundesco (1991): Comunicación Social 1991/Tendencias. Informes Anuales de Fundesco. Madrid: Fundesco.

Fundesco (1992): Comunicación Social 1992/Tendencias. Informes

Anuales de Fundesco. Madrid: Fundesco.

Fundesco (1993): Comunicación Social 1993/Tendencias. Informes

Anuales de Fundesco. Madrid: Fundesco.

Fundesco (1994): Comunicación Social 1994/Tendencias. Informes

Anuales de Fundesco. Madrid: Fundesco. 
Fundesco (1995): Comunicación Social 1995/Tendencias. Informes Anuales de Fundesco. Madrid: Fundesco.

Fundesco (1996): Comunicación Social 1996/Tendencias. Informes Anuales de Fundesco. Madrid: Fundesco.

García Santamaría, J.V. (2014) (Coord.): El negocio de la prensa digital. Madrid: Universidad Internacional de la Rioja (UNIR).

García Santamaría, J.V. y Aboal, M. y Clemente, D. (2014): “La organización de las redacciones en los nuevos diarios digitales españoles y su relación con los nuevos modelos de negocio". Textual and Visual Media, $\mathrm{n}^{\mathrm{O}} 6$.

García Santamaría, J. V. (2016): Los grupos multimedia españoles. Análisis $y$ estrategias. Barcelona: UOC.

Gómez Calderón, B.J. (2006): "Bonanza económica frente a estancamiento de la difusión". En Beaumont-Fernández Fernández, J.: Tendencias 06 Medios de Comunicación. El año de la televisión. Madrid: Fundación Telefónica.

Larrañaga Rubio, J. (2009): "La crisis del modelo económico de la industria de los periódicos". En Estudios sobre el Mensaje Periodístico, $\mathrm{n}^{\circ} 15$, p. 61-80.

Larrañaga Rubio, J. (2010): "Industria de los periódicos: nuevos modelos económicos y nuevos soportes". Estudios sobre el Mensaje Periodístico, 59, p. 59-78.

Poulet, B. (2011): La fin des journaux et l'avenir de l'information. Paris: Gallimard.

Reuters Institute for the Study of Journalism (2012 a 2015): Reuters Institute Digital News Report. Universidad Oxford. Disponible en: https://reutersinstitute.politics.ox.ac.uk.

Salaverría, R. (2010): “¿Ciberperiodismo sin periodistas? Diez ideas para la regeneración de los profesionales de los medios digitales”. En Campos Freire, F. (coord.): El cambio mediático, Zamora/Sevilla: Comunicación Social, p. 236-249.

Sánchez-Vicente, C. (2002): El poder de la prensa. Madrid: Ediciones Temas de Hoy.

Zarzalejos, J.A. (2015): Mañana será tarde. Barcelona: Planeta. $2^{\mathrm{a}}$ edición. 


\title{
El arranque de El Español o la dificultad de cumplir expectativas en el mercado mediático digital
}

\author{
Félix Pérez Bahón \\ Universidad Carlos III de Madrid
}

Forma de citar este capítulo: Pérez Bahón, F. (2016): "El arranque de El Español o la dificultad de cumplir expectativas en el mercado mediático digital", en García Santamaría, J.V. y Pérez Bahón, F. (coord.): Los medios digitales españoles: procesos de cambio e innovación. Cuadernos Artesanos de Comunicación, CAC104. La Laguna (Tenerife): Latina.

\section{Resumen}

El 14 de octubre de 2015 se abría oficialmente la web de El Español. Ha sido el lanzamiento más importante -y más esperado- en España en muchos años. Llegó de la mano de Pedro J. Ramírez, un director experimentado en el papel pero que apostataba públicamente de la vieja plataforma para abrazar la nueva fe de internet. En este trabajo descriptivo se exploran los orígenes y primeros pasos de este medio digital que quiere revolucionar la industria periodística y se ha postulado como un nuevo referente de la prensa de calidad en español. Empezó con mucha fuerza tras alcanzar 3,6 millones en una exitosa campaña de crowdfunding y nada menos que 5.624 accionistas para impulsar una empresa con un capital de más de 18 millones de euros. Sin embargo, ha comenzado 2016 con logros de audiencia muy moderados. 
Para la investigación -integrada en un estudio mucho más amplio sobre el negocio de la prensa digital en España ${ }^{5}$-, se han realizado entrevistas en profundidad y otras técnicas cualitativas con el fin de conseguir una aproximación a la web, identificar su elementos internos (estructura y usabilidad) y también externos (aplicaciones para móviles y tabletas). El plazo transcurrido es todavía corto. No obstante, permite observar ya algunas claves que explican por qué, incluso contando con todos los mimbres necesarios para el éxito, no es líder de su franja de audiencia. Parece que el producto no ha resultado tan atractivo cómo prometía y no han sido suficientes la excelente campaña de marketing, la cobertura del capital o el hecho de contar con profesionales de prestigio. Esta experiencia, aún por desarrollarse, demuestra que llave del negocio digital tiene aún que dar varias vueltas en la cerradura.

Palabras clave: cibermedios; crisis de la prensa; El Español; internet; periodismo.

\section{Introducción}

Pocos medios digitales de nuestro entorno han recibido tanta atención antes de nacer que El Español. La web Politico ${ }^{6}$, un medio de gran prestigio internacional, calificó el lanzamiento como 'el acontecimiento mediático más esperado de los últimos años en España'. Sólo el nombre de su director e impulsor, Pedro J. Ramírez, ya trae a la memoria del lector de diarios gestas periodísticas como las de Diario 16 o El Mundo. Esto puede explicar en parte todas las expectativas depositadas en la nueva cabecera.

\footnotetext{
${ }^{5}$ El presente estudio está encuadrado dentro de un proyecto de mayor envergadura: "Modelos de negocio de la prensa en el ámbito digital", grupo de investigación dirigido por el Instituto para la Innovación Periodística 2IP y financiado por la Universidad Internacional de la Rioja desde septiembre de 2012. Dadas la expectación y primeras cifras manejadas por el proyecto \#nohacefaltapapel, se incorporó como anexo al trabajo de campo.

${ }^{6} \mathrm{El}$ artículo, titulado enfáticamente 'News of the future' y publicado el 13 de octubre de 2015, está disponible en: http://www.politico.eu/article/news-ofthe-future-spain-madrid-ramirez/ [Consulta: 19/03/2016]
} 
Al grito de 'No hace falta papel', nombre de la empresa editora, un centenar de profesionales, muchos de ellos curtidos en las redacciones tradicionales, formaron una plantilla dispuesta a demostrar que un medio nativo digital no solo es posible, sino que además puede ser la solución a la crisis en que está sumergida la prensa.

Hasta este momento, los profesionales hemos interiorizado que el periodismo, una vez agotado el papel, no encuentra fórmulas de negocio. La industria mediática está sumergida en una compleja crisis que hace peligrar el modelo tradicional de sostenibilidad, hasta ahora asentado en la publicidad y el quiosco. En un escenario nuevo, con internet como principal campo de batalla, surgen números emprendedores (Pérez Bahón, 2013) que recuperan la autoridad profesional según dos principios: el brand name (el prestigio personal como marca) del propio periodista, y la cultura del 'hágalo usted mismo’ (Lewis, 2011). Con El Español llegó la gran esperanza.

La agonía de los diarios impresos y la necesidad social de salvar el periodismo ha generado numerosa bibliografía, profesional $y$ académica (Casadesús y Ricart, 2010; Casero-Ripollés, 2010; Campos, 2010; Gallardo, 2011). Se pone en entredicho el quehacer profesional y también las decisiones empresariales en un momento en que los paradigmas de la comunicación se han invertido (Orihuela, 2004).

En las redacciones se habla de dinero y negocio, o de su escasez en estos tiempos, mientras que los lectores se preocupan por lo esencial: el periodismo. Debaten por la orientación de los medios y la afinidad política de los columnistas (Cervera, 2013). La explicación hay que buscarla en que la muerte del papel ya no es un augurio, sino una realidad con miles de parados entre los compañeros $\left(\mathrm{APM}^{7}\right)$.

\footnotetext{
${ }^{7}$ El observatorio para el seguimiento de la crisis de la Asociación de la Prensa de Madrid contabiliza el número de trabajadores afectados por la crisis en el sector periodístico madrileño desde mediados de 2008. En: http://www.apmadrid.es/images/stories/Observatorio_APM 22marzo13(2).p df; (Consulta: 11/07/2013).
} 
Los empresarios y sus consejeros, buenos conocedores de la situación porque sus inversiones y negocio están en juego, no esconden su desconcierto. El panorama y las fórmulas son cambiantes, las audiencias apenas conocidas y las fórmulas publicitarias inexploradas. Las producción y comercialización del producto juega a prueba y error con métodos cada vez más imaginativos (Varela, 2011). Las redes sociales cobran un inusitado protagonismo.

El escenario puede verse como apocalíptico; sin embargo, la conciencia generalizada es esperanzadora. Nos encontramos en una etapa de transición en la que se experimenta sobre lo aprendido en los medios tradicionales (Goyanes Martínez, 2013: 419-431).

Los primeros diarios que llegaron a internet lo hicieron a mediados de los años 90. Ya llevamos un cuarto de siglo con desafortunados ensayos de adaptación a la nueva plataforma digital -para muchos, nuevo medio- con el objetivo de ganar lectores y beneficios. Hasta ahora el soporte no ha traído (al menos a los medios) la rentabilidad perdida en el mercado tradicional. Pero las grandes cabeceras, aferradas al mantenimiento y estímulo de sus productos impresos, hace tiempo que hacen guiños al mercado digital. Por si su salvación viene de ese ecosistema tan desconocido para ellas como es internet, donde las tecnológicas han tomado delantera (Díaz Nosty, 2011: 5265).

Como si se tratase de encuestas electorales, los esperanzadores estudios de prospectiva no se han cumplido. Habrá que tomar sus conclusiones como expresadas a muy largo plazo. El año 2008 se señala como fecha negra para toda la industria (AEDE, 2012, gráfico 1). Los diarios, que venían de ejercicios anuales con grandes ganancias no han reaccionado bien. No han asumido que los cambios han de hacerse con la convicción de una expectativa de negocio y no como una miedosa reacción defensiva frente a un enemigo al que no saben poner cara (Boczkowski, 2006). La competencia es anónima y utiliza estrategias desconocidas para el periodismo tradicional. 
Edwy Plenel define la coyuntura empresarial como de 'desorientación digital'. El negocio y la tecnología se afrontan con criterios economicistas, con lo que el espíritu del periodismo se ve sometido a unos principios ajenos a su escala de valores habitual. La información nunca debería plantearse como una mercancía más (Plenel, 2012: 69$70)$.

\section{Gráfico 1: Difusión de los diarios en España}

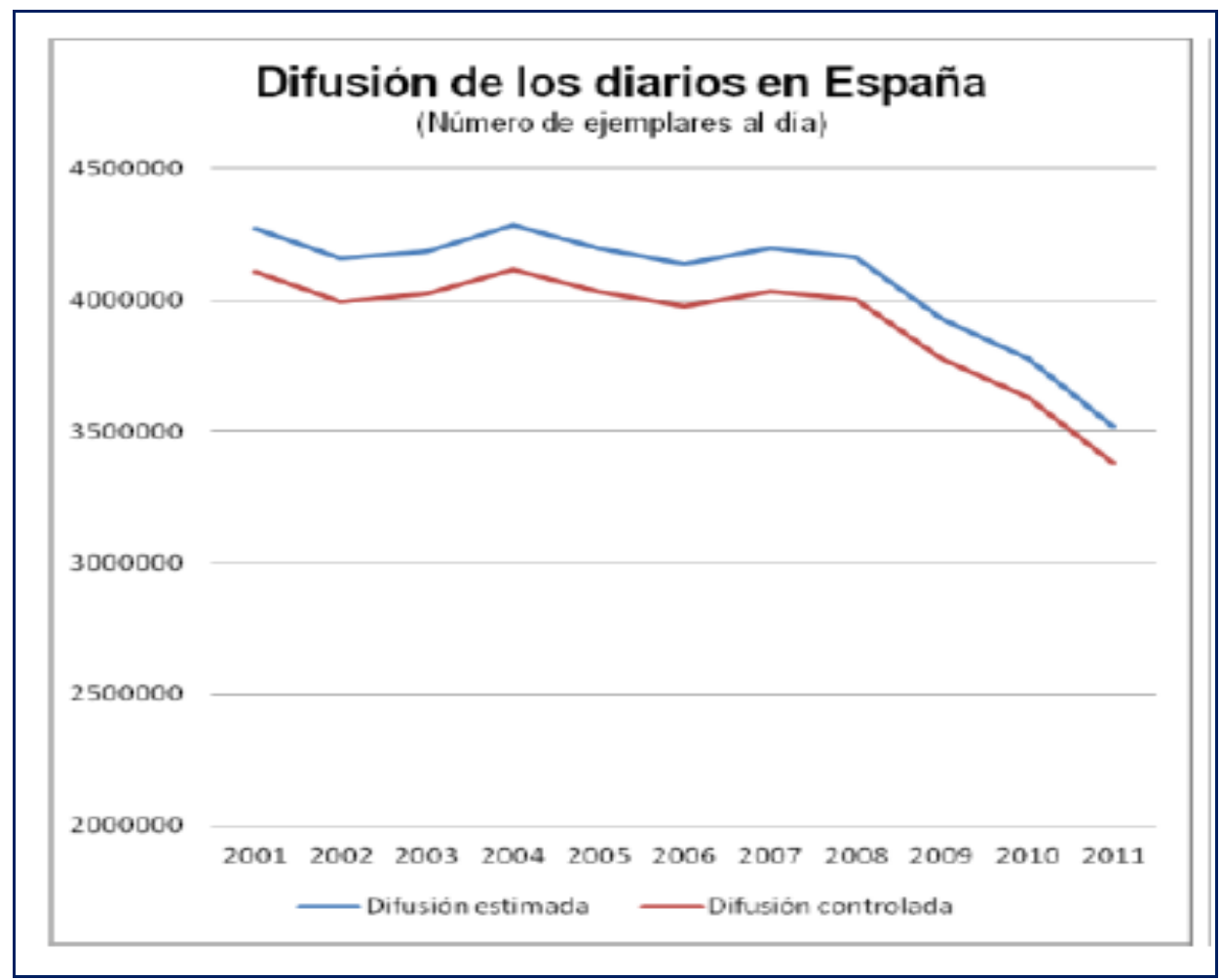

Fuente: AEDE.

Sumidos como estamos en el maremágnum de un cambio tan profundo, resulta arriesgado hacer análisis estables o establecer taxonomías desde la Academia. Cualquier investigación se enfrenta a la obsolescencia en poco tiempo (Nel, 2010). Parece, no obstante, que en todo el mundo hay una solución empresarial constante: la reducción de personal en las redacciones. Como señala Plenel (2012: 16), esto supone que los medios prescinden de su mejor activo: la experiencia de sus periodistas. El resultado lo estamos comprobando en un deterioro de la calidad y en una huida de lectores. 
El problema ya no es económico, se ha hecho social. Sin información no puede haber opinión, y sin ésta no se desarrolla la democracia. El ex director de Le Monde quiere convencernos de que más que al papel, tenemos que salvar al propio periodismo. La solución solo puede venir desde dentro de la profesión: somos los periodistas quienes debemos salvarnos a nosotros mismos sin esperar a que ninguna empresa lo haga (Plenel, 2012: 84). En España, asistimos en 2007 al último gran lanzamiento de un medio generalista con el diario Público ${ }^{8}$. Nació justo en el momento crítico de la recesión económica y murió el 24 de febrero de 2012, cuando se declaró su cierre definitivo en papel. Sólo duró cinco años en el quiosco. Su historia coincide con el periodo más recesivo del sector (Fernández-Sande, 2013).

Tras su desaparición como medio impreso Público se convirtió en un verdadero generador de startups ${ }^{9}$ en el ámbito del periodismo. Dio paso a cinco cabeceras de nuevo cuño, Eldiario.es, Infolibre.es, La Marea, Mongolia y Esmateria.com, y una que continúa en internet el espíritu del diario: Público.es. El problemático proceso de liquidación del periódico en papel lo cuentan con detalle los propios afectados en el 'Informe Mongolia', publicado la revista del mismo nombre y, más tarde, convertido en libro de contundente título: Papel mojado: La crisis de la prensa y el fracaso de los periódicos en España (2013: 55-76). Un análisis

\footnotetext{
${ }^{8}$ Esta afirmación ha de matizarse: el 21 de octubre de 2009 comienza la venta diaria de La Gaceta, de tirada nacional, pero el diario, comprado por Intereconomía en agosto de ese año, ya existía en los quioscos desde 1989 con el nombre de La Gaceta de los Negocios.

${ }^{9}$ Empresas innovadoras de reciente creación. Marek Fodor, emprendedor digital y cofundador de Atrápalo, plantea que no está definido el término de startup, pero que se podría limitar con una serie de criterios como: la empresa ha alcanzado break-even point (umbral de rentabilidad); ya ha contratado una secretaria / recepcionista a jornada completa; la mayoría del personal no trabaja más de 8,5 horas diarias; la fuente principal de inspiración ya son las ideas lanzadas por la competencia; los fundadores ya tienen despachos separados del resto del equipo y pueden ausentarse varios días sin que el trabajo se resienta; la empresa tiene más de 2 años de vida. En:

http://es.marekfodor.com/2008/06/donde-termina-la-fase-startup.html ; (Consulta: 16/07/2013).
} 
más académico es el publicado en marzo de ese mismo año por Manuel Fernández-Sande en la Revista de Comunicación Vivat.

Hemos sido testigos de este proceso como el paradigma del paulatino debilitamiento y desaparición en la red de los grandes 'latifundios mediáticos' (las empresas tradicionales) para dar paso a un novedoso panorama de 'minifundios' en los que los antiguos siervos de gleba (los periodistas) hacen caso a Plenel y se convierten en dueños de sus propios terrenos (nuevos medios). Sin embargo, el análisis puede ponerse en entredicho con la aparición de un nuevo medio: El Español.

Desde la aparición de Público no habíamos asistido a un lanzamiento mediático con tantas expectativas como las generadas por El Español. No es el primer nativo digital de prestigio de nuestro entorno; sin embargo, sí es el primero concebido directamente para dispositivos móviles. Parte de un novedoso lema 'no hace falta papel', que es también el nombre de la empresa editora, y de una promesa: 'los mejor está por venir'.

Toda una declaración de intenciones. Un producto pure player y con vocación gratuita que quiere demostrar que el periódico, como producto, puede sobrevivir sin su soporte tradicional. De momento, sus logros son notables: 3,6 millones de euros en campaña de Crowdfunding (microfinanciación), con 5.624 accionistas (récord mundial); se ha convertido en el primer medio con más de 10.000 suscriptores antes de nacer (una gran campaña viral basada en la fe y en el prestigio de los periodistas implicados en el proyecto), y que ya cuenta con un capital superior a 18 millones de euros para cumplir su gran promesa: reinventar y relanzar el periodismo de calidad.

Este trabajo descriptivo de aproximación tiene un objeto exploratorio y explicativo de cuáles han sido los orígenes y primeros pasos de este pure player. Con el apoyo de un método Delphi ${ }^{10}$ y técnicas cualitativas

\footnotetext{
${ }^{10}$ María Ramírez ha sido la directiva de El Español que se ha sometido ya a la primera parte del Delphi.
} 
se reconoce el camino recorrido hasta el momento por el equipo, tanto en lo empresarial, como en lo redaccional; al tiempo que se identifican y analizan los elementos externos de presentación de la aplicación. Por último, se describe la ideología y la manera efectiva en que se ha expuesto en un momento de baja autoestima del periodismo en España.

\section{Cronología de un proyecto}

El origen de El Español hay que buscarlo en Nueva York, aunque ellos, mucho más poéticos, dicen "Nosotros hemos nacido en Twitter". Hagamos una cronología de su historia:

- 2 de abril de 2014. María Ramírez, hija de Pedro J, y su marido Eduardo Suárez, corresponsales de El Mundo en Nueva York, crean un blog para un congreso de periodismo digital en Austin (USA) al que les había invitado el Centro Knight de Periodismo de las Américas en la Universidad de Texas. El nombre elegido es \#nohacefaltapapel ${ }^{11}$ y el propósito secundario es recoger en él "asuntos que a menudo no cabían en el periódico el que trabajaban en ese momento (El Mundo). Como gestor de contenidos eligieron la plataforma de Wordpress, lo que simplificó el apremio, pues en dos días empezaba el congreso.

- 4 de abril de 2014. Se publica la primera entrada del blog \#nohacefaltapapel. El matrimonio Suárez-Ramírez retransmite al alimón, en directo y sin descanso durante un fin de semana, el programa del congreso ISOJ. Durante los meses siguientes, continuaron tomando el pulso a los estímulos y las ideas que se fraguaban en el periodismo de vanguardia de Estados Unidos. El Tow Center de la Universidad de Columbia y la Online News Association (ONA) de Nueva York les facilitaron, según ellos, mucho el trabajo. Buscan innovaciones en medios jóvenes y novedosos, pero no descartan las aportaciones de medios tradicionales.

${ }^{11}$ http:// nohacefaltapapel.com/ 
- 8 de octubre de 2014. Se constituye, como sociedad limitada, la empresa NoHaceFaltaPapel, S.L con un capital social de 3.000 euros. Los administradores solidarios son María Ramírez y Pedro J. Ramírez, aunque en el registro ella aparece como socio único. La sede está en la octava planta del edificio de la Avenida de Burgos, número 16. Casualmente es la misma oficina que ocupó Lainformación.com, algo que ninguno de los fundadores sabía. Les interesaban unas oficinas amplias, a buen precio y en zona accesible, pero no en el centro de la ciudad. Se lo toman como un buen augurio para ayudar a sacar la espinita que el medio ha dejado en el periodismo digital. El día 17 de octubre se publica en el Boletín Oficial del Registro Mercantil y en el Boletín Oficial del Estado.

- 5 de diciembre de 2014. Periodista Digital anuncia en exclusiva que Pedrojota ha puesto su nuevo proyecto digital en manos de uno los mejores estudios de diseño de periódicos del mundo: la empresa británica Audacity Partners. Su CEO y fundador es Alfredo Triviño, un talentoso español que con solo 37 años ha rejuvenecido cabeceras míticas de la prensa inglesa como The Times, Sunday Times y The Sun. Ex director de Innovación global en News Corporation, Triviño ha sido clave en la implantación de distintos modelos de periodismo de pago en el Reino Unido, Estados Unidos y Australia.

- 31 de diciembre de 2014. Se abre la cuenta de @elespanolcom con un tuit que lleva un enlace a un vídeo de presentación. En tan solo15 horas alcanza 30.000 seguidores. "Hay hambre de buenas historias y de periodismo valiente. Intentaremos no defraudar" dice un tuit el 1 de enero. En once días, la cuenta alcanza los 60.000 followers, y todo parecía ir a más con la campaña de Crowdfunding que se preparaba. Las redes sociales se convierten en la clave para que el pequeño equipo fundador vaya desgranando las claves del nuevo periódico. Resulta curioso que también la cuenta personal de Pedrojota despierta un interés paralelo: mantiene un ritmo de crecimiento de 200 seguidores al día y este ritmo, según un estudio de Pirendo ${ }^{12}$, se duplica a partir del

\footnotetext{
${ }^{12}$ Pirendo, una empresa española dedicada a la inteligencia y analítica en social media, realizado un interesante análisis de la cuenta de Twitter del diario
} 
1 de enero. En las conclusiones de dicha investigación se observa "que@elespanolcom hereda en buena parte el estilo de su fundador, ya que son numerosísimos los tuits emitidos por la cuenta de la publicación en sus pocos días de vida: nada más y nada menos que 1.128 mensajes, en los que se incluyen tuits originales, menciones, respuestas y retuits".

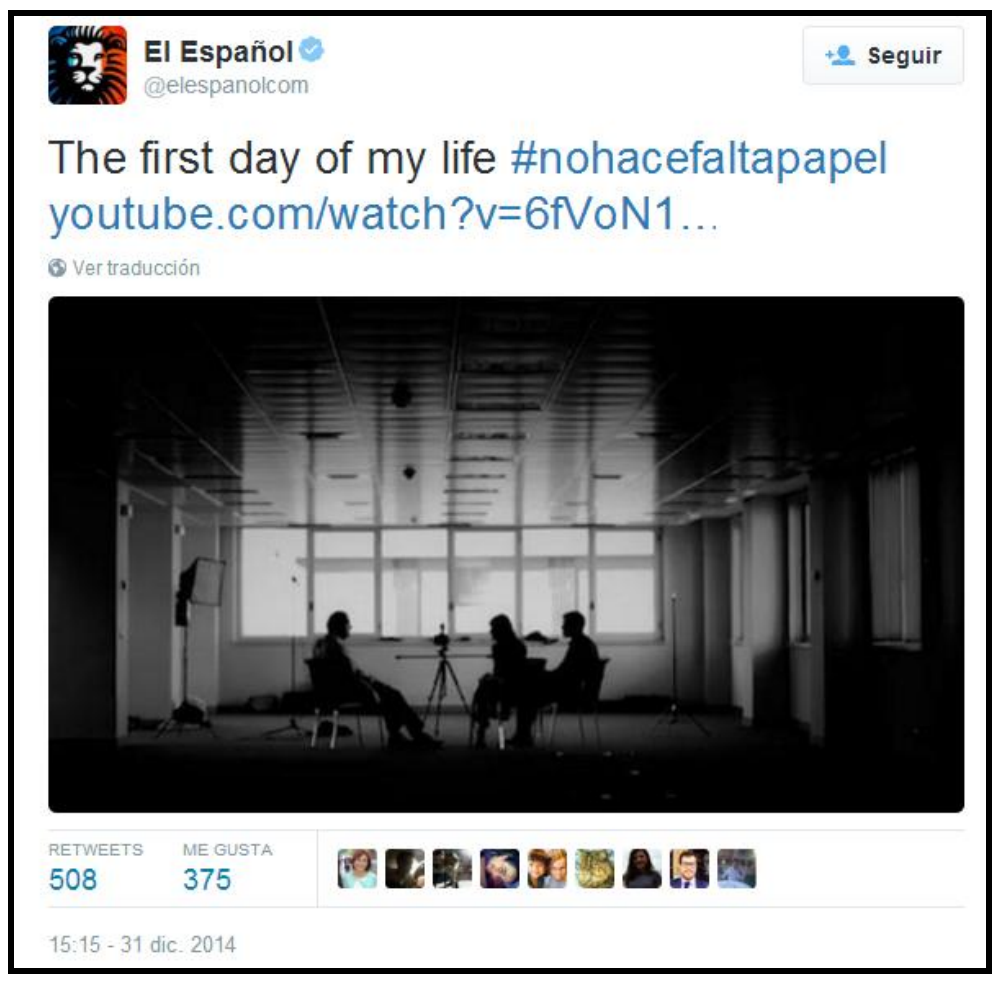

Primer tuit de@elespanolcom el último día de 2014.

- 1 de enero de 2015. Casi con las uvas del nuevo año, Pedrojota Ramírez, conocido periodista y ex director de Diario 16 y de El Mundo, anuncia en su cuenta de Twitter (@pedroj_ramirez, 302.000 seguidores en ese momento) que la maquinaria de El Español ya está en marcha. Será, según sus palabras una nueva publicación exclusivamente digital que estará a pleno rendimiento en otoño de 2015.

- 11 de enero de 2015. Comienza el proceso de inversión por Crowdfunding (microfinanciación) en la empresa editora

(@elespanolcom) y del hastag \#Nohacefaltapapel el día 14 de enero de 2015. Se puede consultar en: http://goo.gl/9VNPJc 
\#nohacefaltapapel SL. El aporte mínimo es de $100 €$ y el máximo de $10.000 €$, que se gestiona a través de la página web www.invierte.elespanol.com. La plataforma elegida para realizar la campaña es Creo en tu Proyecto ${ }^{13}$. Se trata de una ampliación de capital ofrecida para que nuevos inversores se incorporen al proyecto como socios editores en las mismas condiciones que los profesionales que lo fundaron. Hasta el 28 de febrero cualquier persona física o jurídica pudo invertir en el proyecto. La medida "no obedece a una necesidad de dinero, sino a un plan de negocio que quiere innovar en el formato y ser una referencia en una nueva etapa en el periodismo español. Nuestro objetivo fue ampliar la base accionarial para dar entrada a pequeños inversores. Queremos que gran cantidad de prescriptores, propagandistas, socios... que nos acompañen en este proyecto". En principio no se fijó ningún límite respecto a la cantidad de dinero a obtener a través del proceso de crowdfunding, no obstante, en ningún caso podía superar ni igualar la cantidad de cinco millones de euros marcada por la Ley ${ }^{14}$. Todo inversor adquiere a la vez la condición de suscriptor de El Español con un descuento del 50\%. La cuota inicial será de $120 €$ al año, por lo que los accionistas sólo tendrán que pagar $60 €$, si es que así lo desean. Se establece también que los suscriptores tendrán derecho a la descarga de una edición diaria, equivalente a las que se distribuyen a través de Orbyt o KioskoyMas, pero con características propias; además, del libre acceso a todos los contenidos de El Español en todos los dispositivos y soportes y, por supuesto, a todas las ventajas del club de suscriptores, que se pondrá en marcha coincidiendo con el lanzamiento del periódico digital.

- 18 de enero de 2015. Pedro J. Ramírez confiesa en su cuenta de Twitter que su despido de El Mundo fue de 11,1 millones de euros y que, tras cumplir con sus obligaciones con Hacienda, destinará 5,3 millones a su nuevo proyecto. Para hacerse una idea de lo que esto significa -y es solo el principio- Eldiario.es de Ignacio Escolar nació un par de años antes con 600.000 euros de inversión inicial. En una entrevista acaba abjurar del papel: "En España el mejor periodismo se

\footnotetext{
${ }^{13}$ http://www.creoentuproyecto.com

${ }^{14} \mathrm{El}$ contrato de cada inversor con la empresa editora puede consultarse en: http://invierte.elespanol.com/docs/ejemplo-acuerdo-final.pdf
} 
está haciendo ya en los medios digitales: en El Confidencial, en Voz. Pópuli, en eldiario.es... Yo ya me siento parte, yo ya soy de los vuestros. Me siento mucho más cercano a la prensa digital que de los medios del pasado, lo que los medios anglosajones llaman las legacy media, que están muy condicionados por el hundimiento de su modelo de negocio", ha dicho a 233grados.com ${ }^{15}$. Y para evitar suspicacias, insiste en que ya había pronosticado hace dos años y medio, en una conferencia en la London School of Economics, que estamos ante 'una nueva edad de oro del periodismo'. Pero, dice, "me tomaron un poco por visionario y por frívolo cuando lo hice".

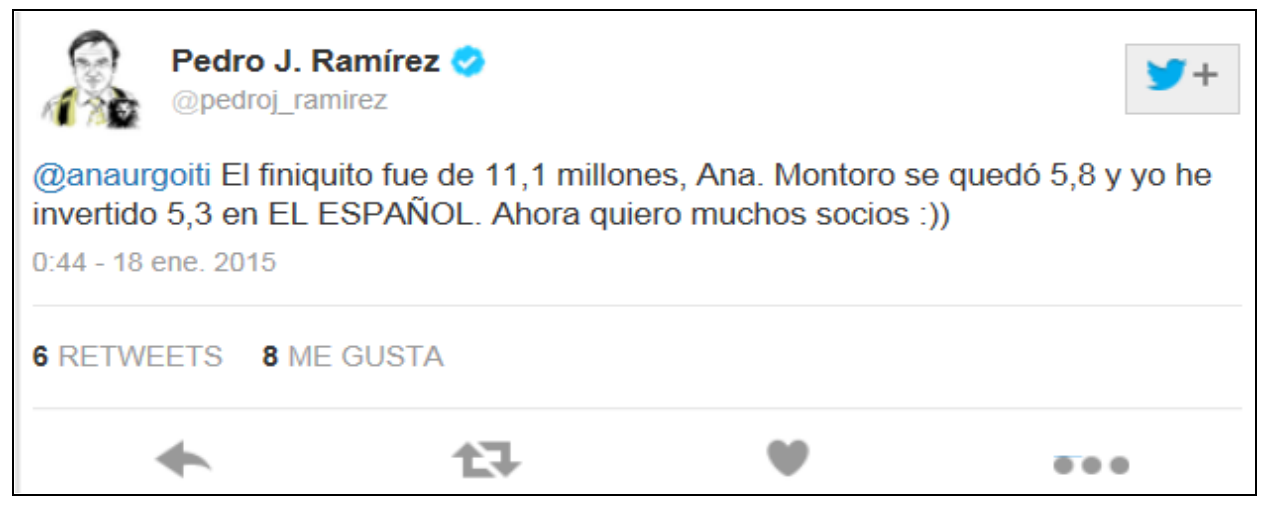

Tuit de Pedro J. Ramírez del día 18 de enero de 2015.

- 11 de febrero de 2015. Empieza a actualizarse el blog de El Español ${ }^{16}$, previo a la aparición del diario. Se elige esta cabecera porque coincide con el periódico que fundó Blanco White en 1810 en Londres para defender la libertad en España. Avisa de que, a pesar del nombre, "será universal, independiente, innovador, combativo, plural, ecuánime, inteligente... será tuitero, será tuyo”. De hecho, se subraya que "todo el mundo se pensó que nos íbamos a llamar El Universal porque se creía que Pedrojota iba a tratar de continuar El Mundo con otro nombre que prorrogara su proyecto". En este blog previo se podía seguir el proceso de gestación del periódico y encontrar también artículos de opinión de distintas personalidades.

\footnotetext{
${ }^{15} \mathrm{La}$ entrevista se puede consultar en: http://233grados.lainformacion.com/blog/2015/01/pedro-j-ramirez.html [Consulta: 17/03/2016] ${ }^{16}$ www.elespanol.com/
} 
- 14 de febrero de 2015. Se dan a conocer oficialmente tres fichajes que muestran cuál es la filosofía de formación del nuevo equipo: Leticia Lombardero será la directora del departamento de Márketing tras su paso por El Mundo, donde ha sido responsable de proyectos estratégicos; Mabel Cobos asumirá la dirección de tecnología como CTO (siglas de chief technology officer), uno de los departamentos en los que más cuidado se pondrá. Procedente de El País, ha estado en el desarrollo de las principales webs del grupo PRISA, como Cadena Ser, Cinco Días, Los 40, El País o AS; por último, José Vicente González, ligado hasta ahora a Público y Mediapro, será el director de Desarrollo de Negocio.

- 24 de febrero de 2015. Presentación de las cifras detalladas del plan de negocio del nuevo medio. El escenario es un encuentro organizado por Nueva Economía ${ }^{17}$ en el que el ex director de El Mundo pronuncia una conferencia. Ramírez anuncia que van a apostar por un modelo mixto de negocio, basado en la publicidad y en las suscripciones para una oferta adicional de servicios y contenidos. La consejera delegada de la empresa editora, Eva Fernández, detalló las cifras del plan de negocio del nuevo medio durante la presentación de la conferencia. Asegura que se trata de un business plan quinquenal "prudente". Según sus cálculos, al acabar el primer año de negocio, tendrán un número de usuarios únicos equiparable al de un medio regional "y, después de cinco años, simplemente los habremos duplicado".

Exactamente, El Español tiene como punto de partida 5,3 millones de euros de capital de la indemnización Pedro J. Ramírez, más 1,8 millones recaudados hasta esa fecha de 3.110 accionistas, en lo que se había convertido ya en el récord mundial de financiación colectiva (crowdfunding) de un medio de comunicación (veremos que aún fue más). Esta inversión, junto a aportaciones de socios fundadores, hará que terminen en ese momento con unos 9 millones de euros " $y$ tras negociaciones que están manteniendo con 'diversos socios

\footnotetext{
${ }^{17}$ Información del propio Foro en: http://www.nuevaeconomiaforum.org/noticias/el-espanol-valdra-100millones-dentro-de-cinco-anos [Consulta: 17/03/2016]
} 
institucionales', la cifra total de capital estará en torno a los 15-18 millones". Pedro J. tiene asegurado que siempre mantendrá directa o indirectamente la mayoría de la sociedad en sus manos. Lo más sorprendente entre toda la contundencia de lo ya recaudado fue el anuncio de que, al final de los cinco años, la compañía se situará “en torno a los 100-120 millones de euros, lo que supone multiplicar por cinco o seis el valor de la empresa en el momento del lanzamiento". La propia conferencia de Ramírez fue notable. Entre otras cosas avisó del futuro de la prensa escrita en España. Incluso aventuró que ninguno de las 20 o 30 cabeceras que se editarán desde Madrid tendrá ediciones impresas en una década. "Hay un modelo de negocio que se está derrumbando irremisiblemente (...) y la prensa digital trae más creatividad y más libertad que los medios tradicionales". Pedro J. está convencido de que los medios tradicionales están lastrados por cuatro pesadas piedras, cada una con su coste: el papel, la impresión, la distribución y el punto de venta.

- E1 28 de febrero de 2015. Acaba el proceso de inversión con un resultado espectacular. En apenas mes y medio, la campaña recibe el apoyo de 5.471 inversores, lo que la convierte en todo un récord mundial de crowdfunding: se consiguieron 3.612.900 euros en total. La marca más alta alcanzada por un medio de comunicación con este sistema fueron los 1.300 .000 euros que reunió el diario digital holandés De Correspondent en 2013. A partir de aquí, las cantidades anotadas se transforman en participaciones sociales de la entidad, a través de lo que se conoce como aumento de capital por compensación de créditos. Cada $100 €$ invertidos dan derecho a una participación. Eso significa que cada inversor puede tener hasta un máximo de 100 participaciones. A continuación \#nohacefaltapapel se transforma en sociedad anónima, las participaciones pasan a denominarse acciones y los socios se convierten en accionistas. Los accionistas minoritarios tienen los derechos propios de una sociedad anónima. Pueden intervenir y votar en las juntas generales de la sociedad y transferir sus acciones dentro de los límites de sus estatutos. Además tomarán parte en el desarrollo del propio medio mediante un proceso de información y consulta que el equipo fundador se compromete a mantener abierto de forma permanente. 
- 7 de abril de 2015. La empresa se transforma de S.L. a S.A. con un capital social de 17.134.900 euros. El modelo de negocio se compondrá durante el primer año de un $80 \%$ de ingresos por publicidad, eventos y patrocinios y un $20 \%$ de suscripciones. Se planea alcanzar el equilibrio a los cinco años mediante la incorporación de comercio electrónico y formación. Hasta el tercer año no se esperan beneficios. Pero el colchón financiero de partida aguantará las pérdidas de los dos primeros ejercicios.

- 21 de abril de 2015. Última entrada del blog \#nohacefaltapapel.

- 23 de abril de 2015. Cuatro meses después de su debut en Twitter, la cuenta@elespanol, el perfil de El Español en la red social, alcanza los 100.000 seguidores.

- 28 de mayo de 2015. Se celebra el primer consejo de administración de la empresa Nohacefaltapapel SA, sociedad editora de El Español. Sus 12 miembros se reúnen en la planta donde muy pronto se ubicará la redacción. Pedro J. Ramírez es el presidente de la empresa y Eva Fernández, la consejera delegada. Los diez consejeros restantes son: Víctor Gómez Frías, Francisco Moreno, Andrés Rodríguez, María Ramírez, Antonio Camuñas, Nieves Segovia, Javier Gómez de Liaño, Cruz Sánchez de Lara, Javier Cremades y Enrique Dans $^{18}$. Se subraya que incluye a cuatro periodistas, cuatro abogados y cuatro personalidades vinculadas a la Universidad y la docencia. Todos aportan experiencias complementarias de gestión. Un tercio son mujeres, porcentaje muy superior al de la mayoría de las empresas españolas.

- 25 de junio de 2015. Nace formalmente El Español con la celebración de la primera Junta General Extraordinaria de Accionistas del autoproclamado "primer medio creado por crowdfunding (compras abiertas y posibles para todo tipo de públicos)". El escenario es en el Palacio Municipal de Congresos de Madrid en IFEMA, abarrotado

\footnotetext{
${ }^{18}$ Las biografías de los consejeros pueden consultarse en: http://blog.elespanol.com/noticias-accionistas/composicion-del-consejo-deadministracion-de-el-espanol/ [Consulta: 17/03/2016]
} 
por más de 1.500 personas. Se bate aquí un nuevo récord: es la mayor junta general de la historia de los medios de comunicación en España. En el acto se presenta el logo de la publicación, un león que "rugirá para denunciar los abusos del poder". Se trata, como se dice entonces, del más antiguo de los símbolos de los españoles, un emblema utilizado desde los romanos hasta la actualidad. Pedro J. presenta también su equipo de redacción y sus líneas informativas. Prevé empezar a funcionar con un equipo de 86 personas (en ese momento son 35), de las que 60 serán periodistas, muchos de prestigio profesional, como Fernando Gaeta, María Peral, Ana Romero, María Ramírez o Eduardo Suárez.

Esta circunstancia subraya el objetivo de convertir a El Español en "un periódico de periodistas", donde la redacción va a tener "más peso". El ex director de El Mundo se muestra satisfecho y muy optimista. Considera que su nuevo medio "va a ser el mayor creador de empleo en el sector periodístico de los últimos 7 u 8 años". Su intención es lograr "un pacto entre generaciones, va a ser una combinación de periodistas consagrados que sirvan de ejemplo de modelo a los jóvenes periodistas, que alcanzaran el 30 por ciento del total". El acto sirve también para presentar al Consejo de Administración: cuatro periodistas, cuatro abogados y cuatro profesionales del mundo de la universidad ${ }^{19}$ con el fin de establecer una "conjunción de conocimientos muy equilibrada y complementaria”. Entre ellos se encuentra la Eva Fernández, primera mujer consejera delegada de un medio de comunicación. En su intervención, Fernández recuerda la caída en inversión publicitaria en papel (del 20,7\% en 2012, del 11,2\% 2013 y del 2,3\% 2014; en total, desde 2007 , del 67\%), y 'no hay visos de que eso se vaya a recuperar'. La promesa de un nuevo periodismo entusiasma a los presentes. La organización calcula que los asistentes representan más del $83 \%$ del capital en manos de los 5.624 accionistas. Pedro J., fundador y presidente, es ratificado en la junta como director del periódico. Afirma entonces que la publicación digital 'va a batir un nuevo récord', ya que 'nunca tantos españoles ayudaron a un español' que,

${ }^{19}$ N. del E.: de universidades privadas, que no públicas. 
además, 'todavía no había nacido'. Más tarde escribirá: "Personalmente me siento muy orgulloso y feliz de haber sido ratificado por la Junta General como director del periódico. Hemos querido que fuera así para subrayar que El Español sólo se debe a sus accionistas y nunca se someterá a ningún otro poder. Justo cuando se acaban de cumplir 35 años de mi nombramiento como director de Diario 16 y al cabo de un cuarto de siglo al frente de El Mundo, afronto el reto como una especie de tercera salida de Don Quijote. No en vano decía Alfred de Vigny que 'una gran vida, una vida plena es aquella que culmina con la defensa en la madurez de los ideales de la juventud". Por último, se avanza que Alejandro de Vicente será el nuevo vicepresidente de la compañía, además del máximo responsable del área comercial.

- 2 de septiembre. Bajo el título "Mar gruesa en El Español: Javier Negre deja a Pedro J. y regresa a El Mundo", Voxpopuli informa de que hay problemas en el nuevo diario digital que prepara Pedro J. Ramírez. Negre es uno de los varios periodistas que Pedro J se ha traído de su antigua empresa. Algunos se consideraban pesos pesados de la plantilla de Unidad Editorial, como Fernando Baeta, Esteban Urreiztieta o María Peral. Negre, periodista especialista en política, decide dar marcha atrás y rompe el contrato que le unía a El Español para volver a El Mundo, donde hasta hace unas semanas escribía en el suplemento Crónica. Distintas fuentes aseguran que toma la decisión impulsado por las dudas que le genera el proyecto. Además, "siente que no encaja su forma de hacer periodismo". Más que la guerra soterrada entre Pedro J. Ramírez y su empresa anterior, queda en evidencia que hay nerviosismo en la gestación del diario que se anuncia para ese mismo otoño. Es importante que salga ya debido a la inminencia de las elecciones catalanas, cuyo pico informativo se quiere aprovechar para el lanzamiento. Según Voxpopuli ${ }^{20}$, "hay cierto nerviosismo y malestar en buena parte redacción". Se cree que no será el único retorno y que tampoco se llegará a tiempo para cubrir la cita electoral. Entonces se desconoce la fecha exacta de salida.

\footnotetext{
${ }^{20} \mathrm{El}$ artículo completo, firmado por Rubén Arranz, se puede leer en: http://vozpopuli.com/economia-y-finanzas/67606-mar-gruesa-en-el-espanoljavier-negre-deja-a-pedro-j-y-regresa-a-el-mundo [Consulta: 17/03/2016]
} 
Además, señala "ciertas desavenencias que existen entre los miembros de su equipo directivo sobre el rumbo que debe tomar el proyecto, en cuanto a sus contenidos.

Eduardo Suárez y María Ramírez quieren potenciar los reportajes en profundidad y los artículos más asociados a las publicaciones dominicales. En el extremo contrario se encuentra Fernando Baeta, hombre de confianza de Pedro J. en El Mundo, que apuesta porque El Español se centre en la actualidad 'pura y dura' y sus periodistas concentren sus esfuerzos en la búsqueda de exclusivas relacionadas con la política y la corrupción".

- 7 de octubre de 2015. El nuevo periódico digital dirigido por Pedrojota Ramírez ofrece una página web en versión beta en exclusiva para sus casi 11.000 suscriptores fundadores, que se convierten así en earlier tester. El deseo es convertirlos en "una especie de consejo asesor permanente", pero con la puntualización de que se trata de un estilo de comunicación "participativo, no asambleario".

- 14 de octubre de 2015. Lanzamiento oficial de El Español ${ }^{21}$.

- 29 de octubre de 2015. Se lanza la aplicación para tabletas y móviles de El Español. La descarga de la app es gratuita (iOs y y Android), aunque tiene zonas exclusivas para suscriptores.

\section{Elementos de presentación de la web}

El nuevo periódico digital se presenta como el primero proyectado en España para dispositivos móviles. El diseño de Alfredo Triviño se presenta con una estructura muy sencilla y ordenada en la web: dos columnas, una doble que en ocasiones se parte, para presentar el contenido de las distintas secciones con gran despliegue gráfico y audiovisual, y otra sencilla a la derecha que presenta 'El Río'. Sobre fondo negro, unas cajas grises en forma de 'tarjeta' con tipografía en blanco presentan la información de última hora 'que hay que leer'. Los titulares aquí son muy sintéticos como en un servicio urgente que

${ }^{21}$ www.elespanol.com/ 
permite informarse de todo lo importante sin cambiar de pantalla. Con solo pulsar sobre cada tarjeta se accede a la información ampliada. Así queda en una parte de la página las noticias. A la izquierda de la cabecera, la 'Zona $\tilde{N}$ ' abre ofertas exclusivas para suscriptores. A la derecha, el logotipo del león invita a pulsar y acceder a la sección 'La edición'.

'La Edición' diría es un ejercicio que intenta actualizar el periódico digital, no sustentado por el papel. Se entiende como un producto con principio y fin, con una jerarquización muy clara para un lector tradicional, pero con vídeos, efectos sonoros, animaciones y otras herramientas que enriquecen la experiencia hipertextual y multimediática. En esta sección se alojan las exclusivas más llamativas y los reportajes más cuidados. Para los diseñadores es "un viaje por la actualidad diaria en un momento en que el usuario tiene ganas de una lectura reposada de un diario que le resuma lo que se ha perdido, le entretenga con buenas historias para leer y le sorprenda con lo que marcará la agenda al día siguiente".

La web permite acceder a los artículos con una navegación horizontal y vertical. Es un producto de diseño agradable y de fácil uso (los comentarios en la AppStore lo confirman que ocurre lo mismo con la aplicación para dispositivos móviles). Sorprende la concentración de secciones, menos de las que añaden los periódicos tradicionales. Su objetivo es estar más centrados en las noticias del día. Durante este corto periodo de vida, lo que más éxito ha tenido $-\mathrm{y}$ lo que distingue su estilo frente a la competencia- son los grandes reportajes (como los desarrollados con motivo de la las elecciones en Grecia o Cataluña), los perfiles, el periodismo de datos y las noticias exclusivas sobre corrupción política y económica (parte de la redacción, con nombres como Daniel Montero o Esteban Urreiztieta se dedican a esto en exclusiva). Todas las informaciones se pueden compartir en las diferentes redes sociales con una sola pulsación sobre el logotipo. El Español incorpora a su web funcionalidad innovadoras como un botón para accionistas, con el que estos pueden valorar las noticias y establecer un feedback con la empresa. La innovación se adaptará, según los promotores del periódico, al proceso creativo, tanto 
editorial como tecnológico. Por ejemplo, la app tiene una banda sonora, algo inusual y avisa con un sonido del cambio de sección. Sin embargo, no olvida los guiños a la prensa tradicional. Por ejemplo, la tipografía de la cabecera es la Berlingske, del diario danés fundado en 1749, y la cabecera utiliza un león de emblema, como hace el Times de Londres, que luce un león y un unicornio. El león, en el caso este caso, no está parado ni siempre se observa desde la misma perspectiva.

La aplicación, disponible tanto para iOs como para Android, es gratis para todos los lectores, pero mantiene la llamada 'Zona N', como una parte exclusiva solo para suscriptores. Allí encuentran ofertas de productos y promociones de todo tipo de espectáculos, incluido fútbol. En el momento de escribir esta comunicación, El Español ya cuenta con 11.000 suscriptores que han pagado 10,99 euros mensuales (primer mes es gratis) u 84 euros si han optado por la oferta anual.

Aparte la app ofrece otros tres entornos, en los que se navega con un movimiento lateral del dedo sobre la pantalla: "En Portada", con las historias actualizadas durante el día, "El Río", con lo último y "La Edición", el producto estrella de la cabecera. Un globo rojo en la parte superior izquierda significa que hay nueva información preparada.

'En portada' ofrece información múltiple en cascada, con los artículos de actualidad y las noticias más combativas. Si se desea navegar por la secciones, se puede desplegar un menú y acceder a lo que interese más, sea 'Economía' o 'Deportes'. Si lo que se quiere es ir a otros entornos (o zonas), basta con deslizar el dedo en sentido horizontal (para hojear rápidamente) y vertical (para una lectura pausada).

En la aplicación para dispositivos móviles, la sección 'El río' hace que, al pulsar sobre las tarjetas con la información sintetizada, éstas se viren y muestren más detalles, con imágenes y vídeos. En este 
caso contiene contenido en exclusiva para los suscriptores, como artículos de grandes firmas.

\section{Ideología: necesidad de regeneración}

La filosofía de El Español queda reflejada ya desde la constitución de la propia sociedad. Es el primer gran medio español (si el tamaño lo define el capital inicial y el número de trabajadores) que usa crowdfunding como inversión y convierte en accionistas a quienes han contribuido a financiar el proyecto. Será el primer periódico de la historia de España, y probablemente del mundo, que nace con más de 10.000 suscriptores antes de haber mostrado el producto.

Por si fuera poco, parte de una ideología expresada en el mismo nombre de la empresa: No hace falta papel. En este contexto, los fundadores del periódico digital buscan una 'diversificación total de las fuentes de ingresos. Parten de los modelos existentes: la publicidad y la suscripción, pero no renuncian a nuevas oportunidades como puede ser la organización de eventos.

Con una vocación 'regeneracionista'22 y una cabecera que rinde homenaje al periodismo político y cultural de finales del siglo XIX y comienzos del XX, la cabecera de "El Español rinde homenaje a Blanco White, el director del primer periódico con este nombre. Se fue a Londres en 1810, pues estaba en contra del gobierno de los invasores franceses y también contra la ideología que se estaba fraguando en las Cortes de Cádiz. Estaba convencido de que la Constitución de 1812 no iba a funcionar, como así fue. Pero el nombre también homenajea a Andrés Borrego, que fundó en Madrid en 1835 el primer periódico moderno digno de tal nombre. Es el descubridor de Mariano José de Larra, quien escribió en El Español algunos de sus mejores artículos."

\footnotetext{
${ }^{22}$ El periódico ha publicado sus '30 obsesiones', consensuadas con los suscriptores, que son las que reflejan su espíritu regeneracionista, que defenderá a los ciudadanos frente todo tipo de poderes. Pueden consultarse en: http://blog.elespanol.com/actualidad/las-30-obsesiones-de-el-espanol/ [Consulta: 17/03/2016]
} 
Sorprende un posicionamiento ideológico anclado el periodismo político y cultural de finales del XIX y principios del XX y la utilización de la letra eñe en la cabecera, poco adecuada para navegar por la red (su URL cambia esta letra por una ene). Sin embargo, los promotores quieren hacer realidad que se escribe en uno de los grandes idiomas de Internet y quieren potenciar su expansión. Al mismo tiempo, en clave nacional interna, aspiran a que su pensamiento quede claro frente al debate constitucional actual. Esa es la explicación al calificativo 'regeneracionista'. Están dispuestos a 'disparar sobre la oligarquía corrupta que socava la democracia'. La sociedad no acepta posiciones dominantes entre los accionistas minoritarios, lo que quiere decir que ningún inversor se hará con un $30 \%$ de la participación. Además, siempre se respetará el 51\% del accionariado en control del 'núcleo duro' y no se permitirá la entrada de firmas "que puedan crear conflictos de intereses". También proclaman que "ninguna empresa del IBEX va a estar en el accionariado de El Español y que van a defender a los ciudadanos en tanto que consumidores, en tanto que contribuyentes, en tanto que usuarios de los servicios públicos, en tanto que inversores en empresas cotizadas". En definitiva, quieren contribuir a mejorar la calidad de nuestra democracia reinventando y reimpulsando el periodismo $^{23}$.

El emblema del periódico es el león, un antiguo símbolo español desde tiempos remotos como sinónimo de fortaleza y representación de soberanía popular. Ruge para denunciar abusos y es, además, otro símbolo para la monarquía parlamentaria. El logotipo creado por el diseñador bielorruso Sergey Kovalenko bajo la batuta de Audacity Partners, el estudio londinense del Alfredo Triviño que se encargó de definir la imagen del periódico. También hay un tema musical, que lo convierte en el primer diario de la historia con banda sonora

\footnotetext{
${ }^{23}$ Los periodistas de El Español se comprometen a proporcionar a los ciudadanos una información veraz de la más alta calidad. Para alcanzar ese objetivo se han redactado 26 normas de conducta, que se pueden consultar en: http://blog.elespanol.com/actualidad/normas-de-conducta-de-la-redaccion-deel-espanol/ [Consulta: 17/03/2016]
} 
patentada. Ha sido creada expresamente por el joven compositor Alex Baranovsky, ganador de un premio "Tony”.

\section{Conclusiones}

El 2 de febrero de 2016, Pedro J. Ramírez analizó la actualidad en el primer desayuno con una veintena de accionistas y suscriptores y también aprovechó para hacer un repaso de los primeros meses de la cabecera. En la cita se hizo mención explícita a los logros por los contenidos publicados. Exclusivas como la del 'caso Pujol' contribuido a destapar escándalos de corrupción. También se ha utilizado con profusión el nuevo periodismo de datos, sobre todo en las informaciones sobre elecciones, tanto en España como fuera. Se alabaron también las piezas políticas en profundidad, la información de tribunales y el enfoque que se ha dado a los perfiles detallados de ciertos personajes, un verdadero hallazgo periodístico. Sin embargo, en el ambiente flotaba una sensación de éxito a medias: El Español no es aún líder en la red como era su intención.

El modelo de negocio planteado combina ingresos publicitarios con la suscripción, porque no se quiere dejar que la coyuntura económica influya en los contenidos de calidad. Es una ventaja clara frente a otros medios nativos digitales que continuamente piden contribuciones y ayudas a sus lectores con el fin de poder 'mantener el periodismo libre'. En un momento de precariedad en el mercado, El Español ha invertido en profesionales. "Hay medios que gastan más en comprar papel que en pagar a los periodistas y eso no es lo que nosotros queremos", ha comentado María Ramírez. El 85\% de los gastos de la editora (si se exceptúan los dos millones de euros invertidos este primer año en el lanzamiento) van a ir destinados al pago de salarios y contenidos.

24 'Pujol mintió a Hacienda para salvar su fortuna oculta'. Disponible en: http://www.elespanol.com/espana/20151111/78492153 0.html [Consulta: 17/03/2016] 
Sin embargo, también aquí se han producido algunas disensiones en el seno de la redacción. La más llamativa es la de Esteban Urreiztieta, el investigador estrella de la casa, que después de nueve meses de aventura en El Español ha decidido volver a El Mundo, de donde salió $^{25}$. Las negociaciones no están cerradas definitivamente, pero si la marcha del investigador principal del caso Noos y otros escándalos relevantes se confirma y Urreiztieta vuelve al diario de papel, Pedro J. recibirá un golpe de revancha del medio del que fue director durante 25 años y del que se ha llevado una decena de profesionales. Además, la salida forzada de dos redactores - Ana Tudela, de Economía, y Salvador Carmona, de Deportes- en febrero pasado ha puesto sobre la mesa un problema aún sin resolver: quién manda en la redacción. La coordinación de las secciones la ha asumido un equipo de una decena de profesionales que constituyen la médula del diario, con nombres como Ana Romero, Vicente Ferrer, John Müller o el propio Urreiztieta. Fernando Baeta es director en la práctica, pero María Ramírez influye mucho en los contenidos con una bicefalia de facto. Pedro J. está volcado en la promoción de cara a los inversores.

Las redes sociales explican el inmenso éxito de las primeras cifras expuestas por el periódico digital. El Español tenía ya presencia en Twitter, Instagram y Facebook el primer día de 2015. Le han ayudado a explicar sus posiciones, quiénes están detrás y a exponer sus propósitos de regeneración social, política y periodística a pesar de no tener aún contenido. Esta circunstancia exige un estudio pausado y profundo de una campaña, dirigida a unos usuarios muy segmentados, pero interesados en información de actualidad y política. Se llevó a cabo una fragmentación por nombres, palabras clave vinculadas a la actualidad, audiencias de programas de televisión afines, así como tres audiencias personalizadas: visitantes de elespanol.com, visitantes del formulario de inversión y usuarios que acabaron de formalizar el proceso. Para generar interacción y participación entre los seguidores y usuarios de Twitter

\footnotetext{
${ }^{25}$ La noticia de la marcha de Urreiztieta, aún por confirmar, la da el 16 de marzo PR Noticias. Disponible en: http://prnoticias.com/prensa/periodico-elmundo/20150416-el-mundo-ultima-con-esteban-urreiztieta-su-vuelta-comosubdirector-de-investigacion [Consulta el 16/03/2016]
} 
(@elespanolcom), además de publicar diferentes piezas de actualidad, se enriquecieron los tuits promocionados con la utilización de Website Cards, lo que generó tráfico desde la red social a la web de El Español. Sin embargo, los datos de ComScore no lo sitúan como líder del mercado digital.

El crowdfunding de El Español, como toda su campaña viral en redes sociales, se presenta en realidad como una confirmación de que "el factor tecnológico ha actuado como un potente facilitador de nuevas formas de interacción, intermediación y actuación colectiva", sin las cuales no hubiera sido posible el despegue definitivo del crowdfunding (Rodríguez de las Heras, 2013: 103). Es interesante el funcionamiento de la aplicación móvil, que permite compartir noticias desde lo que se ha llamado 'La Edición', el producto más valorado por los suscriptores, que lo reciben cada día a las 21:30. Pero, lo cierto es que el producto requiere familiarizarse con la nomenclatura de las secciones. ¿Qué entiende un internauta que llega nuevo a la web por 'El Río' o, sin ir más lejos, por 'La Edición’?

En la red funcionan mejor las plataformas sencillas, en las que el internauta no tenga que pensar en el formato. Google ha dado una gran lección con ello: llegas y ves un cuadro en donde plantear las búsquedas. El diseño de El Español es bonito y la navegación cómoda para el suscriptor ya habituado. Sin embargo, para muchos lectores no es así. Les resulta molesto e incómodo y preferirían la fórmula de "convertir en PDF las noticias más interesantes y ofrecerlas de forma sencilla, con vídeos incrustados o lo que quiera".

El gestor de contenidos por el que se ha optado "resulta incómodo y necesita un numeroso equipo tecnológico para presentarlo dignamente"26. Lo más reseñable en este punto es que, en principio, se utilizó una tecnología al alcance de cualquier otro usuario de la red: una plataforma de Wordpress fue la palanca de lanzamiento de todo el gran proyecto. Pero el diario ha ido complicando las exigencias

\footnotetext{
${ }^{26}$ Comentarios del analista de medios Joaquín Abad. Disponible en: http://difusion.com.es/noticia/7856/por-que-el-espanol-de-pedro-j.-no-es-ellider.html [Consultado el 14/03/2016]
} 
técnicas a medida que incorporaba periodismo de datos, vídeos y tablas interactivas.

Precisamente, como proyecto de emprendimiento empresarial, El Español cumple de alguna manera con la regla de las tres efes (del inglés friends, family and fools, o lo que es lo mismo, amigos, familia y locos). En este caso, en la familia había más de cinco millones de euros recogidos por Pedro J. Ramírez de su despido. Los locos, que probablemente no lo son tanto, son los 5.624 accionistas. Tampoco lo son sus 11.000 suscriptores.

Todavía es pronto para sacar conclusiones definitivas. Mientras realizábamos este trabajo, Eduardo Inda, sin tantas alharacas como Pedro J., pero claramente enfrente de él, ha lanzado su propio medio digital, okdiario.com, que en tres meses se ha situado en el puesto 14 de ComScore, con casi tres millones de usuarios en un espacio que hasta ahora se consideraba saturado. La red ofrece un ecosistema difícil para los medios, sin duda, pero el dinero y la profesionalidad no son garantía de éxito arrollador. Aunque a El Español no le ha ido mal, tiene aún mucho que decir y, lo que es más importante, goza de un buen colchón económico para aguantar unos años.

\section{Bibliografía}

AEDE (Asociación de Editores de Diarios de España) (2013): Libro blanco de la prensa diaria 2013. Madrid: AEDE.

Cervera, J. (2013): Prólogo, en Anderson, C.W.; Bell, E. y Shirky, C. (Periodismo postindustrial: adaptación al presente. Huesca: Editorial eCícero. Asociación de Periodistas de Aragón.

Astigarraga, E. (2003): El método Delphi [en línea]. San Sebastián:

Universidad de Deusto. En:

http://www.unalmed.edu.co/ poboyca/documentos/document os $1 /$ documentos-

Juan\%20Diego/Plnaifi_Cuencas_Pregrado/Sept_29/Metodo_del phi.pdf; (Consulta 20/09/2015). 
Boczkowski, P. (2006): Digitalizar las noticias. Innovación en los diarios online. Buenos Aires: Manantial.

Campos, F. (2010): "Las empresas de medios de comunicación revisan y amplían sus modelos de negocio" [en línea], Razón y Palabra, $n^{\circ} 74$, "http://www.razonypalabra.org.mx/N/N74/VARIA74/16Freire V74.pdf; (Consulta 02/09/2015).

Casadesús-Massanell, R. y Ricart, J. E. (2009): “From Strategy to Business Models and to Tactics" [en línea], Harvard Business Review School, "http://www.hbs.edu/faculty/Publication\%20Files/10036.pdf; (Consulta 28/09/2015).

Díaz Nosty, B. (2011): "La crisis en la industria de la prensa. Vida más allá del papel”, Telos: Cuadernos de comunicación e innovación, $\mathrm{n}^{\mathrm{O}}$ 86 , pp. 52-65.

Fernández-Sande, M. (2013): "La crisis de la prensa en España: Análisis del caso Público, un diario nacido a contracorriente", Revista de Comunicación Vivat Academia, no 122, pp. 22-39.

Fidler, R. (1998): Mediamorfosis: comprender los nuevos medios. Buenos Aires: Granica.

Gallardo Olmedo, F. (2011): "En la era de los contenidos digitales. Nuevos modelos de negocio para la prensa", Telos: Cuadernos de comunicación e innovación, $\mathrm{n}^{\circ}$ 86, pp. 76-86.

García Santamaría, José Vicente (coord.) (2014): El negocio de la prensa digital. Madrid: UNIR.

Goyanes Martínez, M. (2013): "Estrategias y modelos de negocio: aclaración de conceptos y terminología de la prensa en Internet", Estudios sobre el mensaje periodístico, vol. 19, n 1 , pp. 419-431.

Iinforme MONGOLIA (2013): Papel Mojado: La crisis de la prensa y el fracaso de los periódicos en España. Barcelona: Editorial Mong.

Kawulich, B. B. (2006): "La observación participante como método de recolección de datos" [en línea], Forum Qualitative Sozialforschung/Forum: Qualitative Social Research, vol. 6, n 2, 
“http://nbn-resolving.de/urn:nbn:de:0114-fqs0502430; (Consulta 10/10/2015).

Lewis, S. C. (2011): “The Knight News Challenge: How it works, what succeeds, and why that matters for the shaping of journalism innovation". Comunicación presentada en el International Symposium on Online Journalism, 2 de abril. Austin, Texas (USA).

López García, X. (2012): Movimientos periodísticos. Salamanca: Comunicación Social.

Llorca Abad, G. (2010): "El crowdfunding y los nuevos modelos de negocio info-digital". I Congreso Internacional de Comunicación Audiovisual y Publicidad: Internet y la Información. Universidad Miguel Hernández. Alicante 79-98. Disponible en: https://www.academia.edu/1278162/El crowdfunding y los nu evos modelos de negocio info-digital (Consulta 10/10/2015).

Nel, F. (2010): "Where else is the money? A study of innovation in online business models at newspapers in Britain's 66 cities", Journalism Practice, vol. 4, $\mathrm{n}^{\circ} 3$ (Special Issue: The Future of Journalism), pp. 360-372.

Orihuela, J. L. (2004): "Los diez paradigmas de la e-Comunicación" [en línea]. En:

"http://www.agetec.org/ageteca/Los $\% 2010$ Paradigmas $\% 20 \mathrm{de} \% 2$ 0la\%20e-Comunicacion.pdf; (Consulta 12/11/2015).

Orihuela, J. L. (2013): "Los periódicos han dejado de ser papel impreso" [en línea], eCuaderno, "http://www.ecuaderno.com/2013/09/18/los-periodicos-handejado-de-ser-papel-impreso/ (Consulta 15/11/2015).

Pérez Bahón, F.; Clemente, Mª D. y López Aboal, Ma (2013):

"Estrategias de supervivencia en tiempos de crisis: la desintegración y metamorfosis digital de Público como paradigma del nuevo emprendimiento empresarial". Actas del V Congreso Internacional de Ciberperiodismo y Web 2.0. Servicio Editorial de la Universidad del País Vasco, pp. 352-381 
Pérez Bahón, F.; Clemente, $M^{a}$ D. y López Aboal, Mª (2015): El crowdfunding periodístico transforma el escenario mediático en España. Comunicación en el XXI Congreso Internacional de la Sociedad Española de Periodistica (SEP) Zaragoza, 20 de junio.

Pérez Colomé, J. y Domínguez Martín, E. (2012): Microperiodismos: Aventuras digitales en tiempos de crisis. Barcelona: Editorial UOC.

Pérez-Latre, F. J. y Sánchez Tabernero, A. (2012): Innovación en los medios: La ruta del cambio. Pamplona: Universidad de Navarra.

Plenel, E. (2012): Combate por una prensa libre. Barcelona: Edhasa.

Rodríguez de las Heras, T. (2014): El crowdfunding como mecanismo alternativo de financiación de proyectos. Revista de Derecho Empresarial, 1, 121-140.

Salaverría, R. (2007): "Los diarios frente al reto digital", Chasqui, no 97, pp. 4-9.

Tateb, N. N. (2012): El cisne negro. Nueva edición ampliada y revisada: El impacto de lo altamente improbable. Barcelona: Paidós.

Varela, J. (2011): "Perspectivas y retos. Periodismo mutante", Telos: Cuadernos de comunicación e innovación, no 86, pp. 107-110. 



\title{
La Marea como modelo de negocio: nuevas formas de organización, financiación e innovación en el producto
}

\author{
Gema Alcolea Díaz
}

Universidad Rey Juan Carlos

\author{
María José Pérez Serrano \\ Universidad Complutense de Madrid
}

Forma de citar este capítulo: Alcolea Díaz, G.; Pérez Serrano, M.J. (2016): “La Marea como modelo de negocio: nuevas formas de organización, financiación e innovación en el producto", en García Santamaría, J.V. y Pérez Bahón, F. (coord.): Los medios digitales españoles: procesos de cambio e innovación. Cuadernos Artesanos de Comunicación, CAC104. La Laguna (Tenerife): Latina.

\section{Resumen}

La experiencia empresarial de La Marea constituye un claro exponente de los nuevos modelos que emergen en la industria de la comunicación en la transición digital. La innovación ha sido un factor que ha recorrido los vértices de la financiación, la estructura y el propio producto, en un proceso convergente que ha dado como resultado nuevos modelos de negocio. Se considera este caso como representativo de la búsqueda de nuevas fórmulas en el sector que se está llevando a cabo en todo el mundo y que, aunque se trata de un movimiento propio de todas las etapas históricas en el devenir de los media, se actualiza en el escenario de los medios digitales. El presente trabajo aborda desde la filosofía hasta el funcionamiento, las 
estrategias y los resultados fruto de la estructura cooperativa que sustenta La Marea, a modo de case study que aporte conocimiento sobre nuestro entorno empresarial.

\section{Palabras clave}

Empresa de comunicación; gestión de medios; transición digital; modelos de negocio; medios digitales

\section{Introducción}

$\mathrm{E}$ L surgimiento de La Marea tiene como telón de fondo los 579 nuevos medios nacidos en España desde 2008 (Asociación de la Prensa de Madrid, 2015), durante la última crisis económica. En este escenario, la industria mediática ha llevado a cabo una profunda revisión de los modelos de negocio anteriores, dando paso a nuevas relaciones comerciales y productivas, como respuesta a las dificultades vividas por el sector. Una transformación que se ha hecho aún más urgente y necesaria en el de la prensa, debido, fundamentalmente, al drástico descenso del número de lectores y de la inversión en publicidad.

Así La Marea, que emerge de los "rescoldos" de un medio tradicional, tras el cierre de la cabecera Público, en el año 2012, en su edición en papel y el despido de gran parte de su plantilla, es claro exponente del proceso de búsqueda de nuevas formas de organización, fuentes de financiación y la innovación en el producto.

Con una financiación basada en la captación de socios y suscriptores -a lo que se une la realización de donaciones-, expresión del valor de utilidad para el lector; una publicidad con claras limitaciones éticas; y una estructura bajo la forma de Sociedad Cooperativa formada por lectores y trabajadores que es, en sí misma, un elemento de comunicación de la reputación, transparencia y credibilidad, reflejo de la solidaridad en la actividad económica y la participación como eje esencial de su funcionamiento; convierten a esta experiencia empresarial en referente de los nuevos modelos mediáticos en la transición digital. 


\section{Fundamentos metodológicos}

En el plano de la metodología, hay que centrarse en cuatro aspectos concretos. En primer lugar, se ha elegido este diario digital, y su correspondiente revista mensual en papel, a modo de case study y ejemplo de los nuevos modelos de negocio, por la singularidad que representa esta experiencia empresarial en nuestro país al converger los tres vértices antes descritos de estructura, financiación y output, teniendo en cuenta que, como singularidad, en esta ocasión vamos desmontar el título y abordaremos, en la progresión del discurso, primero el producto y, después, su estructura económica.

Con todo ello, y teniendo que cuenta que esta fórmula se está llevando a cabo en todo el mundo, y no sólo es algo propio de épocas recientes, buscamos conocer su filosofía, estructura, funcionamiento, estrategias y resultados, para, con una metodología inductiva, lograr entender $-\mathrm{y}$ explicar- mejor nuestro environment empresarial.

De este modo, construimos esta investigación a partir de la técnica metodológica del estudio de caso que para Walker (1983) es el "examen de un ejemplo en acción", cuya base epistemológica es, según Stake (2007: 46) "existencial (no determinista) y constructivista" y pone el énfasis en la interpretación. Se trata, pues, de un modelo de investigación fundamentado en la inducción (segundo aspecto), o el estudio de una porción de la realidad para obtener conclusiones presumiblemente generalizables o sintomáticas de la realidad.

A partir de este análisis se pretende alcanzar los siguientes objetivos:

O1_Entender el binomio "negocio dedicado a la comunicación y cooperativa", desde el punto de vista de su repercusión en los contenidos y en la estructura organizativa.

$\mathrm{O} 2$ _ Comprender algunos cambios en el sistema de medios en España tras la crisis económica iniciada en 2008. 
Se debe explicar (tercer aspecto) como se van a cohesionar las tres ideas que aparecen en el título. Se va a hacer bajo el término triangulación. Como señalan Hernández-Sampieri y Mendoza (2008), "dos nociones fueron importantes para la concepción de la investigación mixta: la referente a la triangulación y la de la utilización de varios métodos en un mismo estudio para incrementar la validez de análisis e inferencias". "El concepto triangulación tiene sus raíces en otros ámbito de conocimiento diferentes al de la investigación social.

Concretamente, en la topografía, en la navegación e, incluso, en la logística castrense" y consiste en tomar varios puntos de referencia para localizar la posición de un objeto en el mar". Jick (1979) propuso que cuando una hipótesis o resultado sobrevive a la confrontación de distintos métodos, tiene un grado mayor de validez que si se prueba por un único método y, más allá, cuando se utilizan múltiples puntos de referencia, y la mezcla de elementos cuantitativos y cualitativos, para analizar un objeto "se logra una mayor precisión que la alcanzada mediante la aplicación de un único punto de referencia" (Cea D’Ancona, 1999: 47). Este es nuestro caso.

Finalmente, es preciso matizar que la elaboración de estas páginas han estado guiadas por la estructura típica de la redacción técnica en Ciencias Sociales (el sistema conocido como IMRyDC+B introducción, metodología, resultados y discusión y conclusiones, más bibliografía-), aunque, por supuesto, adaptada a las necesidades y especificidad del objeto de estudio, y que las limitaciones metodológicas de este estudio se centran en que es una investigación basadas en técnicas inductivas y los resultados son el reflejo del análisis de un único, es decir, por lo limitado de la muestra, los correlatos obtenidos eran sintomáticos y no representativos.

\section{Marco teórico}

Abordar un estado de la cuestión sobre el tema que nos ocupa supone asumir una multiplicidad de variables que configurarían, en un 
análisis profundo, un planteamiento complejo, rico y poliédrico de la realidad empresarial comunicativa actual.

Sin llegar ahí, partimos de la base de que estamos en el entorno de la Economía Política de la Comunicación que estudia "las relaciones sociales, especialmente de las relaciones de poder que mantienen los sujetos que producen, distribuyen y consumen los medios de comunicación" (Mosco, 2006: 57-59) y de autores esenciales de la media economics, como Albarran (2010), Picard (1989), Croteau y Hoynes (2001), Croteau (2006) o Doyle (2008), y el análisis de Empresa Informativa (Nieto; Iglesias, 2000), que es un "conocimiento científico de carácter específico que se viene impartiendo en Ciencias de la Información, desde 1971, con la finalidad de facilitar el ejercicio del periodismo profesional y cuyos saberes básicos se centran en el funcionamiento de dichas unidades de negocio, lo que implica la interpretación crítica de la realidad de la industria de la Comunicación: un sector que ha alcanzado un gran protagonismo en esta Sociedad Global de la Información, y en el que la implicación de las nuevas tecnologías pueden transformar decisiones empresariales que afectan a la ciudadanía en su capacidad de elección y opinión en libertad" (Peinado; Fernández Sande; Ortiz Sobrino; Rodríguez Barba, 2011).

Por otro lado, dos conceptos pivotan en análisis: 1) "modelo de negocio" del que Drucker (1954) habla por primera vez, y que se entiende como "instrumento de gestión estratégica que describe y sintetiza la organización de los recursos, competencias y actividades para crear valor" (Campos Freire, 2010: 17); que, según Picard (2002), puede ser definido como la arquitectura del producto, sus servicios y flujos de información, e incluye una descripción de sus actividades, los beneficios potenciales para los intervinientes y las fuentes de ingresos de las que se nutrirán sus presupuestos; que, desde la perspectiva de Timmers (1998) encierra "la arquitectura del producto o servicio, la especificación de los distintos actores que participan en el negocio y sus roles y la definición de las fuentes de ingresos"; que, en palabras de Roses (2010), explica cómo operan las empresas de comunicación para intentar dominar el mercado (producto, 
estrategias, estructuras de costes y modelo potencial de ingresos), y que, en resumen, recoge productos o servicios y su ventaja competitiva, rasgos de organización y estructura económica (ingresos, gastos, costes) y financiera, por otro, de un negocio; y 2) el concepto "innovación", vinculado a la organización, la creación de producto y la mejora tecnológica (Stevenson; Jarillo, 1990).

En línea con esta última idea y los diferentes modelos de financiación en medios escritos, eldiario.es, Infolibre, elconfidencial.com, lamarea.com, esmateria.com, público.es, teinteresa.es, vozpopuli.com y lainformación.com (V. García; Pérez Serrano; Maestro; GómezBorrero, 2015), entre otros, son ejemplos muy a tener en cuenta y de cuyo magma hemos seleccionado La Marea por coincidir en esta experiencia empresarial y periodística nuevas formas de financiación, selección en los ingresos publicidad y una estructura cooperativa, como forma de organización, basada en la participación y el trabajo colaborativo y en equipo, y como modelo de gestión "específico", basada en la Economía Social, que "brota desde sus genuinos valores: centralidad de la persona en la actividad económica y solidaridad" (Morales, 2006: 163).

\section{Discusión y resultados}

Desde el año 2010 se ha venido produciendo en España -y en otros muchos mercados- un destacado número de iniciativas de emprendedores que han puesto en marcha nuevos proyectos informativos, que se ha desarrollado en un contexto en el que se ha desestabilizado todo el andamiaje anterior de la prensa y en el que los grupos de comunicación españoles han perdido buena parte de sus anteriores señas de identidad. Los anteriormente referidos medios creados en nuestro país por periodistas en los últimos años son la bandera de un proceso de destrucción creativa (dentro de la dinámica propia del capitalismo que indicara, desde principios del siglo pasado, Schumpeter) en la industria mediática.

Un proceso en el que, si bien la historia de la destrucción es continuamente referida (con la pérdida de cientos de empleos en el sector y el cierre de cabeceras), no lo es tanto el relato de la 
creatividad, por lo que se hace necesario hacer hincapié en el aspecto de innovación en el periodismo, como tendencia propiciada por estas nuevas experiencias (Bruno; Kleis, 2012). Esta faceta, la de la creación, queda patente en la descripción del proyecto de La Marea que sus promotores relatan, al considerar que con el mismo lo se que pretendía era abrir camino dentro de una profesión que no pasaba por sus mejores momentos y ser una reivindicación del periodismo digno e independiente.

Adentrémonos, pues, en un ejemplo de las iniciativas nacidas en el periodo de tiempo que abarca de 2010 a 2015, en el que, según García-Santamaría, se han producido novedades relevantes que afectan fundamentalmente a la organización del newsroom, los desarrollos tecnológicos y los modelos de financiación (V. García; Pérez Serrano; Maestro; Gómez-Borrero, 2015).

\subsection{De Público a MásPúblico Sociedad Cooperativa: antecedentes y organización}

El cese del diario Público en su edición impresa llevó al nacimiento de nuevos medios, entre ellos, La Marea. Un grupo de antiguos periodistas de aquel diario fundó la cooperativa MásPúblico con el objeto de pujar en subasta por la cabecera Publico.es. La idea era refundar el proyecto tras hacerse con la cabecera, algo que finalmente no pudieron lograr. No obstante, aquella primera acción dejaba ya un importante reflejo del nuevo estilo de implicación de la sociedad en el proyecto desde sus comienzos: mediante una campaña de micromecenazgo popular, a través de la web www.verkami.com, se pretendió alcanzar un mínimo de 30.000 euros (cantidad que fue superada, alcanzándose 33.170) para pujar por Publico.es.

Los promotores continuaron y MásPúblico editó, bajo este nombre, en verano de 2012, dos números especiales impresos distribuidos de forma gratuita -la edición digital estaba teniendo una media de 20.000 visitas diarias (La Marea 16/07/12)-, germen de la posterior publicación mensual La Marea (que en noviembre de 2015 lanzaba su número 32). 
La Ley 27/1999, de 16 de julio, señala, en su art. 1:

"La cooperativa es una sociedad constituida por personas que se asocian, en régimen de libre adhesión y baja voluntaria, para la realización de actividades empresariales, encaminadas a satisfacer sus necesidades y aspiraciones económicas y sociales, con estructura y funcionamiento democrático, conforme a los principios formulados por la alianza cooperativa". Asimismo, "cualquier actividad económica lícita podrá ser organizada y desarrollada mediante este tipo de sociedad".

Con este fundamento jurídico, MásPúblico nació a imagen y semejanza del periódico alemán Tageszeitung (TAZ). De hecho, en la propia radiografía que ofrece de sí misma en su página web, la cooperativa señala a esta publicación con décadas de historia como su principal referente.

Este diario, surgido en los años 70 en Alemania, superó una crisis económica a principios de los 90 con su transformación en un medio cooperativista, constituyendo una nueva sociedad con más de veinte años ya de experiencia. Se reseña como un modelo sostenible de periódico financiado por una cooperativa de 12.000 miembros y con 250 empleados y de la que obtuvieron asesoramiento durante el proceso de constitución (APM, 14/02/2013), además de haber compartido algunos contenidos de su corresponsal en España. Igualmente, MásPúblico tiene otras relaciones de intercambio de contenidos con otras publicaciones, como con el semanario suizo Wochenzeitung o con Occupy.com.

A mediados de julio de 2012 celebraba en Madrid su asamblea constituyente en la que se aprobaban los estatutos y un nuevo Consejo Rector. MásPúblico está constituida como Sociedad Cooperativa integral con una actividad cooperativizada doble: la propia de las cooperativas de trabajo asociado y la de cooperativas de consumidores y usuarios. En sus estatutos de constitución (2012), se señala como objeto de la misma el proporcionar a los socios trabajadores puestos de trabajo así como el suministro de bienes y 
servicios de información y conocimiento; siendo su principal actividad económica la actividad profesional orientada a la investigación, la redacción de información en forma de noticias y su reproducción en todo tipo de medios de comunicación.

El órgano supremo de la expresión de la voluntad social es la Asamblea General de la Cooperativa, que se reúne como mínimo una vez al año, siendo paritario el derecho de voto entre los socios trabajadores y los socios usuarios. Cada socio tiene un voto, pero además en la Asamblea el conjunto de los socios trabajadores computan por el 50\% de los votos, al igual que el conjunto de los votos de los socios usuarios.

En cuanto al órgano de administración, este es el Consejo Rector, órgano colegiado de gobierno al que corresponde la alta gestión y la supervisión de los directivos y la sociedad cooperativa. En sus estatutos se fijó que esté conformado por un mínimo de seis miembros titulares (actualmente se mantiene en este número concreto, y se reúne una o dos veces al mes) y siempre par, elegidos por la Asamblea General de entre los socios, existiendo paridad de representantes de socios trabajadores y socios usuarios.

También los cargos - cuyo ejercicio no da lugar a retribución algunason elegidos por la Asamblea y aunque en un principio en los Estatutos se definió que el Presidente se designara de entre los socios trabajadores, el Vicepresidente y el Tesorero del colectivo de socios usuarios, y fuera indistinto entre los dos colectivos la elección del Secretario, esta distribución quedó revocada en su posterior reforma (2015).

La duración ordinaria del mandato de sus miembros es de un máximo de tres años, pudiendo ser reelegidos sucesivamente por iguales periodos. Además, se contemplaba la existencia de un Gerente y de un Interventor que se erige como órgano de fiscalización de la Cooperativa, cuya principal función es auditar las cuentas anuales. 
Unos estatutos que fueron elaborados de forma colectiva y "pensados para que ningún poder económico o político pudiera controlar ni condicionar" la línea editorial de La Marea (03/09/2015).

El capital social se constituye por aportaciones obligatorias y voluntarias de los socios, acreditadas mediante títulos nominativos en todo caso. En cuanto a las aportaciones obligatorias, se diferencian las de los socios trabajadores y de los socios usuarios. Los socios trabajadores para obtener dicha condición tienen la obligación de suscribir como aportación obligatoria mínima 30 títulos. Estas aportaciones están representadas en títulos de un valor de 100 euros, por lo que supone un total de 3.000 euros.

En el caso de los socios usuarios, debían poseer como aportación mínima 10 títulos (un total de 1.000 euros), cantidad que posteriormente (Estatutos, 2012) se redujo a un mínimo de cinco títulos (500 euros). En ambos casos, era necesario el desembolso del $25 \%$ en el momento de la constitución. Y se establecían las mismas condiciones para los socios que ingresaran con posterioridad a la constitución de la cooperativa. En todo caso, sea cual sea la condición del socio y el tipo de aportación, y tal y como exige la Ley de Cooperativas, el importe total de las aportaciones de cada socio en el capital social no puede exceder un tercio del mismo.

Según datos de septiembre de 2015, el organigrama estaba formado por cinco socios trabajadores y 84 socios usuarios. A estos se sumaban una fórmula creada por la cooperativa, sin refrendo en la legislación actual, que es la del socio colectivo. Esto es, una agrupación de personas puestas de acuerdo para reunir la aportación al capital social y así participar en la cooperativa, con un representante que es el único miembro de pleno derecho, aunque todos los miembros del socio colectivo pueden asistir y deliberar en las Asambleas. En alguna ocasión han referenciado la existencia de ocho socios colectivos representando a 51 personas.

$\mathrm{Y}$, también con cifras de la misma fecha, se señala la existencia de 2.680 suscriptores, quienes son el principal pilar del proyecto junto a 
la venta al número (esta representa algo más del $60 \%$ de la venta total de ejemplares):

"En La Marea no hay accionistas mayoritarios ni inversores de ningún tipo, sólo gente independiente que cree en la necesidad de construir un medio que esté blindado ante cualquier tipo de presión, económica o política. A lo largo de estos dos años, nuestra principal fuente de ingresos han sido las suscripciones" (La Marea, 15/12/2014).

A pesar de su gran crecimiento (de 500 suscripciones en marzo de 2013, cierran ese año con más del doble y con una cifra casi cinco veces superior dos años y medio después), aún su número queda lejos de los 5.000 suscriptores que se han señalado como necesarios para ser sostenibles (La Marea, 08/10/13).

Cabe señalar, en cuanto a su estructura organizativa, que cuenta con una figura que llaman "nodos": lectores organizados por su propia iniciativa para hacer llegar La Marea, distribuyéndola en librerías y otros puntos de la geografía donde no tiene distribución en quioscos, quienes incluso organizan presentaciones para promocionar la publicación. "Los nodos de distribución y difusión de La Marea son una de las muestras más claras de que los medios de comunicación pueden ser horizontales y participativos" (La Marea, 12/05/14).

Esta estrecha relación con el lector, de hecho, se afianza a través de una enorme actividad de refuerzo de vínculos, de sentimiento de comunidad, llegándose a crear, a finales de 2014, el "Club de Amigos y Amigas" -salvando los obstáculos que para la filosofía de la cooperativa supone la propia palabra "club", queriéndose distanciar del matiz de exclusividad-, esenciales para lograr la sostenibilidad del medio:

"Debemos consolidar una comunidad fuerte, la que nos permite rechazar, como ha sucedido este mes, el anuncio de una multinacional de supermercados que revienta precios $y$ condiciones laborales. No se trata simplemente de ser independientes. También queremos ser coherentes. $\mathrm{Y}$ es posible gracias a ti”. (La Marea, 15/12/14). 
Un sentimiento y unos lazos que se refuerzan continuamente. Valgan de ejemplo la fiesta llevada a cabo en marzo de 2015 al cumplirse los 25 números en papel o los numerosos eventos organizados por La Marea, como las tertulias, entre otras acciones.

Hay cuatro tipos de membresía: simpatizante, digital, estrella y mecenas, cuyas aportaciones monetarias -el simpatizante no realiza ninguna en cuanto al hecho de esta vinculación- han variado en cuantía a lo largo del tiempo (con una ligera rebaja) y en condiciones. Los tipos de suscripciones de pago son:

1) Digital. Por 18 euros permite recibir 12 nuevos números de La Marea en formato digital, acceso a promociones especiales (descuentos en ocio, libros, merchandising, etc.), al pdf de todos los ejemplares de La Marea editados y a las Newsletters.

2) Estrella. Por 30/50 euros (más gastos de envío para otros países de la Unión Europea y resto del mundo), se reciben 6/12 números en formato papel y digital, además del regalo de un libro, la invitación a un encuentro trimestral de debate sobre actualidad política y económica, las promociones especiales y el acceso al archivo digital completo y las Newsletters.

3) Mecenas. Por 120 euros (con los mismos gastos de envíos ya señalados), se suman a las condiciones anteriores otros libros de regalo y más invitaciones a actos, como la asistencia a un Consejo de Redacción.

El trabajo promocional para lograr suscriptores es intenso, basado en descuentos en la suscripción y ofertas a los suscriptores de La Marea para adquirir otros productos editoriales, o incluso para regalar en ocasiones especiales como Navidad. 
También es posible la compra de números sueltos, con un coste de entre 1,80 euros y 2 euros. Si además se añade el formato papel, hay que sumar una cantidad adicional de entre 3,20 y 4 euros.

A este sistema de financiación mediante aportaciones de los socios (trabajadores y usuarios), de suscriptores y la venta al número, se le añade la publicidad (que por decisión propio no podría sobrepasar el $15 \%$ y que, como veremos más adelante, está alcanzando en torno al $5 \%$ ) y las donaciones personales.

\subsection{Producto y principios configuradores}

Pero, por si la constitución jurídica y el sistema de financiación no fueran suficientes como elementos diferenciadores de La Marea, existen más componentes que permiten formular este negocio como singular. Nos referimos a sus principios configuradores, la identidad, la cultura y los valores. Estos intangibles corporativos se organizan en un esquema holístico, impregnan a todos los niveles estructurales de la organización y se reflejan en un producto/servicio que es su principal ventaja competitiva (Rodríguez Pallares; Pérez Serrano, 2015).

A la misma vez, constituyen el conjunto de aspectos que, necesariamente, da a conocer la organización sobre sí misma (a través de su apartado "Quiénes somos" de su periódico digital y del "Conócenos" de la página web de su revista) y que, en este caso, reflejan el principio de transparencia de la que hace gala la publicación.

En primer lugar, el periódico subraya su apuesta por un periodismo riguroso y comprometido, los reportajes en profundidad y la cultura, todo ello manteniéndose libre de intereses tanto empresariales como políticos y teniendo por principios los siguientes:

- La libertad.

- La igualdad.

- La laicidad.

- La defensa de lo público. 
- Los derechos y movimientos sociales.

- La economía justa.

- La regeneración democrática.

- La denuncia de la ilegitimidad de la monarquía.

- La memoria histórica.

- La cultura libre.

- El trabajo y la vivienda dignos.

- El respeto por el medio ambiente.

- La autodeterminación de los pueblos.

Este último, el derecho a la soberanía de los pueblos (entendido como el derecho de éstos a ser reconocidos como tales, a definir sus propias formas de gobierno y modelo político y económico, así como a buscar sus propias formas de desarrollo cultural y humano) fue añadido posteriormente, votado en Asamblea el 20 de junio de 2013. Se trataba una cuestión tan de actualidad que "merecía una toma de postura clara" y en coherencia con el objetivo de aspirar a una total independencia, el medio ha tratado sin tabúes el tema de la reclamación independentista en Cataluña, dando VOZ a quienes abogan por esta posibilidad (La Marea, 05/09/13).

Quepa, igualmente, un inciso a la forma de demostrar que sus principios editoriales son totalmente configuradores, como ocurre con el de igualdad: el 100\% de los puestos de responsabilidad de La Marea estén ocupados por mujeres -los puestos de dirección y gerencia son desempeñados por mujeres, al igual que la presidencia y la vicepresidencia de la empresa editora (La Marea, 05/10/2015)-; o una oferta temporal (octubre de 2015) de un 24\% de descuento para las mujeres que quieran suscribirse a la revista, como denuncia de la brecha salarial entre mujeres y hombres, que se sitúa justo en ese porcentaje.

A todo ello se une un código ético publicitario, aprobado en asamblea, que rechaza aquella publicidad que contravenga los principios arriba referenciados, haciendo mención expresa a aquella que provenga de bancos que ejecuten desahucios, empresas con inversiones en armas, arrasan recursos naturales en América Latina, 
de fondos de inversión especulativos así como anuncios sexistas, racistas o que menoscaben la dignidad humana (como los de prostitución). Una defensa que el periódico convertía incluso en noticia (La Marea, 11/12/2015) para explicar su renuncia al jugoso servicio de publicidad de Google, Google AdSense, por incluir algunos anuncios contrarios a sus principios, como era el caso del de píldoras milagrosas para adelgazar utilizando como reclamo la imagen de la mujer, y su rechazo a las frecuentes ofertas de patrocinio de artículos a cambio de dinero, por el alto riesgo de falta de diferenciación de la publicidad.

En su modelo de negocio, como se ha señalado, la publicidad tiene que pesar menos del 15\% (el código ético de inserción publicitaria fija en ese porcentaje el máximo de ingresos posibles por esta vía -La Marea, 03/09/15-).

"El código ético se ha convertido en un sello de identidad de La Marea y ha permitido a sus periodistas trabajar sin la presión que, no pocas veces, ejercen bancos y multinacionales cuando la viabilidad de los medios depende de sus anunciantes. Asimismo, tenemos un compromiso con la transparencia: publicamos el balance de nuestras cuentas regularmente para que todos sepan en qué estado se encuentra la cooperativa (La Marea, Conócenos)".

Por lo tanto, podemos decir que los principios configuradores (entre los que están los “jurídicos y económicos, tanto de la sociedad mercantil que ostenta su titularidad, como de la actividad que lleva a cabo" -Iglesias; Blanco, 2004: 23-) de cualquier organización, y también de La Marea, representan su ADN, y de ellos se desprenden no sólo su estructura económica y jurídica, sino también su actividad (Nieto; Iglesias, 2000) y su cultura, que, por un lado, tiene una naturaleza tangible, que se demuestra en los párrafos antepuestos, y, por otro, empieza a pertenecer a un ideario colectivo que no aparece reflejado y que se asocia con su know how y los valores esgrimidos ya desde su eslogan "Periodismo para gente independiente", que afecta a su edición digital y a la revista. 
En cuanto al producto en sí, el primer número de La Marea apareció el 21 de diciembre de 2012, con una redacción de diez personas, algunas a tiempo parcial, además de colaboradores. Entonces no había dirección en el periódico, porque se quería un modelo más participativo. Tenía un precio de venta al número inicial de 3 euros. Actualmente, este es de 3,5 euros (la editora lamentó el incremento de precio, "pero hacer una revista independiente de intereses empresariales y políticos no es barato, sobre todo con restricciones a la publicidad tan rígidas como las nuestras; en este sentido, dependemos de la venta de ejemplares), aunque por ejemplo, el número 18 costó 4 euros porque tuvo 80 páginas y estuvo en los puntos de venta durante dos meses.

Consta de 64 páginas a color, en papel prensa mejorado, con formato periódico y grapado. Tiene un dossier central que trata en profundidad un tema de actualidad y secciones como Justicia, Sanidad, Privatizaciones, Política, Sanidad, Medio ambiente, Memoria histórica, Teatro, Música, Libros, Historia y Feminismo, Internacional (con hincapié en los contenidos de América Latina) -cabe resaltar en la web la sección de Cooperativas-, entre otras (APM, 20/12/12; APM, 14/02/13). Ha ido ampliando sus formatos, vendiéndose además de en papel en digital -primero en PDF y luego, a partir de febrero 2014 en formato adaptado para smartphones-. Y publica bajo licencia de derechos de autoría Creative commons by-SA (lo que refleja también su filosofía).

La revista mensual en papel se imprime por RotoMadrid (aunque se ha imprimido también en Imcodávila y la ha distribuido Logintegral), con una tirada declarada de 15.000 ejemplares.

La decisión de optar por el papel, al que se suma la versión digital, en un momento de agonía de este soporte y en el que se especula sobre el futuro de los periódicos impresos (Armentia, 2011) fue de los socios. Entre los motivos esgrimidos están que "en el papel se pueden explicar los contenidos de forma distinta" y una publicación en la que prima "el periodismo de investigación con mucha documentación, requería de una publicación impresa" (APM, 14/02/13). 
Respecto a la difusión de la edición digital, según Googleanalytics, tiene una media de tráfico mensual de 370.000 usuarios únicos (septiembre de 2014). El último dato interanual, que toma como referencia los meses de mayo de 2013 y 2014, señala que el número de usuarios únicos creció un $240 \%$, así como el aumento del número de seguidores en redes sociales (Twitter, 64.000; y Facebook, 17.000). $\mathrm{Y}$ todo ello con una muy cuidada edición y un diseño novedoso, $\mathrm{y}$ con una clara apuesta por el tratamiento gráfico, que le ha llevado a lograr varios premios (como la medalla de plata a la revista mejor diseñada en 2013 y 2014 en España y Portugal, certamen "ÑH Lo Mejor del Diseño Periodístico España\&Portugal"). Además, y pese a su corta historia, contó con un rediseño en agosto 2014, hacia un formato más ameno y visual, sin cambiar los códigos de color, las tipografías y la utilización de blancos.

Con respecto a la distribución, la mayor parte de los ejemplares se vende en quioscos en 16 provincias a través de una distribuidora, aunque también venden a través de la red conformada por los "nodos" en distintos puntos de venta.

\subsection{Estructura económica}

Aunque las experiencias societarias no mercantiles han estado presentes en el sector de la comunicación, es destacable del peso específico que, desde la crisis, están cogiendo en los medios escritos (impresos y digitales). Ahora bien, sea cual sea la forma adoptada, la estructura orgánica que la guía toma continuamente decisiones de corte cuantitativo y cualitativo.

En las primeras, el presupuesto y la contabilidad adquieren notoriedad, más aun teniendo en cuenta que en los negocios periodísticos, como es el caso que nos ocupa, su estructura de ingresos es doble (lector -venta y suscripción- y anunciante) y que, después de pasada su fase inicial donde la preocupación máxima es asentarse en un mercado atomizado, sus esfuerzos se centran en consolidar su modelo de negocio.

Quizás, la cooperativa responde a una moda en el ámbito de la gestión -como fenómeno estructural cuya vigencia temporal está en función de su capacidad de resolver problemas más o menos 
generalizados (Morales Gutiérrez, 2006)-, pero no es sólo eso. El hecho de que en Europa proliferen los modelos cooperativistas en el mundo periodístico destaca la búsqueda de horizontalidad y democratización propias de este modelo de organización. Aunque no son sólo eso. Los principios cooperativos se inspiran en los valores de
"La solidaridad, la democracia, igualdad y vocación social [...] elementos indispensables para construir una empresa viable con la que los socios se identifican al apreciar en ella la realización de un proyecto que garantiza su empleo y vida profesional" (Ley 27/1999, Exposición de Motivos).

La cooperativa MásPúblico conseguía el sello de la Xarxa d'Economia Solidària, un distintivo de confianza que identifica y diferencia las organizaciones comprometidas con los principios de economía social y solidaria, para lo que tuvo que realizar un balance social midiendo varios parámetros (la democracia, la igualdad, el medio ambiente, el compromiso social y la calidad laboral y profesional) a través de un cuestionario a los trabajadores y otro a suscriptores.

Aunque nadie sabe aún qué tal funcionarán estos modelos, lo que está claro es que no podrán sobrevivir solamente de los ingresos por publicidad online. Encontrar un nuevo modelo para apoyar el periodismo está en el interés de la sociedad en su conjunto. La Marea en el apartado "Conócenos" de su web cita a Kornelia Gellenbeck, una de las responsables de la cooperativa del TAZ, precisamente resaltando este aspecto, al entender que "los socios no esperan tener un beneficio económico, sino que quieren contribuir a la supervivencia del periódico y a la pluralidad de la prensa, lo que creen importante para la democracia".

Arianne Huffington, cofundadora de The Huffington Post, y que coopera con las organizaciones de noticias financiadas de forma filantrópica, señala que es necesario un cambio de mentalidad entre los donantes: "tenemos que entrar en el hábito de dotar sin fines de lucro las empresas periodísticas, tanto a nivel nacional como a nivel 
local, como la gente dotan sillas en las universidades" (The Economist, 07/07/11).

Las start-ups periodísticas online tienen el objetivo de ir más allá de los modelos previos (persiguiendo diferentes formas de excelencia en sus contenidos), pero todas se enfrentan al reto de encontrar un modelo sostenible (Bruno; Kleis, 2012). Para las sociedades cooperativas, en un mundo cada vez más competitivo y riguroso en las reglas del mercado,

"La competitividad se ha convertido en un valor consustancial a su naturaleza cooperativa, pues en vano podría mantener sus valores sociales si fallasen la eficacia y rentabilidad propias de su carácter empresarial, de otra forma el mundo cooperativo se encontraría en una situación de divorcio entre la realidad y el derecho [...] adecuado equilibrio con el fin último del conjunto de socios, que es la rentabilidad económica y el éxito de su proyecto empresarial" (Ley 27/1999, Exposición de Motivos).

En esta línea, el capital inicial con el que contó el proyecto fue de alrededor de 70.000 euros (APM, 14/02/2013). Los datos de principios de 2013 señalan que el capital social ascendía a 94.000 euros de aportación comprometida, compuesto por las aportaciones de los socios trabajadores y socios usuarios, junto con un excedente (15.737 euros) de la acción de micromecenazgo de mayo de 2012 referida anteriormente -algunos donantes se convirtieron en socios y su dinero computó como capital social; descontando una comisión del 5\%, los 3.712 euros que la Cooperativo Integral Catalana (CIC) cobró por sus servicios y los gastos de edición del número gratuito de MásPublico de julio- y algunos donativos de personas.

Tanto las cuentas anuales como los informes de gestión y del interventor (o auditores) se deben poner a disposición de los socios para su información de forma previa a la convocatoria de la Asamblea. En el primer ejercicio completo, 2013, tuvo unas pérdidas de 98.990 euros que se redujeron hasta 15.766 euros en 2014, según la cooperativa por la reducción de los costes, el esfuerzo de los socios 
trabajadores que renunciaron a cobrar parte de su salario en los momentos más difíciles, como por la subida de las ventas.

En 2014 obtuvo una cifra de negocio de 185.317 euros, un aumento del 2,9\% frente al ejercicio anterior. La fuente de ingresos más importante son las suscripciones (40\% de la facturación), que a mediados de mayo de 2015 ascendían a 2.616 personas e instituciones suscritas. En 2013 el total de ingresos era de 179.981 euros, siendo el $5,1 \%$ debido a ingresos por publicidad (8.561 euros, en su mayoría correspondiente a anuncios breves). Este mismo porcentaje, 5\%, con un total de 8.192 euros, se repetía en 2015, una cifra muy baja reflejo de la situación del sector y del condicionante del código ético de la publicidad de La Marea.

En total, sus gastos, tanto en papel como en Internet, ascendieron a 201.083 euros en 2014 frente a los 278.972 euros de 2013. Las principales partidas del gasto son los salarios de los socios trabajadores (103.334 en 2013 y 72.143 euros en 2014 y) y el pago a colaboradores -autores de los artículos, fotógrafos, ilustradores o diseñadores- (70.933 euros en 2013 y 60.508 en 2014).

La mejora de la situación ha hecho posible que, desde marzo de 2014, se aumente el salario de cada trabajador hasta los 1.000 euros brutos. Cabe señalar que no se aceptan trabajos gratis (incluso en alguna oferta de empleo de 2013 para ampliar plantilla, al solicitar entre otros un becario, se señala expresamente que es con remuneración). Es el reflejo del compromiso ético de pagar por todas las tareas que se realizan, porque supone "la dignificación de una profesión ya demasiado destruida por la precariedad". Sin embargo, algunos colaboradores se han negado a cobrar, por lo que se ha sumado sus importes para convertirlos en socios usuarios y otros han canjeado sus colaboraciones por suscripciones.

La tercera partida es la imprenta, que en 2013 ascendió a 45.617,49 euros, desconocemos si junto a gastos de distribución, que en el caso de 2014, entre imprenta y distribución, se llevó 51.550 euros. El resto se destina a pagar el alquiler de la redacción (en 2013 ascendía a 700 euros mensuales, tras una experiencia previa de trabajo en un espacio 
de coworking a cambio del abono de los gastos corrientes) y los gastos corrientes. Según su web, La cooperativa no tiene deudas y está al día en todos sus pagos.

\section{Conclusiones}

Llegados aquí, y teniendo en cuenta que los objetivos marcados se han satisfecho, corresponde apuntar los correlatos que este trabajo. Se resumen a continuación:

- Todo el sistema, organización, posicionamiento en el mercado parece querer romper con la "prensa tradicional". Desde La Marea parece que una máxima es "salirse de lo que, hasta ahora, ha sido común". Los nuevos proyectos periodísticos online surgidos en Europa en los últimos años han sobrevivido sin entrar en competición con los medios de las organizaciones tradicionales que continúan manteniendo las más fuertes marcas y produciendo más contenido original que la mayoría de los medios incipientes. Pero los que han sobrevivido, y eso es por ahora para la mayoría el éxito, el lograr mantenerse, tienen tres cualidades en común: "el mantener los costes bajo control; diversificar sus ingresos básicos más allá de la publicidad online; satisfacer a una claramente definida audiencia de nicho" (Bruno; Kleis, 2012: 99).

- Parece que el modelo va adquiriendo poco a poco solidez en el mercado. Para las start-ups periodísticas online que no encuentran sostenibilidad comercial la pregunta es si pueden encontrar formas filantrópicas u otras formas de financiación externa (un tipo de financiación de proyectos que en la mayoría de Europa es menos común que en Estados Unidos). Los datos nos demuestran la tendencia hacia la sostenibilidad, si bien todavía queda lejos.

- Desde el punto de vista de la investigación, cabe resaltar que no está controlada por los organismos al uso en la mayor parte de las empresas de medios en España, lo que dificulta su disección analítica, aunque quizás nos tendríamos que acostumbrar al 
cambio: si la realidad empresarial de los medios ya no es la misma, probablemente la forma de estudiarlos tampoco.

\section{Bibliografía}

Albarran, A. (2010): The Media Economy. London: Routledge.

Armentia Vizuete, J.L. (2011): "La difícil supervivencia de los diarios ante la agonía del soporte papel", en Ámbitos. Revista internacional de Comunicación, 20, pp. 11-27.

Bruno, N.; Kleis Nielsen, R. (2012): Survival is success. Journalistic online start-ups in Western Europe. Oxford (Inglaterra): University of Oxford/Reuters Institute for the Study of Journalism.

Campos Freire, F. (2010): "Los nuevos modelos de gestión de las empresas mediáticas", en Estudios sobre el Mensaje Periodístico, 16, pp. 13-30.

Cea D’Ancona, M.Á. (1999): Metodología cuantitativa. Estrategias y técnicas de investigación social. Madrid: Síntesis.

Croteau, D. (2006): The Business of Media. Corporate Media and the Public Interest. Thousand Oaks (California): Pine Forge Press.

Croteau, D. , W Hoynes (2001): The business of media: Corporate media and the public interest. Thousand Oaks (California): Sage.

Doyle, G. (2008): Understanding Media Economics. Sage: New York.

Drucker, P. (1954): The Practice Management. Nueva York: Harper \& Row, Publishers Inc.

García Santamaría, J.V. (2014). El negocio de la prensa digital. Madrid: UNIR.

Hernández-Sampieri, R.; Mendoza, C.P. (2008): “El matrimonio cuantitativo-cualitativo: el paradigma mixto". En 6to. Congreso de Investigación. Universidad Juárez Autónoma de Tabasco, México, 5-8 de noviembre. 
Iglesias, F.; Blanco, M.M. (2004): "Principios editoriales y principios configuradores en el pensamiento del profesor Alfonso Nieto Tamargo", en Doxa Comunicación, 2, pp. 9-26.

Jick, T. (1979): "Mezclando métodos cualitativos y cuantitativos: triangulación en acción”, en Administrative Science Quaterly, 24.

Morales Gutiérrez, A. (2006): "Modas de gestión en el siglo XX y modelo cooperativo: convergencias implícitas hacia una empresa de alto rendimiento", en CIRIEC-España, Revista de Economía Pública, Socialy Cooperativa, 56, pp. 161-186.

Mosco, V. (2006): "La economía política de la comunicación: una actualización diez años después", en Cuadernos de Información y Comunicación, 11, pp. 57-59.

Nieto, A.; Iglesias, F. (2000): La empresa Informativa. Barcelona: Ariel.

Peinado Miguel, F.; Fernández Sande, M.; Ortiz Sobrino, M.Á.; Rodríguez Barba, D. (2011): "Hacia un aprendizaje activo de la Empresa Informativa en el EEES. Aplicación del postcasting y otras herramientas de comunicación 2.0”, en Razón y Palabra, 75, pp. 1-15.

Picard, R.G. (1989): Media Economics: Concepts and Issues. Thousand Oakes (California): Sage.

Picard, R.G. (2002): The Economics and Financing of Media Companies. New York: Fordham University Press

Rodríguez Pallares, M.; Pérez Serrano, M.J. (2015): “Principios configuradores y televisiones autonómicas. El caso de Radiotelevisión de Castilla-La Mancha y su gestión de crisis". En XXX CICOM 2015 "Retos de la televisión autonómica: estructura, financiación, contenido y audiencias". Universidad de Navarra, Pamplona, 12 y 13 de noviembre.

Roses Campos, S. (2010): "Cambio del modelo de negocio de los medios informativos”. En César Herrero, J. (ed.); Pérez-Ugena, Á. (coord.): Materiales para la innovación en Estructura de la Comunicación. Madrid: Universitas, pp. 129-163. 
Schumpeter, J.A. (1934): The Theory of Economic Development An Inquiry into Profits, Capital, Credit, Interest, and the Business Cycle. London: Harvard Economic Studies (46).

Stake, R. (2007): Investigación con estudio de casos. Madrid: Morata.

Stevenson, H.H.; Jarillo, J.C. (1990): “A Paradigm of Entrepreneurship: Entrepreneurial Management", en Strategic Management Journal, 11, pp. 17-27.

The Economist (07/07/2011): "Reinventing the newspaper"; recuperado el 22 de noviembre de 2015 , de http://www.economist.com/node/18904178/print.

Timmers, P. (1998): "Business models for electronics markets", en Electronic Markets, 8: 2, pp. 3-8.

Walker, R. (1983): "La realización de estudios de casos en educación. Ética, teoría y Procedimientos". En Dockrell, W.; Hamilton, D. (eds.): Nuevas reflexiones sobre la investigación educativa. Madrid: Narcea, pp. $42-82$.

\section{Otros documentos}

APM Asociación de la Prensa de Madrid (20/12/12): "Nace La Marea, periódico editado por la cooperativa MásPúblico"; recuperado el 18 de noviembre de 2015, de http://www.apmadrid.es/noticias/generales/nace-la-mareaperiodico-editado-por-la-cooperativa-maspublico.

--, (14/02/13): “La Marea proyecta convertirse en quincenal antes del verano; recuperado el 18 de noviembre de 2015, de http://www.apmadrid.es/noticias/generales/emprendedores-lamarea-ofrece-a-sus-lectores-control-sobre-el-medio?Itemid $=209$

--, (2014): Informe Anual de la Profesión Periodística 2015. Madrid: APM.

--, (2015): Informe Anual de la Profesión Periodística 2015. Madrid: APM.

La Marea (2012): "Estatutos de la Sociedad Cooperativa MásPúblico"; recuperado el 18 de noviembre de 2015, de 
https://www.dropbox.com/s/kzwg8oymzp1rf81/EstatutosCoop MasPublico.pdf

--, (16/07/2012): "La Cooperativa MásPúblico celebra su asamblea constituyente"; recuperado el 18 de noviembre de 2015, de http://www.lamarea.com/2012/07/16/la-cooperativamaspublico-celebra-su-asambleaconstituyente

--, (27/04/2013): “Las cuentas de La Marea”; recuperado el 18 de noviembre de 2015, de http://www.lamarea.com/2013/04/27/las-cuentas-de-la-marea/.

--, 05/09/2013: “La Marea incluye la soberanía de los pueblos entre sus principios editoriales"; recuperado el 18 de noviembre de 2015, de http://www.lamarea.com/2013/09/05/democracia-y-derechoa-decidir/

--, (08/10/2013): “La Marea estrena página web”; recuperado el 18 de noviembre de 2015, de http://www.lamarea.com/2013/10/08/lamarea-estrena-web/

--, (12/05/2014): "Primer encuentro estatal de nodos de La Marea"; recuperado el 18 de noviembre de 2015, de http://www.lamarea.com/2014/05/12/primer-encuentro-estatalde-nodos-de-la-marea/

--, (14/07/2014): "Las cuentas de La Marea en 2013: Cada día más cerca de la sostenibilidad"; recuperado el 18 de noviembre de 2015, de http://www.lamarea.com/2014/07/14/las-cuentas-de-lamarea-en-2013-cada-dia-mas-cerca-de-lasostenibilidad .

--, 15/12/2014: "Nace el club de amigos y amigas"; recuperado el 18 de noviembre de 2015 , de http://www.lamarea.com/2014/12/15/nace-el-club-de-amigos-yamigas

--, (2015): “Texto modificado de los Estatutos”; recuperado el 18 de noviembre de 2015, de http://www.dropbox.com/s/gihztzbw4791316/EstatutosCoopMa sPublico TextoModificado.pdf?dl $=0$ 
--, (05/06/2015): “Las cuentas de La Marea: un paso más hacia la sostenibilidad del medio"; recuperado el 18 de noviembre de 2015, de http:/ /www.lamarea.com/2015/06/05/las-cuentas-de-lamarea-un-paso-mas-hacia-la-sostenibilidaddel-medio

--, (03/09/2015): “¿Quién es el puto amo de La Marea?”; recuperado el 18 de noviembre de 2015, de http://www.lamarea.com/tags/consejo-rector/

--, (05/10/2015): “¿Por qué La Marea es una rareza?”; recuperado el 18 de noviembre de 2015 , de http://www.lamarea.com/2015/10/05/por-que-la-marea-es-unarareza/

--, (11/10/2015): “¿Por qué La Marea ha renunciado a AdSense? ”; recuperado el 18 de noviembre de 2015, de http://www.lamarea.com/2015/10/11/por-que-la-marea-harenunciado-a-google-adwords / 


\title{
Las revistas de nueva creación para tabletas impulsan el mercado editorial 'online' en España
}

\author{
Juan Yunquera Nieto \\ Universidad Carlos III de Madrid
}

\begin{abstract}
Forma de citar este capítulo: Yunquera Nieto, J. (2016): "Las revistas de nueva creación para tabletas impulsan el mercado editorial 'online' en España, en García Santamaría, J.V. y Pérez Bahón, F. (coord.): Los medios digitales españoles: procesos de cambio e innovación. Cuadernos Artesanos de Comunicación, CAC104 La Laguna (Tenerife): Latina
\end{abstract}

\section{Resumen}

El crecimiento continuo de las ventas de los soportes digitales como tabletas y smartphones están creando expectativas en el negocio editorial español. Se establece una nueva forma de dar respuestas a los maltrechos negocios tradicionales de prensa y se apuesta empresarialmente por estos devices que cuentan con un potencial en continuo descubrimiento. Los grandes grupos editoriales pierden peso específico y las pequeñas empresas encuentran un nicho donde moverse con agilidad, ya que sus pequeñas estructuras permiten respuestas de acción rápida ante los continuos cambios de tendencias. A partir de 2012 no ha dejado de crecer el número de publicaciones pure players para tabletas con productos informativos orientados a un público objetivo con targets muy concretos. Nos encontramos ante la cultura de la "información átomo" donde pequeños grupos de periodistas/emprendedores se introducen en el mundo editorial a través de dispositivos móviles ubicuos, como nuevo canal de distribución de contenidos y como nueva forma de emprendeduría. 
En este trabajo se analizan, también, los proyectos más importantes de revistas 'pure players' para tabletas en España.

Palabras clave: Revistas digitales; dispositivos móviles ubicuos; tablets; aplicaciones.

\section{Introducción}

— L 27 de enero de 2010 Steve Jobs, presidente de Apple presentó en sociedad la primera generación de tabletas iPad. Se mostraba como un híbrido entre ordenador y teléfono inteligente y asombró a consumidores y mercados, pero sobre todo supuso un revulsivo para las empresas tecnológicas tanto de gestión y creación de aplicaciones como productores de soportes móviles. En esta presentación Jobs rescató una frase que había publicado un mes antes Martin Peers en un artículo de The Wall Street Journal el 30 de diciembre de 2009 sobre la inminente aparición del iPad con el título "Last time there was this much excitement about a tablet, it had some commandments written on it" (La última vez que hubo tanta expectación por unas tablas, había algunos mandamientos escritos en ellas).

Desde luego, las expectativas no defraudaron a nadie pues ese mismo año, según un informe de IAB Research, se vendieron 18 millones de tabletas en todo el mundo, de ellas 15.300.000 eran de la marca Apple, porcentaje que representaba el 85\% del total.

La era post pc ya había comenzado, el iPad y los smartphones "mataron a la estrella del ordenador" certificando una nueva tendencia en el uso y consumo de tecnología. La posibilidad de leer prensa en formato web ya era un hecho desde hacía varios años, recordemos que en España el primer diario digital creado "solo para web" fue El diario Digital, de Pablo Sebastián, ex director de El Independiente, que vio la luz en 1998 y fue el primer referente de diario online pure player. Los grupos editoriales más importantes ya habían realizado versiones digitales de sus ediciones impresas dando el pistoletazo de salida a diarios como 
El Mundo, El País, La Vanguardia, El Periódico de Catalunya y otros diarios regionales.

En este sentido los editores anduvieron ágiles de reflejos y apostaron por implementar su negocio haciendo un producto específico de distribución online. Aunque al principio fue meramente testimonial, ya que utilizaban este servicio como tarjeta de presentación, más tarde observaron que las entradas online crecían sin parar, sobre todo porque el acceso a la información era gratuito. $\mathrm{Y}$ tuvieron muchas visitas, pero la publicidad, aunque compraba espacios de manera progresiva, seguía sin aportar grandes activos a las cuentas de resultados. Comenzaron, entonces, los muros de pago siguiendo el ejemplo de los diarios norteamericanos como The New York Times o The Financial Times, aunque esa modalidad no cuajó. Se levantaron muros que hubo que derribar después... aunque esa es otra historia.

Pero no solo de diarios viven los grupos mediáticos, los más importantes tienen entre sus productos revistas, suplementos, especiales, etc. De los 15 grupos más importantes editoriales en España la mayoría de ellos se dedican a la publicación exclusiva de revistas y solo unos pocos editan diarios y revistas. Estos grupos pensaron que las tabletas podrían ser una tabla de salvación para dar visibilidad a sus productos e intentar mejorar los balances de cuentas: "En esta era PostPC los nuevos dispositivos conectados como smartphones o tabletas pueden ser la gran oportunidad para los contenidos (Gómez-Borrero, P, 2010).

La consultora Bonnier y la empresa inglesa de diseño Berg llevaban meses investigando en la creación de herramientas para el diseño de revistas digitales; ambas se unieron en un proyecto creando la plataforma Mag+ que posibilitó la realización de la revista Popular Science en versión para iPad a la que llamaron Popular Sciencet. Pocos meses después le siguieron la no menos prestigiosa Sport Illustrated, Time o Wired. Todo un reto si tenemos en cuenta que las empresas de desarrollo de aplicaciones estaban experimentando y mejorando las herramientas sobre la marcha para hacer posibles dichos proyectos editoriales. 


\section{Marco teórico. La irrupción de revistas para tabletas en España}

Desde su aparición en 2010 las ventas de iPad no pararon de crecer, el máximo exponente se alcanzó en diciembre de 2013 con 26 millones de unidades vendidas. En 2014 esta racha alcista se frenó por la saturación del mercado debido al aumento de ventas de otros modelos de tabletas con el sistema android, especialmente las de la empresa coreana Samsung. No es el momento, todavía, de establecer comparaciones con el iPod, el "hermano pequeño" de la familia Apple. El reproductor de música más famoso del mundo inicio su andadura en 2001 pero dejó hace mucho tiempo de ser una estrella. Este producto ya no figura como tal en la cuenta de resultados de Apple y en las tiendas online españolas de la manzana mordida no aparece como producto, sí lo hace en cambio el reloj inteligente $i W$ acht. El iPod está incluido en accesorios en el apartado de música.

Los nuevos smartphones, debido a sus múltiples funcionalidades, han dado un golpe de muerte a este singular reproductor de música. Con las tabletas estamos iniciando un camino que puede parecerse al mencionado iPod, aunque es muy aventurado establecer que seguirán el mismo recorrido. Los smartphones junto con los ordenadores macintosh, sobre todo portátiles, son los que están haciendo de Apple la empresa con más capitalización del mundo. Un ejemplo, el iPhone se ha convertido en la estrella, desde su aparición en 2007 y según las cuentas trimestrales del periodo julio-septiembre de 2015, presentadas por Apple, el número de $i$ Phones vendidos desde su nacimiento supera los 800 millones de unidades y es, además, el producto más rentable; se estima que representa el $60 \%$ de los beneficios de la compañía.

El lanzamiento del iPhone+ con 5,5 pulgadas se acerca al tamaño de la tableta iPad mini que mide 7,9 pulgadas en una tendencia a parecerse cada vez más en cuanto al formato. Las ventas de iPhones compensan con creces la bajada de ventas del iPad, un $20 \%$, en el trimestre mencionado donde acumula caídas por séptima vez consecutiva. Tal vez el iPad sea un producto de transición entre el ordenador portátil y el smartphone, lo que dure esta travesía el tiempo lo dirá. 
España es uno de los consumidores más importantes de dispositivos móviles, situándose a la cabeza de Europa en cuanto a la penetración de smartphones. Según el informe La Sociedad de la Información en España 2014, de Fundación Telefónica publicado en enero de 2015, nuestro país lideró con un $81 \%$ la penetración de teléfonos inteligentes respecto al total de móviles, lo que supone un 10\% más sobre la media europea.

Es indiscutible que el concepto mobile first está en la mente de todos los agentes implicados en el mundo de la información y sus respectivos negocios. Si, como se ha comentado en este trabajo, las ventas de smartphones superaron en 2010 a la venta de ordenadores, según un informe de la consultora Gartner realizado en 2014 se preveía que en 2015 las ventas de tabletas superarían a las de ordenadores y que el $88 \%$ de las ventas de todo tipo de dispositivos corresponderían a smartphones y tabletas, la mitad de ellos con el sistema operativo android.

Los editores de medios impresos ante la caída de ventas en quiosco crearon réplicas digitales de sus revistas. La instauración en el mercado de plataformas y quioscos digitales dio visibilidad a numerosas cabeceras impresas, ahora réplicas online. Es el caso de Zinio, la mayor plataforma de venta de revistas fundada en 2005 que dispone de más de 5.500 cabeceras además de otros quioscos digitales como Magzter, PocketMags o iKiosk y los propios de Apple (iTunes) y Google (Google Play). En España las dos plataformas que más títulos albergan son Orbyt y Kiosko y Más, propiedad de los dos grupos editoriales de prensa más importantes de nuestro país, dueños de las cabeceras El Mundo y El país, respectivamente.

"El escenario es cambiante y parece que la tendencia hará que los quioscos se muden a la red. Son sus avatares digitales los que más atención reciben en este momento de los editores. Sin embargo, el nicho para las publicaciones online ya está colonizado" (Pérez Bahón, 2014) 
Mención especial merece la plataforma Ztory, que fue creada en Suecia en el año 2013 y aterrizó en España en 2014. La "spotify" de las revistas aplica el concepto de suscripción mensual donde se accede a un pool de publicaciones, el coste mensual actual es de 7,99 euros (la cuota el año pasado era de 9,90 euros). Editoriales como MC Ediciones o Axel Springer incluyen algunas de sus publicaciones. Cuando Ztory inició su andadura contaba con 63 revistas, a fecha de noviembre de 2015 superaba las 170. Al "efecto Spotify" también se ha sumado Nubico, empresa de Telefónica y Círculo de Lectores que ofrece libros digitales por suscripción. En marzo de 2005 grupos editoriales como $\mathrm{G}+\mathrm{J}$ o Motorpress Ibérica incorporaron más de 40 revistas al catálogo de Nubico. Libros (más de 8.000) y revistas por una suscripción de 8,99 euros.

En un estudio realizado se constata que las réplicas digitales de revistas impresas ofertadas a través de quioscos digitales suponen un 22,5 por ciento de ahorro respecto a los títulos impresos (Yunquera, 2014). También se señala que dichas réplicas son meros PDFs de las versiones digitales y que solo en unos pocos casos se presentan con formato enriquecido como es la inclusión de vídeos, animaciones u otros recursos multimedia. Una de las conclusiones de dicho trabajo es que las revistas para web (visualizadas en ordenador) que empezaron con cierto brío han quedado relegadas a revistas de empresa o de entidades y organismos públicos. No pasó así con las revistas creadas específicamente para tabletas que empezaron su andadura curiosamente a pocos meses de la aparición del iPad.

$Y$ es que existe una generación que no entiende la vida sin las apps, por ende, sin dispositivos móviles, jóvenes que piensan que existe una aplicación para cada problema (Davis \& Gardner, 2014), o cómo resolver los contratiempos diarios de la forma más cómoda y fácil pero siempre a través de una $a p p$, en definitiva app-dependientes. Para los autores del libro The App Generation, sorprende esta dependencia pero también concluyen que el poder de las aplicaciones puede hacer gente más creativa. 
Contrariamente a lo que pudiera parecer no fueron los grandes grupos los que optaron por esta modalidad. A fechas de 2015 no hay ningún grupo importante que haya creado una revista pure player para tabletas. Si bien es cierto que grupos como Condé Nast o G+J presentas revistas para tabletas modificadas o enriquecidas pero de una forma puntual. Quien sí han conectado con esta vía han sido pequeñas empresas o grupos de periodistas que han visto en estos soportes una oportunidad para mostrar sus inquietudes periodísticas amén de intentar rentabilizar económicamente dichos proyectos.

Esta eclosión se debe a la autonomía y no dependencia de corporaciones, grupos o empresarios editoriales que les liberan de contenidos mediatizados o doblegados a algún poder establecido. A la parte de los contenidos se añade otro componente no menos importante, el espíritu emprendedor que acompaña a cada uno de estos proyectos como nueva opción de trabajo/negocio.

Tengamos en cuenta que al ser microempresas no tienen la misma visibilidad mediática que los grupos editoriales establecidos que pueden hacer campaña de sus productos bien a través de sus medios o bien a través de campañas de publicidad en otros soportes como TV, radio, etc.

La precariedad por la que pasan los grupos editoriales, donde se han cerrado muchas revistas, hace que éstos no incluyan en sus proyectos la creación de revistas para tabletas no solo por falta de una estrategia clara de negocio sino por el escaso conocimiento mediático de estos productos.

Hay que destacar que ya existe una tecnología avanzada a través de programadores que crean aplicaciones a demanda y a medida de los presupuestos disponibles. También existen empresas que proporcionan herramientas donde no es necesario programar y solo hay que tener los suficientes conocimientos de diseño y maquetación a través de programas de autoedición como Indesign o Quarkxpress y conocimientos de las herramientas que facilitan las empresas distribuidoras entre las que destacan Mag+, DPS (Digital Publishing 
Suite), Aquafadas, Interactive 480 o Planet Tablet entre otras, con paquetes a suscripciones temporales o números simples.

La mayoría de las revistas para tabletas son gratis y están englobadas en la categoría lifestyle. Esta opción es la que soporta una redacción menos costosa ya que las piezas redaccionales son mayoritariamente del género interpretativo, con temas basados en sociedad, tendencias, consumo, cultura o tecnología y alejados de la información propiamente dicha y la investigación. Con esta dinámica se intenta abarcar un espectro importante del abanico publicitario donde caben la mayoría de las campañas de las agencias de medios.

\section{Marco práctico}

Aunque algunas publicaciones pure players remarcan en sus claims ser las primeras revistas creadas para tabletas, la verdad es que ese mérito hay que atribuírselo a la revista $i M a g$ de los periodistas Carolina Denia, directora y Juan Castromil, redactor jefe. El 1 de febrero de 2011 publicaron el primer número con una redacción de 7 personas fijas y otros tantos colaboradores.

iMag apareció solo 11 meses después de que Steve Job presentara el iPad. Los dos emprendedores se aferraron a un proyecto pionero en España en el que atisbaron una oportunidad para iniciar una nueva vía periodística al margen de los poderosos mass media existentes. La revista, de periodicidad mensual, se podía descargar gratuitamente a través del Apple Store. Su claim promocional rezaba: "La primera revista interactiva solo para tablets", y en este caso era totalmente cierto.

En el primer número aparecía muy destacado 'Número Gratis', tal vez pensando en la posibilidad de abrir un muro de pago si la revista alcanzaba cuotas de éxito. IMag tenía todas las funcionalidades y recursos como vídeos en $p$ p-up (se activan al ir a la página), acceso a música en Spotify, vídeos, audición de canciones, animaciones, fotos en modo carrusel, tráilers de películas, ventanas desplegables con información, enlaces a iTunes, vídeos musicales, posibilidad de 
escuchar una música recomendada para el tipo de lectura de ese momento, acceso a documentales o YouTube, concursos interactivos, test o juegos de lógica, encuestas, acceso a redes sociales, componer o variar colores en objetos, coches o prendas de vestir que rotan 360 grados, etc. Multitud de opciones multimedia que, aunque ahora a los usuarios de tabletas no les sorprenden, en los albores de esta tecnología les "enamoraban". La publicación solo estaba disponible en $i$ Pad.

Apostaban por un periodismo comprometido, Carolina Denia daba fe de ello en una entrevista publicada en Periodista Digital el 16 de febrero de 2011: "Lo que hace falta son contenidos de calidad, no queremos quedarnos en una revista cuya plataforma es muy bonita y espectacular, nos interesa lo que está detrás, los periodistas que hacen la información. Nos diferenciamos de The Daily en un pequeño detalle, en el diario de Murdoch trabajan unas cien personas, sin contar la capacidad financiera de un grupo como News Corp".

Pero la ilusión y la tenacidad de estos jóvenes que apostaban por este vehículo nuevo de comunicación en la pretensión de que la gente estuviera "más y mejor informada" se mantuvo sólo durante 4 números y en abril de 2011 tuvieron que abandonar el proyecto. Entre las causas del 'desastre' (Yunquera, 2014) destaca la dependencia tecnológica de la todopoderosa Adobe, dueña de la aplicación con la que se creó iMag (DPs, Digital Publishing Suite), nada ágil con los tiempos de cierre de la revista; otra vuelta de tuerca a las tesis de (Smith, 1984) sobre la reconversión estructural y tecnológica de los medios.

El precio de alojamiento en el store de Apple y los cobros por descarga fueron otras de las trabas a sumar, a la que se añadió como remate final la lenta incorporación de la publicidad específica para estos soportes, debido a la falta de arrojo de empresas y agencias de publicidad para experimentar en estos soportes. El resultado, por tanto, la poca inserción de espacios publicitarios tradicionales y la casi nula inclusión de publicidad rich media. Y es que a veces los productos mueren de éxito, casi siempre por causas que no acompañan a estas 
experiencias o véase por qué fracasaron, entre otras muchas, Secondlife, Myspace, Hi5 o FriendFeed. En el caso de estas dos últimas la primera fue tocada y la segunda hundida (comprada y cerrada) por el gigante Facebook. Recordemos que Facebook Messenger cuenta con 700 millones de usuarios mensajes activos y WhatsApp 900 millones. Datos para pensar.

A iMag le siguió Actualidad 7, creada en el verano de 2011 con periodicidad semanal. Su empeño era parecerse a un semanario de información, de ahí el título. Tuvieron que optimizar recursos y evitar este despliegue de funcionalidades que habíamos visto en iMag, ya que estas son costosas, no solo tecnológicamente hablando sino por el tiempo empleado en realizarlas. Con una redacción de 20 personas empezaron con 66 páginas y más tarde se estabilizaron en un promedio de 100 .

La visualización, al contrario que su antecesora, solo se podía efectuar en disposición horizontal. En esta apuesta casi exclusivamente informativa no aprovecharon todos los recursos multimedia que ofrece este soporte restando empoderamiento a la publicación con poco valor visual añadido. Pero Actualidad7 no tuvo demasiada difusión ante el gran esfuerzo realizado. Al ser gratuita contaba con la publicidad como medio principal de monetización, pero la realidad era la que era y la página de publicidad costaba alrededor de 1500 euros; en el número 44 sólo llevaba dos páginas de publicidad. El último número publicado fue el 52 con fecha de septiembre de 2013.

A pesar de estos fracasos se estaba creando una corriente donde los pequeños editores o grupos de periodistas ansiaban crear modelos de negocio diferentes. Asistimos a principios de enero de 2012 al lanzamiento de uno de los primeros proyectos de éxito de revistas para tabletas. Se trata de $V$ is a $V i$ s, puesta en el mercado en enero de 2012. Ángel Anaya y Laura Blanco, sus directores, esperaban, según rezaba el editorial de presentación, que "este sea uno de los mejores magacines gratuitos especialmente editados para tabletas. Todos y cada uno de nosotros formamos parte de esa nueva generación que no solo se ha educado con ordenadores sino que, además, vive 
pegada a cualquier dispositivo nuevo que sale al mercado". Unos auténticos Geeks, adictos a la tecnología:

"Miembros de la nueva élite cultural, una comunidad de insatisfechos sociales, amantes de la cultura pop y centrados en la tecnología. La mayoría de los geeks se sobrepusieron a un sistema educativo sofocantemente tedioso, donde estaban rodeados de valores sociales detestables y compañeros hostiles, para terminar creando la cultura más libre e inventiva del planeta: Internet y la World Wide Web. Ahora manejan los sistemas que hacen funcionar" (Katz, 2001).

Pensada para iPad (no podía ser de otra manera para unos geeks) y centrada en el concepto life style (estilo de vida, cultura y tendencias), $V$ is $\grave{A} V$ is tuvo éxito mediático desde sus inicios, sobre todo en los corrillos periodísticos consiguiendo en el primer número 29.000 descargas y situándose en el ranking de aplicaciones Apple en el tercer lugar entre los más vendidos en la modalidad estilo de vida. Detrás de este proyecto se encontraba Ploi Media una empresa española de proyectos multimedia que además de revistas propias crean aplicaciones para clientes, amén de cualquier proyecto relacionado con la tecnología y las apps. La revista tiene 50.000 descargas de cada número y cuentan con 10.000 socios. $V$ is $\grave{A} V$ is es el referente de las publicaciones españolas para tabletas.

Mac Today 'salió a la calle' el 10 de noviembre de 2011, focalizada totalmente en el mundo Mac. Steve Job, el creador de Apple, había fallecido un mes antes y el primer número fue un homenaje al creador de la compañía de la manzana mordida. Sus intenciones son claras y así lo manifiestan en su claim promocional: "Cuando morder la manzana dejó de ser pecado". El target a quien va dirigido lo definen en su web: "Mac Today es la revista digital definitiva para usuarios Apple (iPhone, iPad, iPod, Mac)". Mac Today es mensual, gratuita y utiliza el vídeo como principal recurso multimedia. La revista cuenta con varias secciones como actualidad, rumores, especiales, reportajes, viajes, fotografía móvil, aunque las de más peso son las de análisis de aplicaciones, ranking de las mismas, laboratorio o tutoriales. La 
visualización sólo se hace en formato vertical y como es de esperar sólo está disponible en el Apple Store.

UnBreak apareció en abril de 2013. Es una publicación mensual que aunque al principio sólo se accedía a través del Apple Store, unos meses después tenía versiones para Android y Windows Phone. La publicación está enmarcada dentro del estilo life style y apuesta por secciones como moda, series, cine, deportes, vídeojuegos, entrevistas, sexo o cocina. El elemento diferenciador es el guiño que hacen en portada a la propia cabecera. En todos los números, bien sean fotografías o ilustraciones, el personaje de portada aparece haciendo con las manos el gesto de ¡Tiempo! que se emplea en los partidos de baloncesto; la idea es tomarse un descanso, un tiempo para leer la revista. El claim que utilizan es: "Unbreak, la revista que se mueve". La publicación no escatima en elementos interactivos y multimedia y tiene una proyección global con el mundo hispano donde cuenta con ediciones en 18 países de este entorno.

Èvoque apareció en julio de 2013, unos meses después de UnBreak. Creada por jóvenes emprendedores, el proyecto es originario de DSS Network, una editorial sevillana especializada en comunicación sobre estilo de vida y tendencias. Utiliza menos recursos multimedia y funcionalidades que su antecesora y se visualiza tanto en posición vertical como horizontal. Para Juan Francisco Sánchez, CEO y fundador de DSS Network: "El mundo editorial es uno de los que más cambios está experimentando en los últimos años. No sólo por la crisis del sector publicitario, sino por la necesidad de adaptarse a un nuevo público y a nuevos formatos. Èvoque es una nueva publicación gratuita para iPad dirigida a un público apasionado por la moda, la música, las nuevas tendencias, la tecnología, los viajes y sobre todo, nacida en una 'era online' donde el consumo de medios se produce a través de dispositivos móviles".

Mine es otra publicación de la factoría Ploi Media, creadora de Vis À Vis que vio la luz en agosto de 2013. Es una revista pensada para iPad y para el público masculino: "Mine, los pecados del hombre". De periodicidad mensual tiene un target de hombres de clase media y 
media/alta con contenidos elaborados y bien presentados. Su diseño es claro con un ritmo de maquetación y lectura sosegado que invita a la lectura. Utiliza una paleta de colores reducida y composiciones tipográficas no estridentes. Usa preferentemente el formato vertical y recurre al horizontal para contenidos extras. Mine quiere parecerse a otras revistas impresas del mismo segmento y de mucha calidad como es el ejemplo de Esquire, a la que imita en su diseño y composición de portada. Utiliza muchos recursos multimedia aunque por ello no resulta artificiosa.

Fase Extra es una revista de videojuegos que inició su andadura en agosto de 2013 para el formato iPad. Su fuerte principal son los videojuegos y su entorno, con noticias del mercado de este sector puntero, no solo español sino también internacional. Como era de esperar los recursos multimedia abundan sobre todo en los formatos audiovisuales y especialmente en la realización de entrevistas. Entre sus secciones destacan presentaciones de juegos, vídeos de producción propia, análisis y test de videojuegos y novedades y tendencias. Una revista que "ataca" un nicho de mercado al alza con una gran proyección tecnológica y económica. Es mensual y gratuita.

La revista Don apareció en noviembre de 2013: "Cultura popular para mayorias selectas" rezaba su claim de presentación. Don se puede ver en iPad y también en tabletas con sistema Android. La revista presenta un diseño elegante y cuidado con un uso muy estudiado de las tipografías. Se nota la mano de los diseñadores que provienen del grupo PRISA así como los directores de la revista, Rafael Benítez y Javier Moya, curtidos en $G Q$ y Esquire. Han recibido varios premios internacionales como el Best of 2013 que otorga Apple, el premio Laus al mejor diseño en $A p p s$ para móviles y tabletas y ha sido finalista en los Tabby Awards que se entregan en Estados Unidos y en el Mobile Innovation Awards de Reino Unido. Es de periodicidad mensual y gratuita. Lo edita The Tab Gang con una redacción compuesta por 9 personas.

A otros proyectos que surgieron en 2013 como InCover, de periodicidad mensual y formato lifestyle o iSweet Magazine (bajo la 
dirección del maestro pastelero Paco Torreblanca) hay que añadir la experiencia proveniente del diario El Mundo como publicación pure player para tabletas. El Mundo de La Tarde apareció como diario vespertino el 4 de noviembre. Cada día se publicaba una edición a las seis de la tarde coincidiendo con el cierre de los mercados bursátiles. Además de la información generada cada día se implementaba con firmas, opiniones, secciones como 'Una mirada al exterior' donde corresponsales del diario a través de podcasts hacían una crónica de lo ocurrido en otros países o un informativo en formato audiovisual en el que se profundizaba en la noticia del día. Esta iniciativa fue pionera en España, aunque ya existían otras publicaciones de este tipo en Europa como es el caso del diario británico The Daily Mail, que en 2012 creó Mail Plus o el brasileño O Globo que, en enero de ese mismo año, publicaba O Globo a Mais. Se podía acceder a El Mundo de la Tarde si se estaba abonado a Orbyt o mediante suscripción por 4,99 euros al mes.

Al director de El Mundo en ese momento, Pedro J. Ramírez, no le salieron las cuentas como él pensaba. Después de 11 meses de andadura tuvo que ser cerrado por el director que le sucedió, Casimiro García Abadillo, en septiembre de 2014. El Mundo de la Tarde no alcanzó nunca las suscripciones deseadas y en ningún momento fue rentable. Pedro J. Ramírez, muy vinculado a las nuevas tecnologías digitales (La empresa editora del recién aparecido diario online El Español se llama No Hace Falta Papel) también ha incorporado para tableta una edición especial de la versión de El Español, curiosamente se llama 'La Edición' en donde cada noche lanza a modo de revista, numerada y con fecha, un bloque de entre 25 y 35 noticias con la usabilidad típica del formato tableta.

En 2014 sigue el goteo de revistas pure players entre las que destacan MasMag de periodicidad bimestral y MayDay mensual, ambas situadas en la categoría 'estilo de vida'. En To set Out (bimestral) encontraremos "La primera publicación para iPad y iPhone donde conocerás proyectos e iniciativas que contribuyen a mejorar nuestra sociedad"; con Top Padel 360 estamos ante "La primera revista de pádel diseñada exclusivamente para iPad y iPhone totalmente gratuita" 
y en la bimestral $W$ alk Magazine encontraremos "la primera revista de música alternativa para tabletas". Elite Sport, de periodicidad mensual, quiere mostrar la otra cara de los deportistas de elite: "el lado humano del deporte".

En 2015 afloran, de igual manera, títulos y cabeceras donde los editores siguen remarcando ser los primeros en su género; es el caso de la bimestral 5 Senses Wine, donde se presentan como pioneros en el mundo de las publicaciones del vino o la revista Clapp, de periodicidad mensual donde aseguran ser "la primera revista digital de cine, gratuita y nativa, de España". Muster, de periodicidad trimestral se cataloga como "la primera revista digital e interactiva de comunicación gráfica nacional para iPad" y Arqtist será la primera revista de Arquitectura y Arte diseñada para dispositivos móviles.

Pero el caso más importante a tener en cuenta es el de Mediazines, tanto por su reciente aparición, enero de 2015, como por la propuesta innovadora. Siguiendo la estela del modelo Spotify, ya mencionado en este trabajo, Mediazines propone un quiosco digital en el que ofertan publicaciones de las más variadas tendencias como Westinghouse (economía); Selfie (para chicas independientes); Malas (para la mujer del siglo XXI) Streaming (cine, televisión y series); Curved (mundo del automóvil); Coolscience (ciencia y tecnología); Nevermind (rock nacional e internacional); Playlist (tendencias en música); ProScenium (mundo de la escena); Plan de Chicas, (actividades entre amigas) e IHSTORIA (sobre historia desde un punto menos academicista), el propio titular, que está correctamente escrito, hace un guiño a este desenfado.

Mediazines está pensado como un quiosco global de publicaciones para soportes móviles ubicuos. Busca una proyección internacional, enfocado especialmente para el mundo de habla hispana. El inicio de partida del proyecto está realizado por La Communitat, una editorial especializada en diseñar y desarrollar revistas y libros interactivos para tabletas. Su primera incursión en el sector de publicaciones digitales fue con la publicación pure player, UnBreak. Para el proyecto la financiación se realizó mediante aportaciones personales de los socios. Comenzaron en el Parque Científico y Tecnológico de la 
Universidad de Girona (UdG), donde aprovecharon las sinergias de la propia universidad en cuanto a conocimiento y repercusión mediática en la comunidad universitaria.

La progresión de esta pequeña startup (comenzaron con diez personas en plantilla) ha sido llamativa. Además de consolidar la revista unbreak con más de 75.000 usuarios activos, a partir de septiembre de este año han incorporado a su kiosco las revistas oficiales de Gran Hermano 16 (reality), Champions Total (deportes), David Bisbal (música) y El Hormiguero (televisión). El precio de suscripción a Mediazines es de 1,99 euros mensuales.

\section{Conclusiones}

La edición de revistas digitales pure players para tabletas y smartphones así como la producción de contenidos para estos formatos ha generado un nuevo escenario en el mundo editorial español. Estamos viendo cómo las publicaciones digitales para dispositivos móviles ubicuos van tomando identidad propia y buscan su hueco junto con el resto de publicaciones tradicionales. Las revistas creadas específicamente para tabletas están apareciendo en el mercado de una manera regular, no masiva pero sí constante.

Los grandes grupos mediáticos editores de prensa dejan de lado este tipo de publicaciones, bien por una visión cortoplacista del negocio o bien porque la gestión de contenidos no son adaptables a sus estructuras empresariales. Son las microempresas y pequeños grupos editoriales los que se han lanzado de lleno a la publicación de revistas digitales. La composición de sus redacciones permiten la realización de proyectos comunicativos ágiles y con costes más bajos que los grandes grupos mediáticos; además, tienen más capacidad de supervivencia ya que son estructuras con pocas personas, con más agilidad para abordar campos relacionados con las herramientas digitales y capaces de solucionar tareas demandadas por terceros en trabajos de diseño y desarrollo de aplicaciones, acciones comunicativas editoriales, gestión de proyectos multimedia, programación, audiovisual, videojuegos, asesoría, etc. 
La edición de revistas para dispositivos móviles, por tanto, está dibujando un nuevo escenario en el mundo editorial en un claro proceso de transición donde se están situando las distintas piezas que componen el complejo tablero de la edición digital. Aún es pronto para elaborar un mapa conceptual representativo y fiable de las publicaciones digitales pure players en España, pues como hemos visto en este trabajo la aparición de títulos se suceden "casi a diario" con planteamientos profesionales bien diferentes por lo que es necesario dar un tiempo para la observación y poder establecer una línea de investigación que represente de forma fidedigna las relaciones existentes entre las nuevas publicaciones y la usabilidad de los dispositivos móviles ubicuos.

\section{Bibliografía}

Clark, D. (1999): "Implications of Local Loop Technology for Future Industry Structure", en Competition, Regulation and Convergence: Current trends in telecommunications policy research, recuperado el 1 de noviembre de 2015, de http://groups.csail.mit.edu/ana/Publications/DDCImplicationsofLocalLoopTechnology.pdf

Davis, K \& Gardner, H. (2014): The app generation. "The App Generation: How Today's Youth Navigate Identity, Intimacy, and Imagination in a Digital World". New Haven and London. Paperback.

Gómez-Borrero, P. (2010): Prensa e Internet. ¿Dónde está el negocio? Madrid: MediosOn.

Katz, J. (2001): Geeks: How Two Lost Boys Rode the Internet Out of Idaho. New York: Broadway Books.

Peers, M: "Last time there was this much excitement about a tablet, it had some commandments written on it, en The Wall Street Journal; recuperado el 3 de julio de 2015, de 
http://www.wsj.com/articles/SB1000142405274870351030457 $\underline{4626213985068436}$

Pérez Bahón, F. (2014): Metamorfosis de los quioscos de prensa en el escenario digital, en Unir Revista; recuperado el 3 de julio de 2015, de http://revista.unir.net/3343-metamorfosis-de-losquioscos-de-prensa-en-el-escenario-digital

Smith, A. (1984): Goodbye, Gutenberg. The newspaper revolution of the 1980s. Barcelona: Gustavo Gili.

Yunquera, J. 2016: Revistas y diarios digitales en España. Historia de una evolución. Barcelona. UOCPress. 


\title{
Publicidad digital: del retorno monetario en los soportes tradicionales al valor añadido de los medios sociales
}

\author{
Lidia Maestro Espínola \\ Universidad Internacional de La Rioja
}

\begin{abstract}
Forma de citar este capítulo: Maestro Espínola, L. (2016): "Publicidad digital: del retorno monetario en los soportes tradicionales al valor añadido de los medios sociales", en García Santamaría, J.V. y Pérez Bahón, F. (coords.): Los medios digitales españoles: procesos de cambio e innovación. Cuadernos Artesanos de Comunicación, CAC104 La Laguna (Tenerife): Latina.
\end{abstract}

\section{Resumen}

El sector publicitario ha sufrido una revolución en todos sus ámbitos desde la aparición de internet. Este trabajo repasa la evolución de la publicidad interactiva y las ventajas que aporta, tanto a soportes publicitarios, como anunciantes. Ponemos el foco de atención en el estudio del retorno de la inversión en medios tradicionales y su evolución dentro de los medios sociales. El objetivo principal de este capítulo es analizar los resultados que pueden ofrecer los soportes publicitarios al aplicar criterios de rentabilidad en la esfera digital. Podemos concluir que los criterios tradicionales que aportan valor a los soportes publicitarios siguen sin encontrar identificación en los medios digitales. 
Palabras clave: métricas digitales, evaluación, planificación publicitaria, monitorización, redes sociales.

\section{Introducción}

T A publicidad digital presenta numerosas características que benefician a soportes y anunciantes: la afinidad con el público objetivo, el aumento de la segmentación, la reducción de costes, la posibilidad de efectuar acciones que fidelizan o la generación de notoriedad de marca, entre otras.

La publicidad ha encontrado en la red un nuevo canal. En concreto, Internet ha permitido multiplicar las opciones para transmitir sus mensajes, que ahora pueden llegar bajo diferentes formatos a múltiples soportes. El esquema tradicional que la publicidad ha gestionado durante décadas experimenta una eclosión que afecta a todas sus fases.

Estos nuevos usos y formatos han transformado la manera de crear, planificar e investigar los espacios publicitarios. El cambio de paradigma ha roto la cadena de valor donde el anunciante saturaba los espacios intentando llegar a los consumidores de cualquier forma.

Las nuevas oportunidades que se abren a los anunciantes y a los usuarios han provocado un proceso de adaptación de los soportes publicitarios. La gestión de la publicidad ofrece un mayor beneficio a los anunciantes y a los soportes, pero tiene que abrirse a las nuevas formas de retorno de la inversión que van más allá de los resultados monetarios.

\section{Objetivos e hipótesis}

El objetivo de esta investigación es analizar los criterios de rentabilidad presentes en la esfera digital, en especial el referido a la publicidad digital y su evolución dentro de los medios sociales. Estos criterios han dejado de identificarse con las tradicionales medidas de valor aplicadas a los soportes off line. Se parte de la hipótesis principal 
de que la evaluación del retorno de la inversión a tiempo real no supone un aumento de rentabilidad respecto a lo que sucedía en el escenario tradicional.

El trabajo realizado se centra en las métricas disponibles de retorno de la inversión presentes en la esfera digital. Estas interfieren en la gestión de la prensa como soporte publicitario digital. La evolución de los ingresos, el problema de la unificación de las mediciones y las nuevas métricas de retorno de la inversión, que abren la posibilidad de incrementar la eficacia de las inversiones, son algunos de los aspectos fundamentales para valorar los criterios de rentabilidad de la prensa digital como soporte.

\section{Metodología}

El trabajo presentado parte de un análisis teórico sobre las posibilidades de obtener beneficio tomando como punto de partida las inversiones realizadas en el soporte digital. Los soportes publicitarios mejoran sus inversiones en base a las posibilidades de retorno de la inversión que ofrecen a sus anunciantes. Los datos de penetración de internet corroboran el seguimiento de diferentes portales pero la gestión publicitaria es compleja dentro de un entorno que excede sus sitios web corporativos. La aparición de las redes sociales, donde los usuarios cada vez asumen más actividades, o la multiplicación de nuevos dispositivos ponen en valor el conocimiento técnico de las métricas publicitarias. El estudio de los criterios de rentabilidad publicitaria incorpora el análisis no sólo de la inversión publicitaria, sino también de los problemas que afectan a la consolidación de dichas inversiones y el conocimiento de las métricas que permite la esfera digital.

La evolución de las audiencias se realiza a través de datos de los informes anuales de Infoadex, que es el mayor referente del sector, y de IAB Spain, entidad especializada en la investigación de medios digitales. Ambas instituciones manejan puntos de vista diferentes. IAB Spain no abarca un universo tan extenso e incluye en sus 
mediciones sobre inversión publicitaria a buscadores y otros soportes que no son aceptados en la definición de medios convencionales. Si bien hay que conocer y valorar las diferencias de medida existentes, ambos estudios son necesarios para profundizar en el mercado, y para apuntar y definir tendencias.

La consolidación de las inversiones se han visto afectada por los problemas ante la unificación de las audiencias digitales pero paralelamente han surgido otros aspectos que necesitan y pueden ser medidos. "La competencia que antes se realizaba entre los grandes medios se ha convertido en un proceso complejo lleno de nuevos actores" (Maestro, 2013:60). Estos aspectos además marcan una diferencia fundamental con respecto a las posibilidades que los soportes tradicionales ofertan. Cabe destacar los siguientes:

- La medida de la efectividad de las inversiones digitales, en especial los enlaces patrocinados que suponen la mayor parte de la inversión que llega a internet.

- El cambio aportado por la comunicación comercial llevada a cabo en las llamadas redes sociales: la efectividad de interacción con los usuarios que con estas herramientas podemos conseguir no se había planteado hasta ahora.

- La generalización del uso de teléfonos inteligentes y tabletas que permiten el acceso móvil a la red y varían las posibilidades de la comunicación comercial. Ello aporta nuevas posibilidades que deben estar incluidas en la estrategia del soporte. La efectividad y penetración de este tipo de comunicaciones resulta fundamental.

La medición de audiencias es igual de importante que la evaluación posterior y el cálculo de la eficacia conseguida. Computar lo que se conoce como retorno de la inversión (ROI) es uno de los pasos más importante para cualquier empresa que realiza una inversión de este tipo. El ROI mide el beneficio que se obtiene a partir de las inversiones realizadas. Es un marcador financiero que sirve para cuantificar la efectividad de las inversiones en planes de medios. Su 
resultado es el margen que la empresa ha conseguido. Para ello hay que ver la relación que se establece entre los beneficios y los costes publicitarios. El conocimiento de esta herramienta es imprescindible para los anunciantes y para la mejora de la oferta que pueden realizar los soportes.

\section{E1 mercado de la publicidad en España}

Después de unos años de continuo ascenso de la inversión publicitaria, a partir de 2007, la crisis económica afectó al sector. Tras seis años de continuos descensos, las cifras de 2014 y 2015 indican un cambio de tendencia y pese a la pequeña subida experimentada en 2015, el sector no ha vuelta alcanzar las cifras de hace una década.

Gráfico.1: La inversión publicitaria total en España (2002-2015). En millones de euros.

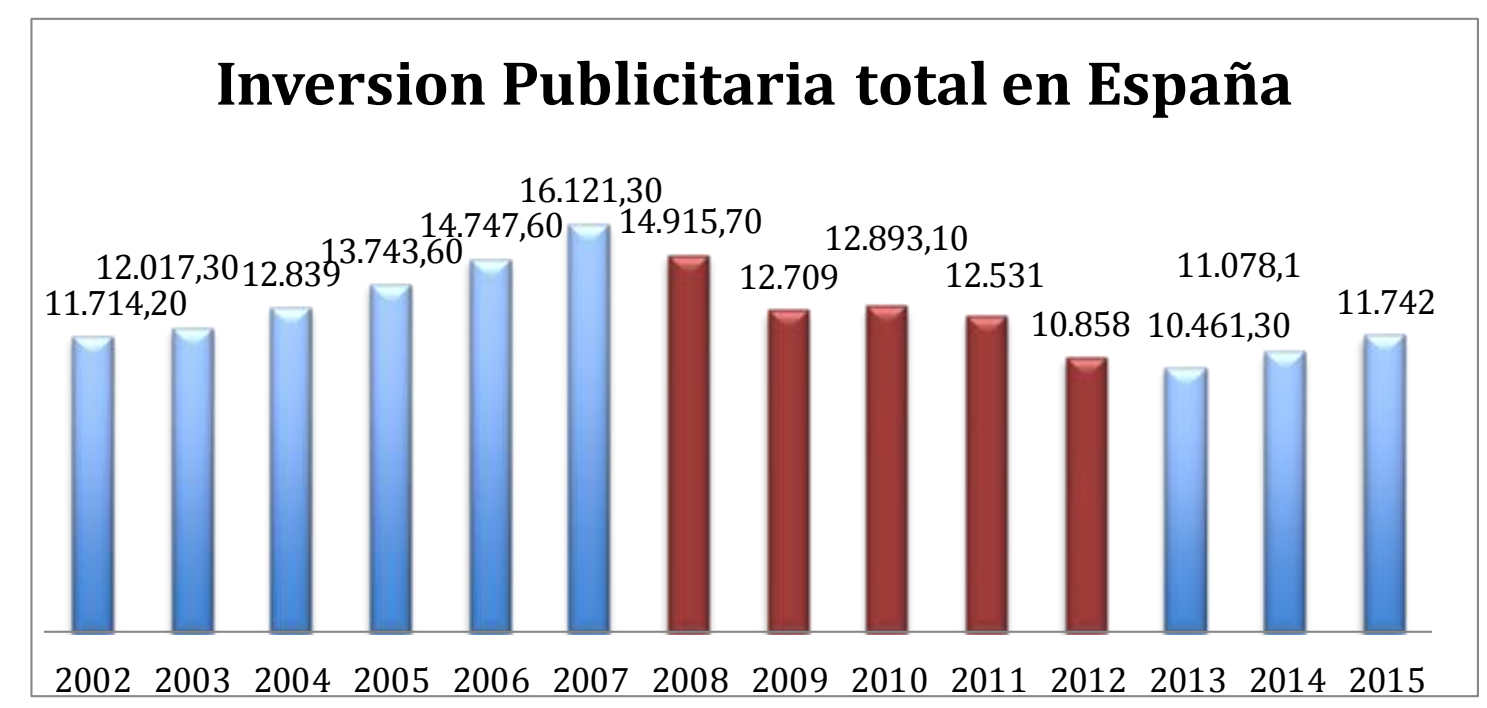

Fuente: Elaboración propia con datos de Infoadex.

Desde el año 2007 se ha acumulado una pérdida del 47\% de la inversión, lo que supuso una cantidad de 3.724 millones de euros. A pesar de todo, Internet se erigido como pieza fundamental en la planificación publicitaria que desarrollan las agencias de medios. 
Conviene tener en cuenta que "la utilización de diversas plataformas posibilita el incremento y el aprovechamiento de las nuevas opciones publicitarias existentes" (Maestro, García Santamaría y FernándezBeaumont, 2014:177).

Gráfico 2: Participación de mercado de la inversión publicitaria 2014.

\section{Cuota de la Inversión Publicitaria}

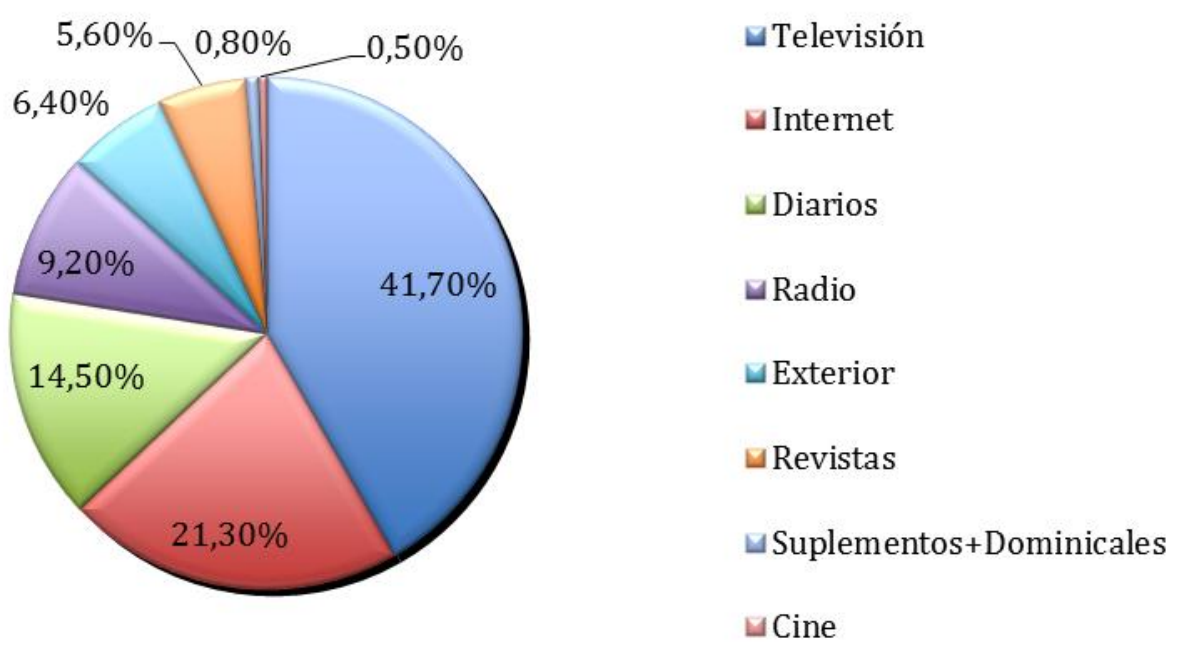

Fuente: Elaboración propia con datos de Infoadex

Las posibilidades de retorno de la inversión y el aumento de la notoriedad, confianza y eficacia de este medio frente a otros han provocado que internet se haya situado en el segundo puesto en cuanto a cuota de mercado. Sin embargo, la evolución de las mediciones digitales afecta al crecimiento de las inversiones.

\section{Medición de las audiencias digitales}

La planificación publicitaria se enriquece ante un escenario con una combinación de medios:

"El medio digital puede ayudar mucho a una estrategia global de medios. Con todas las posibilidades que ofrece en cuanto a integración y combinación de disciplinas puede trabajar como un 
multiplicador de la campaña en medios y de los propios valores de la marca" (Suances, 2011).

Pero la realidad es que los anunciantes buscan en la red "la mejora de la interacción con sus clientes e incrementar sus ventas" (Celaya, 2008:146; Castelló, 2010:50).

Las ventajas de la publicidad digital son numerosas: la afinidad con el público objetivo, el aumento de la segmentación, la reducción de costes, la posibilidad de efectuar acciones que fidelizan, la generación de notoriedad de marca, entre otras. Todo ello conlleva la ventaja de evaluar de una forma más adecuada el retorno de la inversión en tiempo real. Además, "las nuevas métricas y posibilidades de segmentación de audiencias deberían ser herramienta suficiente para poder ampliar el long tail de anunciantes" (Fernández-Beaumont, Maestro y García Santamaría, 2014:6).

La medición de audiencias, que ha supuesto un freno para la consolidación de la inversión, es igual de importante que la evaluación posterior y el cálculo de la eficacia conseguida. Calcular lo que se conoce como retorno de la inversión (ROI) es una de los pasos más importante para cualquier empresa que realiza una inversión de este tipo.

En las campañas digitales del tipo de enlaces patrocinados o publicidad contextual, resulta importante conocer el número de clicks o de impresiones que se obtienen. Pero es determinante saber cuántas acciones (compras, registros, descargas, etc.) se han conseguido (seguimiento de conversiones). Para calcular el ROI realizamos la siguiente fórmula:

\section{(Beneficios-Inversión)/Inversión=ROI}

Las campañas de marketing off line calculaban el ROI (Return of Investment) en base a campañas completas de marketing. Se calculaba la inversión según el aumento de ventas y después de una planificación publicitaria dirigida a varios medios. En la era digital, el ROI puede calcularse monitorizando datos en cada acción de 
marketing digital llevada a cabo. Para cada tipo de campaña (enlaces patrocinados, banners...) podemos conocer el ROI que ofrecen. Aunque en las redes sociales todo se ha vuelto más complejo, y conocer la influencia en cada compra de la conversación digital no resulta tan sencillo. Son infinitos los aspectos que ahora tenemos que medir: identidad de marca, reconocimiento, escucha activa sobre la marca, relación directa, fidelización, atención digital del cliente, anticipación a las necesidades, resolución de problemas, segmentación y promoción adecuadas...

En la publicidad digital hay que medir mucho más que el ROI; se debe hacer una evaluación de forma integral, pero adaptada a cada objetivo. Aparecen así lo que se conoce como Indicadores Clave de Desempeño o Key Performance Indicators (KPIs). Aunque se ha planteado un cierto debate entre los profesionales sobre qué define estos indicadores, aquí proponemos una definición y algunos ejemplos. KPI debe ser una métrica que pueda ayudar a la empresa a definir estrategias y tácticas que les permita aumentar su rentabilidad. Existen cuatro KPIs básicas para cualquier análisis:

- Porcentaje de conversión.

- Porcentaje de abandono.

- Porcentaje de usuarios fieles, recurrentes.

- Porcentaje de usuarios que visitan el site en menos de un minuto.

\section{Más allá del retorno de la inversión}

En este contexto no podemos olvidar la importancia que han adquirido las llamadas redes sociales. Como ya se ha señalado, Internet se ha convertido en un sitio donde la conversación no cesa. El desarrollo de las empresas en la red se ha vuelto determinante para las empresas, pero, en el caso de los medios de comunicación, la importancia es aún mayor. Los medios de comunicación han incorporado el contenido; la conversación que se establece en las redes sociales de una u otra manera. Por ello resulta fundamental el 
estudio del ROI en lo que se conoce como Social Media. Este es un tema delicado que se encuentra en evolución y sobre el que todavía están por consensuar los parámetros y herramientas más adecuadas ${ }^{27}$.

En principio, se pueden diferenciar tres retornos en el Social Media:

- El retorno en cuanto a gestión de marca; acercar nuestra marca al usuario, introducirnos en la conversación e interaccionar con el usuario. Es una de las mejores herramientas para hacer branding, algo fundamental para los medios tradicionales presentes en la red.

- El retorno de información del usuario, que permite conocer tanto a nuestros usuarios como lo que se dice de nuestra marca. En este sentido, las herramientas de monitorización son fundamentales para saber dónde y cómo escuchar la conversación.

- El retorno en forma de ingresos, una estrategia adecuada en redes sociales permite aumentar las ventas de una empresa. En el caso de los medios de comunicación, especialmente la prensa, chocamos con la negativa generalizada a pagar por la información; aunque se pueden mejorar los datos de micropagos o suscripciones a través de estrategias de comunicación en las redes sociales adecuadas.

Existen muchas métricas generadas a raíz de las actividades en los medios sociales. Es lo que se conoce como ROI social (Impact On Relationship, IOR), pero también hay otros conceptos como el retorno de la atención (ROA), retorno de tráfico cualificado.... El IOR mide el impacto de las relaciones que se establecen entre marcas y sus seguidores en redes sociales según diferentes variables (Castelló, 2013:200).

\footnotetext{
${ }^{27}$ Para Cavalcanti y Sobejano (2011) los medios sociales ponen especial foco en las relaciones obtenidas debido a que esto es el retorno esperado. No es un retorno comercial y las ventas, por el momento, no se realizan directamente en los medios sociales. Este hecho hace difícil la justificación de las inversiones a través de la fórmula matemática tradicional del ROI.
} 
Se trata de aplicar valores a cuatro variables:

- La autoridad del contenido de la marca (menciones, enlaces de contenido, etc.). Es la variable que más impacto tiene sobre una marca y está relacionado con el contenido que una marca comparte en los medios y las menciones que obtenga fuera de sus redes corporativas. La autoridad la generan los propios usuarios con sus referencias. El valor de la referencia tendrá que ver con el lugar donde se realice (por ejemplo, en un blog o publicación de referencia de una determinada actividad).

- La influencia de la marca en los medios sociales (número de seguidores en redes sociales, otras medidas y su evolución). Es la segunda variable de impacto y se mide por el número de seguidores que tiene una marca en los distintos medios sociales (cantidad de suscriptores, números de fans de Facebook, número de seguidores de Twitter...). Por sí sola no es una variable que tenga referencia, sino que ha de ir acompañada de otro tipo de información relevante.

- La participación y actividad de los seguidores desde perfiles de la marca en redes sociales hacia los sitios web corporativos. Es la siguiente variable en valor, pero es determinante a la hora de calcular el éxito de presencia de una marca en un medio social. A través de la participación conocemos también cómo es la relación de la marca con los usuarios. Se puede calcular por los comentarios obtenidos en un blog, las valoraciones en el Fanpage de Facebook o las menciones en Twitter, por ejemplo.

- El tráfico generado a partir del contenido de las redes sociales y dirigido a la web corporativa. Es la variable de menor valor y la más fácil de contabilizar. Deseamos que el usuario acceda a nuestro sitio web. Es el entorno que mejor podemos controlar: si el resto de variables se realiza correctamente, el tráfico está asegurado. Para calificar el tráfico existen diversas herramientas. Una de ellas es Google URL Builder que permite introducir parámetros a las URLs para que diferencien desde dónde ha venido el tráfico hacia nuestra herramienta analítica. 
Estas variables del IOR obtendrán un rango de valores que dependerá del impacto que tenga el propio IOR en cada marca. Según los objetivos necesarios en cada momento estarán diseñadas un tipo de actividades que permitan favorecer la variable que más lo necesite.

Para conocer cuáles son las exigencias puntuales será necesario monitorizar cada marca. Las ya nombradas RSS (Really Simple Syndication) nos ofrecerán la posibilidad de monitorizar nuestro IOR según la sindicación de contenidos que ofrecen. El lector RSS permite tener un monitor online que posibilita calcular el IOR de una marca. Algunas de las herramientas que podemos utilizar son estas:

- Twitter Search: hace búsquedas dentro de Twitter sobre actualizaciones, conversaciones, menciones, etc.

- Google Blog Search: realiza búsquedas de palabras claves en blog.

- Blog Pulse: realiza búsquedas por palabras en Blogs y ofrece gráficas de la evolución de un término.

- Google News Search: lleva a cabo la búsqueda de noticias en internet.

- Icerocket. dirige sus búsquedas en la web, Twitter, Myspace, noticias e imágenes. Ordena la información en diferentes pestañas.

- Social Mention: realiza las búsquedas en blogs, microblogs, network, marcadores, comentarios, eventos, imágenes, noticias $\mathrm{y}$ videos.

- Netvibes: es un lector de RSS completo que ofrece datos de varios medios sociales y permite monitorizar webs completas. Mediante su suscripción podemos controlar, tener los resultados actualizados y calcular nuestro IOR en todo momento.

Volviendo al ROI social, según el tipo de actividad que la empresa lleve a cabo dentro de las redes sociales, la agencia Ignite Social propone diferentes retornos:

- ROI directo: el desarrollo de actividades que directamente generan una compra o acceso a un servicio. 
- ROI correlativo: se genera gracias a acciones colaterales o llevadas a cabo en un periodo de tiempo mayor. El seguimiento temporal aporta datos de cómo se comportan los usuarios según evoluciona la actividad social de una empresa.

- ROI relativo: cuando las ventas se producen directamente por la actividad social, habrá que analizar el impacto que produce la actividad social frente a los esfuerzos en medios tradicionales.

- ROI Proxy: se trata de averiguar el impacto a largo plazo de la actividad social a través de otras métricas.

Estas variables se tienen que comprobar en un análisis de conjunto en el que hay que tener en cuenta otros aspectos cualitativos subjetivos que son difíciles de medir.

\section{Conclusiones}

La evolución de las inversiones publicitarias depende cada vez más de las posibilidades de retorno de la inversión que los anunciantes consigan. Y como es lógico, buscan obtener resultados cuantitativos cada vez mayores. Con los nuevos medios sociales la búsqueda de un rendimiento con un componente monetario se ha visto sustituida por la obtención de relaciones directas. Muchos de los resultados que podemos conseguir son "intangibles". Sin embargo, la búsqueda del ROI y del IOR resulta indispensable para cualquier agencia de publicidad o central de medios.

Es imposible evaluar qué proporción de ventas procede del desarrollo comunicativo en las redes sociales sin planificar correctamente qué datos hay que medir. Aspectos como la reputación, eficiencia, diferenciación, retención de clientes o establecer un canal directo de comunicación con los clientes, son fundamentales para conseguir un peso específico de la marca en los social media. Es fundamental que las empresas tengan una actividad continua en la red y monitoricen la conversación a tiempo real. 
La importancia que ha ido adquiriendo la esfera digital obliga a las empresas a incrementar los esfuerzos comunicativos en este canal. Las estrategias de medición online varían en función de los objetivos necesarios en cada momento. Cuando hablamos de analítica web, nos estamos refiriendo a métricas como usuarios únicos, páginas vistas, tiempo de duración y alguna KPI determinada. Sin embargo, a tenor de los resultados presentes en la investigación, podemos afirmar que se cumple la hipótesis principal ya que la evaluación del retorno de la inversión a tiempo real no supone un aumento de rentabilidad respecto a la esfera tradicional.

\section{Referencias bibliográficas}

Asociación de Editores de Diarios Españoles (AEDE) (2013): Libro Blanco de la Prensa Diaria 2014. Madrid: AEDE.

Cabalcanti, J. y Sobejano, J. (2011): Social Media IOR. Las relaciones como moneda de rentabilidad. España: Bubok Publishing.

Castelló, A. (2010): Estrategias empresariales en la web 2.0. Las redes sociales online. Alicante: ECU Editorial Club Universitario.

Castelló, A. (2013): LADM: la agencia de medios. Alicante: Observatorio Comunicación en cambio.

Celaya, J. (2008): La empresa en la web 2.0. Madrid: Gestión 2000.

Fernández-Beaumont, J. Maestro, L. y García Santamaría, J.V. (2014): «Los condicionantes del sector publicitario en los nuevos modelos de negocio de la prensa», Revista de la Asociación Española de Investigación de la Comunicación, 1(1), páginas 1 a 11 ; Disponible en : file:///C:/Users/lidia.maestro/Downloads/39138-1-PB\%20(2).pdf

Maestro, L. (2014): « Publicidad ». En VV.AA, El negocio de la prensa digital, en García Santamaría, J.V. (Coord.)Madrid : Unir.

Maestro, L., García Santamaría, J.V. y Fernández-Beaumont, J. (2014): «Los retos de las nuevas formas de explotación 
publicitaria en la financiación de la prensa digital », adComunica, (7), páginas 171 a 189; recuperado el 15 de julio de 2015 en file:///C:/Users/lidia.maestro/Downloads/180-535-1PB\%20(1).pdf DOI: http://dx.doi.org/10.6035/21740992.2014.7.

Morales, M. (2010): Analítica Web para empresas: arte, ingenio y anticipación. Madrid: Ediciones UOC.

Ordozgoiti, R., RodrÍguez, D., Olmos, A. y Miranda, J.A. (2012): Publicidad online. Las claves del éxito en Internet. Madrid: ESIC Editorial.

Sánchez-Revilla, M.A. y Villa, P. (2014): Estudio INFOADEX de la inversión publicitaria en España 2011. Resumen. INFOADEX, SA Recuperado el 13 de abril de 2015 en http://www.infoadex. Es[Links].

Suances, N. (2011): Seminario Campañas digitales dirigidas a resultados. Recuperado el 20 de enero de 2012 en http://recursos.anuncios.com/files/415/65.pdf 


\title{
Innovación en radio y nuevo modelo de negocio. El caso de StreamRadio
}

\author{
Miriam Rodríguez Pallarés Universidad Complutense de Madrid \\ Dolores Rodríguez Barba Universidad Complutense de Madrid \\ Fernando Peinado-Miguel Universidad Complutense de Madrid
}

\begin{abstract}
Forma de citar este capítulo: Rodríguez Pallarés, M., Rodríguez Barba, D. y Peinado-Miguel, F. (2016): "Innovación en radio y nuevo modelo de negocio. El caso de Stream Radio", en García Santamaría, J.V. y Pérez Bahón, F. (coord.): Los medios digitales españoles: procesos de cambio e innovación. Cuadernos Artesanos de Comunicación, CAC104 La Laguna (Tenerife): Latina.
\end{abstract}

\section{Resumen}

En una sociedad en desarrollo, la Comunicación y la Innovación son conceptos básicos, cuya conjunción, en la actualidad, está directamente vinculada con los avances tecnológicos. En este contexto, el grupo de investigación MediaCom UCM se plantea el estudio de la actividad radiofónica corporativa, ejemplo de innovación audiovisual a partir de las sinergias que emergen de la estrategia empresarial, el marketing y la radio digital.

La metodología aplicada en esta ocasión se fundamenta en el estudio del caso StreamRadio, paradigma de la radio corporativa nacional, y el uso de técnicas como la entrevista en profundidad y la observación indirecta. Los resultados obtenidos indican nuevos caminos para la explotación empresarial radiofónica que configuran un escenario 
favorable en este nuevo mercado diverso y fragmentado, multisoporte y dependiente de las nuevas tecnologías.

Palabras clave: Innovación; Empresa Radiofónica; Radio Corporativa; Audiobranding; Soundbranding; Modelo de negocio.

\section{Introducción}

$\mathrm{C}$

OMUNICACIÓN e innovación son elementos sustantivos de una sociedad de progreso a la que se debe acompañar con filosofías económicas enmarcadas en industrias que necesitan del emprendimiento. La innovación en comunicación, como es consustancial al propio concepto, rompe las barreras sectoriales y explora continuamente las posibilidades que nos ha traído la era de expansión tecnológica en la que nos encontramos. En el marco de la empresa radiofónica se pueden identificar manifestaciones muy variadas en los diferentes ámbitos de la actividad comunicativa (Peinado y Rodríguez Barba, 2011).

En este estudio, se pone el foco en lo que se refiere a la comunicación corporativa, más concretamente, al estudio de las radios corporativas, uno de esos nuevos fenómenos emergentes que han sido impulsados, por un lado, por el deseo y la necesidad de innovación, cusa y consecuencia de la consolidación del perfil profesional emprendedor entre los periodistas y los profesionales de la comunicación audiovisual y, por el otro, por la necesaria implantación de estrategias empresariales de bajo coste ligadas a la coyuntura socio-económica.

Existe una vasta literatura científica que trata sobre las imágenes e ideas de las cosas que se crean a partir de los estímulos visuales y auditivos (Arroyo, 2003) y donde podemos encontrar estudios en profundidad sobre el sonido, utilizado como uno de los recursos más potentes para fijar una imagen de marca en el consumidor (D'Amato, 2015). Este potencial ha sido largamente aprovechado en publicidad, de forma particular en la radio y, en este momento, se desarrolla bajo el concepto de audio branding, también sound branding, sonic branding o acoustic branding. 
"Audio Branding describe el proceso de desarrollo y gestión de la marca por el uso de elementos audibles en el marco de la comunicación corporativa. Es parte de la comunicación de marca multisensorial y diseño integral de marca. Audio Branding tiene como objetivo construir sólidamente un sonido marca que represente su identidad y sus valores de una manera distintiva. El logotipo de audio, sonidos funcionales de marca, música marca o la voz de la marca son elementos característicos de Audio Branding" (Audio Branding Academy, 2015).

Un diseño de audio branding se concreta en diferentes productos y servicios comunicativos que aprovechan la saturación de estímulos visuales para trabajar de nuevo con las imágenes auditivas. Tradicionalmente, y de forma muy particular, desde la aparición de la televisión como medio de comunicación mayoritario, las empresas han invertido mucho tiempo y dinero en la marca visual de la propia compañía y de sus productos, mientras que el sonido ha sido tratado como un elemento secundario o complementario a la imagen o, en el mejor de los casos, destinado a la radio exclusivamente, sin ninguna vinculación directa con la estrategia general de identificación de marca, simplemente como complemento.

El surgimiento de nuevos medios de comunicación con clara vocación de desarrollo y experimentación en narrativas transmedia (Scolari, 2013; Martínez-Costa, 2015) y la generalización del uso de dispositivos con una función de entrega de audio con calidad suficiente para la distribución de contenidos en formato podcast y en streaming -especialmente los teléfonos inteligentes- han ampliado las oportunidades para la comunicación corporativa en cuanto al diseño de marca de audio, pero también han aumentado los riesgos de provocar excesivo ruido y cacofonías, por lo que la eficacia y la eficiencia de la comunicación de marca pasa por la aplicación sistemática y bien estructurada de los estímulos acústicos.

El branding audio puede ayudar en la optimización de la comunicación de la marca y en el diseño de un mejor entorno de sonido (ABA, 2015). 
Con todo lo anterior, se puede avanzar una de las conclusiones que expondrá este trabajo: probablemente, la manifestación más completa de una aplicación sistemática y bien diseñada de las técnicas de branding audio sea la radio corporativa (Piñeiro-Otero, 2015), porque explica a los consumidores o usuarios la identidad, las acciones, la misión y valores de las organizaciones de forma estratégica y en el mismo lugar de consumo o de uso. $\mathrm{Y}$ todo ello desde el lenguaje radiofónico, desde el medio que, a día de hoy, ha demostrado mayor capacidad para conseguir credibilidad y complicidad con la audiencia sin necesidad del sacrificio de la dedicación exclusiva.

Este medio, aprovecha, además, las ventajas de consumo bajo demanda que ha traído el podcasting (Gallego, 2010; Sellas, 2011 y 2012). Es tan efectiva la radio en la construcción de la reputación que, como se verá en el estudio del caso elegido, StreamRadio, ya existen muy buenos ejemplos de desarrollo de radio corporativa como herramienta de magníficos resultados en comunicación interna, motivación y desarrollo de cultura empresarial.

En este trabajo, identificaremos las empresas españolas e internacionales que ofrecen entre sus servicios productos de radio corporativa y que presentan casos de éxito. Además, estudiaremos en profundidad, aplicando la metodología del estudio de casos, el modelo de negocio de StreamRadio, seleccionado por estar ideado y explotado por un equipo de periodistas y mantener entre sus principios configuradores la aplicación de las técnicas y narrativas del lenguaje radiofónico, como especialización del periodismo, en todos los contenidos que elaboran para sus clientes.

\section{Estado de la cuestión}

Como ya se ha avanzado anteriormente, el desarrollo de internet ha provocado la aparición de nuevas formas de distribuir contenidos asociados a las diferentes actividades comunicativas y nuevos usos de los contenidos tradicionales. Tal es el caso de la radio que, más allá de la comunicación masiva, ha encontrado un hueco particular como herramienta de comunicación empresarial cuando se aplican las técnicas de audio branding y lo hace en forma de podcasting. 
Aunque audio branding es un término reciente, ya están muy bien categorizadas la mayoría de sus expresiones: logo sonoro (sogo), claim sonoro, voz de marca o corporativa, canción de marca o corporativa, paisaje sonoro de la marca, diseño sonoro del producto, jingles y asociaciones con artistas (Piñeiro-Otero, 2015) y con la explosión del branded content podemos añadir una más, la radio corporativa en formato podcasting con una doble vertiente: externa e interna.

En su desarrollo externo, su objetivo es compartir con el consumidor contenidos atractivos y de calidad, concebidos para enriquecer la experiencia de marca del cliente o usuario; de cara a la organización, de forma interna, su objetivo es contribuir al desarrollo de cultura empresarial y apoyar las dinámicas de motivación de las plantillas.

Como se desprende de nuestro estudio de caso, se pueden encontrar cuatro modelos básicos de radios corporativas (Sánchez, 2010): staff radio, radio institucional, brand radio e in store radio.

- Staff radio es un canal de comunicación interna con formato radiofónico convencional pensado como elemento de motivación organizacional y de comunicación interna. Existen casos de éxito como en Apple y Orange. En España, StreamRadio desarrolla, por ejemplo la radio corporativa del Grupo Thyssenkrupp.

- Radios institucionales. Son emisoras diseñadas para organismos públicos y otras entidades políticas, sociales o culturales. Como las emisoras que operan durante una campaña política a favor de un partido o un candidato, por ejemplo.

- Brand radio. En este caso, es fundamental el contenido, tanto musical como informativo y de entretenimiento, que está orientado a potenciar la identificación del usuario con los valores de la marca y su misión como empresa en el conjunto de la sociedad. Ejemplos de empresas que cuentan con este servicio son Galp FM o Holiday Gym.

- In store Radio es el formato heredero del hilo musical convencional, aunque existen algunas novedades en cuanto a la programación de contenidos, como la inserción de mensajes publicitarios de terceros gestionados por la propia marca y la automatización de las selecciones 
musicales, pero el uso es el mismo: se utilizan para personalizar el ambiente de un espacio comercial o de un lugar de trabajo con la idea de crear un paisaje sonoro que repercuta positivamente en las personas presentes.

En el contexto actual, en el que contamos con herramientas de identificación, catalogación y gestión de contenidos directa por parte del usuario como Shazam, Spotify, SoundCloud, iTunes, etc., a todo ello se le puede añadir una línea estratégica más en los diseños de audio branding: la potenciación de la participación del público al mismo tiempo que las empresas tienen una presencia activa en estas plataformas a través de contenidos musicales, segmentados y sociales, que suponen un paso más en esta experiencia de marca (Castelló 2010).

El término podcasting fue sugerido por primera vez en 2004 por el articulista de The Guardian Ben Hammersley, quién en un texto titulado Audible Revolution, reflexionaba sobre el resurgir de la radio amateur gracias al abaratamiento de costes en la distribución de contenidos de audio que había traído la aparición y generalización del formato de compresión conocido como mp3 y la gran popularidad alcanzada por los reproductores iPod de Apple.

Hammersley proponía junto a podcasting los términos audiobloging y guerrillamedia, intuyendo así las posibilidades para el marketing y la construcción de marca personal y corporativa probablemente inspirado por las experiencias iniciadas por algunos profesionales muy conocidos del momento, particularmente Adam Clark Curry, presentador de MTV, conocido como Podfather. Adam Curry, como en otras ocasiones de la historia de los medios, supo aprovechar el momento tecnológico y pegarlo al más universal de los contenidos, la música, convirtiéndose así en el verdadero pionero de la distribución de contenidos de audio a través de internet y uno de los primeros creadores de marca personal en la web. Desde el 13 de agosto de 2004, junto a John C. Dvorak realiza el programa diario No Agenda Show y fundó la empresa PodShow en 2005.

En junio de 2005, Apple se decide por apoyar definitivamente la distribución de contenidos radiofónicos y musicales bajo demanda 
cuando comenzó a distribuir la versión 4.9 de iTunes para reproducir música en los ordenadores tanto en entorno Windows como Machintosh, sincronizando con los reproductores iPod.

Desde ese momento, el número de medios de comunicación, webs informativas, sitios corporativos y blogs que empezaron a ofrecer contenidos de audio descargables fue exponencial. Desde 2004, momento en que Google ofrece una búsqueda de la palabra podcast (Checa, 2013) podemos encontrar 235 millones de entradas.

El desarrollo y consolidación de la comunicación en movilidad -lo que implica la democratización de los dispositivos móviles y el acceso a banda ancha- ha redefinido los hábitos de consumo de los usuarios. Los cambios tecnológicos necesarios para que esta comunicación móvil prolifere están relacionados con la cultura de la participación y la inteligencia colectiva como estrategia para gestionar y producir conocimiento (Blanco et al., 2013).

Por lo tanto, es cuando este tipo de comunicación y la tecnología que la soporta se convierten en habituales en la sociedad, cuando el podcast -base, como se viene diciendo, del servicio de radio corporativa- se populariza y se yergue como nuevo canal de distribución, cuyo consumo parece incrementarse "alcanzando las seis escuchas semanales por usuario de podcasts" como revela Aguayo (2015) quien también recupera el que, actualmente, parece un acertado pronóstico que alienta el modelo de negocio de la radio corporativa y fue difundido en un artículo de la revista Forbes, en noviembre de 2014 por parte de Dorie Clark -estratega de marketing de la Fuqua School of Business (Universidad de Duke)-, en el que se vaticinaba que en 2015 el podcast sería la herramienta de comunicación que sufriría un mayor crecimiento de audiencias.

A continuación, se resumen en la siguiente tabla las empresas identificadas con un modelo de negocio fundamentado en el desarrollo de productos de radio corporativa con una trayectoria suficiente -según la información facilitada por la propia empresacomo para argumentar uno o más casos de éxito entre sus clientes. 
Tabla 1. Resumen selección de empresas de la muestra que ofrecen servicios de radio corporativa, con casos de éxito reconocidos.

\begin{tabular}{|c|c|}
\hline \multicolumn{2}{|l|}{ Internacional } \\
\hline $\begin{array}{l}\text { My R@adio. Milán, Italia } \\
\text { www.myradiostore.it } \\
\text { Grupo Planet Media. Desde 2005, la división de Nuevos } \\
\text { Medios desarrolla Brand Radio }\end{array}$ & $\begin{array}{l}>\text { Brand Radio } \\
\text { In Store Radio }\end{array}$ \\
\hline RadioBrand. Macerata, Italia www.radiobrand.it & $\begin{array}{l}>\text { Brand Radio } \\
>\text { In Store Radio }\end{array}$ \\
\hline $\begin{array}{l}\text { Alaireweb. Colombia } \\
\text { www.alaireweb.com } \\
\text { Nace con función de dinamización sociocultural y deriva } \\
\text { en emisora corporativa en } 2004\end{array}$ & $\begin{array}{l}>\text { Bran Radio } \\
\text { In Store Radio } \\
>\text { Staff Radio }\end{array}$ \\
\hline $\begin{array}{l}\text { EARDUM (Comercial Radio Brand Campaign) Pyrmont, } \\
\text { Australia. } \\
\text { www.eardrum.com }\end{array}$ & $\begin{array}{l}>\text { Radio Advertising } \\
>\text { Digital } \\
>\text { Sonic Branding } \\
>\text { Website Audio } \\
>\text { TV Voice Casting \& Directing } \\
>\text { Branded Content } \\
>\text { Station Branding }\end{array}$ \\
\hline $\begin{array}{l}\text { Niuradio. Santiago de Chile } \\
\text { www.niuradio.cl }\end{array}$ & $\begin{array}{l}>\text { Bran Radio } \\
>\text { In Store Radio } \\
>\text { Staff Radio }\end{array}$ \\
\hline $\begin{array}{l}\text { Self Native Radio Brand. B. A., Argentina } \\
\text { www.snrb.com.ar }\end{array}$ & $\begin{array}{l}>\text { Brand Radio } \\
>\text { In Store Radio }\end{array}$ \\
\hline $\begin{array}{l}\text { Bauer Media Group } \\
\text { Su división Media, operando en Reino Unido está } \\
\text { desarrollando experiencias muy interesantes con algunos } \\
\text { de sus canales de radio que pueden servir de modelo } \\
\text { para el desarrollo de la radio corporativa }\end{array}$ & $>$ Brand Radio. \\
\hline \multicolumn{2}{|l|}{ Nacional } \\
\hline $\begin{array}{l}\text { Goodit, España } \\
\text { www.goodit.es } \\
\text { No se presenta como una empresa dedicada a la radio } \\
\text { corporativa, sino como una empresa que ofrece servicios } \\
\text { de comunicación corporativa }\end{array}$ & $\begin{array}{l}>\text { Bran Radio } \\
>\text { Staff Radio } \\
>\text { Eventos streaming } \\
>\text { Creación y desarrollo de } \\
\text { contenidos de audio. } \\
>\text { Seguimiento de medios. }\end{array}$ \\
\hline $\begin{array}{l}\text { Stream Radio, España } \\
\text { www.streamradio.es }\end{array}$ & $\begin{array}{l}>\text { Bran Radio } \\
>\text { In Store Radio } \\
>\text { Staff Radio }\end{array}$ \\
\hline $\begin{array}{l}\text { Diseño Musical, España } \\
\text { www.disenomusical.com } \\
\text { Nace en } 2006 \text { como una empresa especializada en la } \\
\text { sonorización de espacios y está empezando a ofertar } \\
\text { servicios de radio corporativa. }\end{array}$ & $\begin{array}{l}>\text { Radio Corporativa } \\
>\text { Servicio Multicanal } \\
>\text { Radio } 4 \text { Brands } \\
>\text { Proyectos Diseño Musical }\end{array}$ \\
\hline $\begin{array}{l}\text { Sono on Lorem, España } \\
\text { http://www.sonoonlorem.com }\end{array}$ & $\begin{array}{l}>\text { Radio Corporativa } \\
>\text { Radio Eventos } \\
>\text { Radio temática }\end{array}$ \\
\hline
\end{tabular}




\section{Metodología}

La construcción de este artículo se fundamenta en un enfoque metodológico cualitativo, cuya base epistemológica es "existencial (no determinista) y constructivista" y pone el énfasis en la interpretación (Stake, 2007: 46), es decir, no se trata de establecer una norma, sino de aplicar la lógica inductiva a los datos obtenidos tras un proceso de observación. La línea metodológica aplicada se basa en el case study o la investigación sistematizada de diferentes realidades en base a un mismo modelo de análisis y se desarrolla a través de la entrevista en profundidad de tipología semiestructurada y la observación indirecta o la corroboración de los datos a través de otras fuentes (Tamayo y Tamayo: 2004).

De forma coherente a lo que se venía relatando, el caso seleccionado para su análisis se ubica en el nicho de la radio corporativa y parte de dos premisas fundamentales: su operatividad en el ámbito español y su consolidación como empresa activa en este sector. Así, nuestro universo se centra en la empresa StreamRadio, como ejemplo de modelo radiofónico corporativo en España. Para la elaboración de esta investigación, se establecen los siguientes objetivos que se imponen como detonante y fin del estudio:

O1_ Identificación y descripción de la radio corporativa, intersección entre la innovación comunicativa y la estrategia empresarial de bajo coste.

O2_ Radiografía del modelo de negocio de StreamRadio como ejemplo activo de radio corporativa.

Es preciso hacer una breve mención a las limitaciones de esta investigación en términos muestrales ya que, como se explicitaba anteriormente, el tratarse de un solo caso imposibilita la presentación de los resultados obtenidos como norma o extensibles a la generalidad. Sin embargo, se considera que este estudio aporta datos significativos para comprender la realidad analizada y sentar las bases para proyectos futuros con perspectivas más abarcadoras. 


\section{Estudio de caso: StreamRadio}

Después de que Peter Drucker, principal teórico de la escuela neoclásica de la administración, estrenara el concepto de modelo de negocio, se sucedieron múltiples definiciones para este significante: Amit y Zott (2001: 511) consideran que "un modelo de negocio explicita el contenido, la estructura y el gobierno de las transacciones designadas para crear valor al explotar oportunidades". Timmers (1998: 3) cree que un modelo de negocio es aquel que "incluye la descripción de la arquitectura del producto o servicio, la especificación de los distintos actores que participan en el negocio y sus roles y la definición del as fuentes de ingresos". En el ámbito del sector de la comunicación, Sergio Roses (2010) señala que los modelos de negocio explican cómo operan las empresas informativas para dominar el mercado: "describen su producto, estrategias, estructuras de costes y modelo potencial de ingresos. $\mathrm{Y}$ de forma específica en lo que afecta a la empresa radiofónica, Peinado y Rodríguez Barba (2011) establecen los cauces por donde discurrirán esos nuevos modelos en la radio.

En este caso, siguiendo la lógica de Magretta (2002), prestaremos atención en el análisis a cuál es el valor que la empresa proporciona a sus clientes y cuáles son las estrategias que aplica la organización para obtener un beneficio al ofrecer su servicio a los consumidores.

Con este contexto como base, se subdivide este apartado en los siguientes puntos descriptivos que servirán como elementos organizadores e hilo conductor del texto. Vale la pena matizar que la lógica de la división responde a criterios de descripción transversales y no a un fin detallista que exigiría otro tipo de estudio:

Identidad y Antecedentes.

Producción y distribución.

Recursos materiales y humanos.

Recursos económicos y modelo de ingresos.

Estrategias de comunicación y servicios de control y medición.

Perspectivas de futuro. 


\subsection{Identidad y antecedentes}

StreamRadio, radio digital corporativa a través de internet, define su servicio del siguiente modo: "StreamRadio ofrece a empresas, organismos e instituciones la posibilidad de incorporar a su estrategia de marketing la creación de una plataforma propia de radio para dar a conocer sus productos y promociones y difundir información de interés corporativo" (StreamRadio.es)

El proyecto surge con la idea del modelo In Store Radio, es decir, con el concepto de hilo musical y tomando a la empresa americana InStore Broadcasting Network (IBN) como referencia, para después ampliar sus servicios. La idea se testea incluso antes de consolidarse como empresa, en Colombia, colaborando con la creación de una marca radiofónica como herramienta de propaganda del partido político liderado por Antanas Mockus, el Partido Verde. El éxito de la experiencia alentó la continuación y puesta en marcha de lo que inicialmente fue Expressa Radio y posteriormente, por razones prácticas y de marketing, cambia su indicativo a StreamRadio que se crea como Sociedad Limitada en Londres.

Los tres socios iniciales e impulsores de la idea provienen del ámbito de la comunicación radiofónica -así es que el proyecto cuenta con marcados tintes periodísticos como background- $\mathrm{y}$ dan el pistoletazo de salida en 2006, sin realizar estudios de mercado previos y con un plan de viabilidad limitado por el presupuesto inicial.

El proyecto piloto se aplicó a la empresa The Phone House, perfil del modelo In Store Radio y a partir de entonces se multiplicó el número de clientes y servicios. Actualmente, según sus datos oficiales, operan en 50 idiomas, en 80 países y en más de 900 puestos de trabajo.

\subsection{Producción y distribución}

StreamRadio categoriza su oferta de servicios en tres tipos de radio corporativa que incluyen servicios como multiplataformas, servicio de podcast, plataformas multi-idiomas, locuciones profesionales $\mathrm{o}$ soluciones interactivas: 
- Brand Radio: se define como "un modelo de radio digital por internet cuyo objetivo fundamental es potenciar el reconocimiento y la identidad de marca. El sistema brand radio permite diseñar una emisora de radio personalizada y de alta calidad con contenidos musicales e informativos asociados a los valores de marca [...] permiten desarrollar canales específicos para promocionar un producto o una línea de productos concretos, para conectar con segmentos de consumidores diferenciados o para reforzar campañas publicitarias puntuales" (StreamRadio.com). Es ejemplo de la comunicación corporativa externa, es decir, no necesariamente pensada para el audio en el entorno laboral, generalmente se centra en la emisión de señal en formato digital y online, aunque también contemplan la explotación de aplicaciones móviles.

- In Store Radio: este modelo "permite personalizar los centros comerciales con una solución musical, informativa y publicitaria homogénea e integrada [...] son un nuevo escenario de comunicación comercial muy eficaz para fomentar el consumo y maximizar el efecto de las campañas publicitarias" (StreamRadio.com). Se trata de un servicio pensado para cadenas con diferentes ubicaciones físicas, se basa en el concepto de hilo musical personalizado con la inclusión de elementos publicitarios e indicativos de la empresa matriz.

- Staff Radio: su objetivo es "dotar a los centros de trabajo con una solución musical e informativa personalizada [...] permiten estructurar canales de música adaptados a cada tipo de empresa y a su perfil de empleado y emitir mensajes específicos dirigidos a los trabajadores como, por ejemplo, información sobre la compañía, el sector, eventos, cursos e, incluso, felicitaciones de cumpleaños o aniversarios" (StreamRadio.com). Aplica la lógica de la comunicación interna en formato sonoro, al tiempo que aporta contenidos musicales.

Principalmente en las dos últimas modalidades se apuesta por la emoción como complemento a la practicidad y la fidelización a la empresa/marca. Así se presentan formatos que van más allá de una newsletter sonora, es decir, se incluyen secciones como "quién es quién", recordatorios de eventos y cumpleaños, entrevistas personales a trabajadores de la plantilla, buzón de sugerencias, etc. Se trata, en 
definitiva, de fomentar la comunicación formal y no formal en el entorno empresarial.

Aunque el Director de Comunicación y Marketing de StreamRadio describe sus esfuerzos orbitando alrededor de estos tres tipos de servicios, en su web site, se incluye una cuarta modalidad, Event Radio o la retransmisión en directo mediante streaming de cualquier evento interesante para el contratante. Se trata de un servicio compatible con los demás ofertados, cuya esencia, al igual que en el campo de la radio convencional, no deja de ser el audio, independientemente del fin comunicativo o del canal de transmisión.

No obstante, aun con perfiles de servicios definidos, cuya direccionalidad de señal péndula entre lo interno y lo externo a la organización beneficiaria -en formato web o app móvil de acuerdo a la voluntad del cliente- y conjuga contenidos musicales e informativos -no desde una perspectiva generalista, estos últimos, sino vinculados a los intereses del cliente-, el cliente es el elemento clave para la producción ya que esta se adapta a sus exigencias y a sus particularidades como empresa, desde el vocabulario empleado al diseño de la escaleta y el reloj musical o incluso al canal de distribución.

De acuerdo a este razonamiento, el cliente objetivo varía en función del servicio. Así, para el modelo Staff Radio, el perfil potencial es el de una empresa con ubicaciones múltiples y un número significativo de empleados en movilidad. Ejemplo de ello es el caso de ThyssenKrupp, cuyo principal objetivo era llegar a los trabajadores desplazados de sus empresas dependientes y así fomentar el sentimiento de pertenencia a la organización matriz.

En el caso de In Store Radio, el cliente objetivo es aquel cuyo negocio se disecciona en diferentes locales y que exige personalización por localización, es decir, diferentes idiomas o promociones en función de su posicionamiento geográfico. Ejemplos de ello son empresas como The Phone House o Mercadona.

Y, finalmente, si nos referimos a Brand Radio, el abanico se abre a las voluntades del cliente y a sus recursos propios, empresas del sector de 
las telecomunicaciones o ejemplos consolidados y con gran recorrido en el campo de la promoción de eventos cuentan con un backup de contenidos propios disponibles para componer la programación de su propia radio corporativa nada desdeñables, por ejemplo, en casos contrarios la estrategia pasa por diseñar contenidos para cumplir objetivos.

En cualquiera de los casos comentados la ventaja competitiva del servicio ofertado se fundamenta en los activos intangibles de una organización, en el capital humano y el valor de marca. Se trata de una actividad estratégica para la empresa cuyo eslabón es la comunicación corporativa direccionada hacia el oyente-empleado o el oyente-consumidor. Pero este prisma estratégico, aunque define el marco contextual del ecosistema de la radio corporativa, no es parte de la estrategia de la empresa ofertante, StreamRadio, que se define como productor, la comercialización y el marketing del servicio radiofónico y la publicidad externa es competencia del cliente, igual que la selección de contenidos de lo que es, en definitiva, su propia emisora de radio corporativa.

La fortaleza de StreamRadio se basa en la personalización del servicio a sus clientes, por esta razón no se contempla, hasta el momento, dar valor a sus contenidos como activo intangible para su propia organización, como elementos susceptibles de ser reutilizados en diferentes proyectos y optimizar así el proceso de producción que le es atribuido a la empresa analizada. Sin embargo, dichos contenidos no dejan de ser custodiados en formato digital, a modo de copia de seguridad, sin mayores pretensiones de descripción documental. Estos contenidos se archivan de forma sistemática en el mismo CPD del servidor de StreamRadio y, por otro lado, cada cliente posee los podcast de su propia emisión en su intranet (esperamos a que mañana nos confirme si utilizan otro sistema de archivo o qué plataforma es la que utilizan).

En términos de distribución, StreamRadio depende de un servidor ajeno ubicado en EE.UU que replica la señal en Alemania. A través de un juego de servidores aseguran la no caída del servicio que, hasta el momento, no ha dado el salto a plataformas de distribución de audio en línea como SoundCloud o Ivoxx, por ejemplo. 


\subsection{Recursos materiales y humanos}

StreamRadio cuenta con cuatro oficinas representativas en Europa y EE.UU (Madrid, Londres, Lisboa y Miami). La sede de Madrid, se ubica en Pozuelo de Alarcón y, aunque poseen estudios físicos, es tendencia que los propios locutores sean los que graban en sus equipos particulares los contenidos que venden a los clientes. Como se decía en el apartado anterior, esta es la única función desempeñada en España en su totalidad, ya que la sede de la empresa está en Londres y sus servidores fijos, contratados de forma externalizada, están ubicados en EE.UU., así es que legalmente la empresa solo opera en España a nivel locución.

Por su parte, el capital humano de la empresa está constituido fundamentalmente por los tres socios iniciales que son además gestores y a los que se les atribuyen los puestos de Dirección General y CEO (Nacho Montero), Dirección Comercial y Marketing (Francisco Sánchez) y Dirección de Contenidos (Cristina Mosquera Álvarez) y por otros seis socios en forma de consultores o business angels. Mención especial merecen los cuatro partners que se identifican como socios tecnológicos: Audioemotion, Serverroom, Centova y Cristaliza.

En lo que respecta a la gestión de recursos humanos al margen de la directiva, pueden dividirse dos grandes etapas condicionadas por variables vinculadas a proyectos encargados y a la madurez de la empresa. De este modo, en una primera etapa, que coincide con los principios de StreamRadio y con proyectos que implicaban un elevado número de locutores y muchas horas de grabación (como el prestado a Holiday Gym), se contaba con locutores en plantilla. Actualmente, sin embargo, todos los locutores son colaboradores, es decir, son freelance autónomos, generalmente contratados por obra y servicio y capaces de grabar sus piezas bien en las instalaciones de StreamRadio, bien en las suyas propias, que hacen llegar a la empresa de forma limpia -es decir, sin fondo musical- y es allí donde se montan.

Así es que, en definitiva, el equipo se reduce a la siguiente tríada: los tres gestores y fundadores que trabajan directamente en el proyecto 
de radio corporativa, los socios colaboradores y a un pool de locutores a los que recurrir en función de las necesidades de cada proyecto y las particularidades de cada cliente.

\subsection{Recursos económicos y modelo de explotación}

StreamRadio nació con un capital inicial de 3.000 euros. Desecharon formatos de ayuda al emprendedor como lanzaderas, aceleradoras o viveros y se lanzaron al mercado con sus recursos propios. Tras abordar su primer proyecto con The Phone House, decidieron ampliar capital con formato business angel, en contraposición al venture capital o fondos de capital riesgo. Los business angels aportaron un capital que oscilaba entre los 15.000 y los 20.000 euros, hasta completar una inversión total cercana a los 100.000 euros y sumar un máximo del $49 \%$ de la empresa, quedando el $51 \%$ en manos de los tres socios iniciales.

El perfil de los business angels es heterogéneo, no necesariamente vinculado al mundo de la comunicación, sin embargo, sí se impuso una condición inicial para esta figura: aportar valor añadido al proyecto más allá de una cuantía económica en formato de relaciones públicas, nexos de unión con otros sectores o conocimientos específicos o complementarios en la materia. De este condicionante se infiere la implicación colaborativa.

El modelo de ingresos de StreamRadio responde a la lógica del pago por servicio ofertado, con presupuestos cerrados que huyen de la variable del éxito y están totalmente adaptados a las necesidades puntuales del cliente. StreamRadio cuenta con clientes a quienes se les hace el diseño de radio corporativa y no mantienen ninguna otra relación comercial mientras el diseño funcione como se espera; clientes a quienes se les hace el diseño y se les elabora, locuta y comercializa los contenidos, tanto informativos, como publicitarios; y clientes a quienes se les produce y locuta los contenidos informativos pero sólo se graban los contenidos publicitarios, mientras que la gestión y comercialización de los anunciantes la realiza el departamento comercial del cliente. 


\subsection{Estrategias de comunicación y servicios de control y medición}

La estrategia de comunicación externa se centra en promocionar sus propios casos de éxito y su actividad en diferentes escenarios que abarcan el ámbito universitario o la participación activa en obras colectivas con el fin de posicionarse como referente en el nicho de la radio corporativa. De modo complementario y como altavoz por excelencia del siglo XXI, las redes sociales están presente en su estrategia comunicativa y su gestión depende directamente del propio equipo directivo que avala con su formación en comunicación esta responsabilidad, así la administración de Twitter es competencia del CEO de la empresa, la de Facebook del Director de Comercial y Marketing y la Directora de Comunicación se responsabiliza de los comunicados oficiales y notas de prensa.

En este sentido y asumiendo como principal estrategia de comunicación los casos de éxito de sus proyectos, la medición de audiencias se convierte en un aspecto clave. El control de usuarios responsabilidad de StreamRadio se fundamenta en dos aspectos: las IP conectadas al servidor y la descarga de podcast. Cabría preguntarse en este punto qué ocurre con los casos del servicio In Store Radio, cuyos oyentes son clientes móviles de la empresa receptora del servicio de StreamRadio, la respuesta implica a dicha empresa y a StreamRadio y se reduce a una aproximación numérica resultado de la cuantificación de clientes diarios y las IP conectadas al servidor; los sistemas de gestión de StreamRadio y de sus clientes no están conectados, así es que es el propio cliente el que, a posteriori, compara la parrilla de emisión con sus ventas y puede extraer conclusiones válidas sobre la eficacia del servicio en términos de rentabilidad. Si nos ceñimos al servicio Brand Radio, la medición usuarios online en internet y en APPs es un campo cuestionado en términos de eficacia real, "el mercado digital continúa sin ofrecer de manera homogénea un dato que satisfaga a todos sobre su audiencia online" (GómezBorrero y Herrero-Tejada, 2014), existen diferentes mediciones aproximativas como las ejecutadas por comScore, Quantcast, Alexa o Nielsen de forma ajena a la empresa propietaria, por ejemplo. 


\subsection{Perspectivas}

"Darnos a conocer mucho más" (Francisco Sánchez, 17-11-15). Se confía en que el salto a la radio digital sea un propulsor de su servicio que minimice los efectos adversos que supone la cultura del respeto al cambio arraigada en las potenciales empresas clientes de StreamRadio. Parece que, por el momento, no se han consolidado estrategias conjuntas con actores que históricamente han colaborado como impulsores de los cambios tecnológicos radiofónicos, como los coches de alta gama -determinantes para la popularización de la FM e incluso de la telefonía móvil (TAV)-. Aunque la dependencia de variables externas como la democratización del acceso a la internet en movilidad o la calidad de la banda ancha en términos económicos, son condicionantes para la radio corporativa, la evolución en este campo vivida en las últimas dos décadas parece jugar a su favor.

\section{Conclusiones}

A lo mejor todo está inventado, pero lo más probable es que podamos mejorarlo e incluso seguir reinventando. La búsqueda de nuevos espacios en el mercado obliga al desarrollo y a la innovación. Este caso de estudio nos deriva hacia uno de esos nichos en el que poder continuar la actividad empresarial radiofónica y donde se aprecia la confluencia del contexto online, la estrategia comunicacional corporativa, el marketing y el audio como contenido estrella, es decir, en el que se conjugan la innovación funcional y la estratégica.

A raíz de los cambios que la tecnología propone y dispone, la empresa radiofónica, como partícipe del cambio social, redefine su actividad a fin de responder a las necesidades de usuarios y beneficiarios, los destinatarios de los nuevos modelos de negocio en la comunicación.

$\mathrm{Y}$ es en este contexto en el que la innovación es un elemento fundamental para transformar algunos determinantes propios del sector y poder asumir el riesgo y el potencial éxito. Así, el ejemplo propuesto, la radio corporativa, propone el aunar las prestaciones de la tecnología y la calidez tradicional del medio radiofónico, que se 
identifica con la cercanía, la credibilidad, la inmediatez y las compatibiliza con sus características más actuales: bidireccionalidad, multimedia, asincronía o fragmentación.

El resultado de este estudio ofrece un panorama favorable a este nuevo modelo de negocio radiofónico, si bien el énfasis social que traslada el posible cambio puede ser su principal enemigo, a costa de superar la debilidad motivada por la inercia que provoca la corriente de innovación tecnológica y estratégica en los últimos tiempos.

Este caso analizado, StreamRadio, nos muestra un ejemplo de consolidación de este modelo de negocio aplicado a la radio, desde el soporte tradicional al propiamente digital, online y especializado. Se trata de una propuesta novedosa que afronta un reto importante, tanto para su actividad como para el propio sector, pero que muestra claros casos de éxito que se pueden convertir en tendencia, algo que, sin duda, provocará un seguimiento activo que permita establecer comparativas con otros casos que nos aproximen a resultados muchos más fiables.

\section{Referencias bibliográficas}

Aguayo López, V. (2015): El podcast como herramienta de comunicación empresarial. Tesis doctoral. Director: A. Méndiz Noguero.

Málaga: Servicio de Publicaciones y Divulgación Científica de la Universidad de Málaga; recuperado 19/11/2015, de http:/ / riuma.uma.es/xmlui/handle/10630/10062\#sthash.mtex KK1x.dpuf

Amit, R. y Zott, C. (2001): "Value Creation in E-Business". Strategic Management Journal, 22, 493-520.

Arroyo, I (2003): “Imágenes mentales: los estímulos visuales y auditivos". Icono14, 1 (1), 16-29. Recuperado el 20 de noviembre de 2015, de http://www.icono14.net/ojs/index.php/icono14/article/view/ 461 DOI: http://dx.doi.org/10.7195/ri14.v1i1.461

Blanco Hernández, M.; AJ López Rivero, A.J.; Rodero Antón, E. y Corredera de Colsa, L. (2013): "Evolución del conocimiento y 
consumo de podcasts en España e Iberoamérica". Trípodos, 33 , 53-72. Recuperado 22/11/2015, de http://www.tripodos.com/index.php/Facultat_Comunicacio_ Blanquerna/article/view/97

Castelló Martínez, A. (2010): Estrategias empresariales en la Web 2.0. Las redes sociales online. Alicante: ECU.

Checa García, F. (2013): "El uso del podcast y wikis como herramientas de generación y gestión del conocimiento". Revista Crítica de Ciencias Sociales y Jurídicas, 40 (2013.4). Recuperado el 21 de noviembre de 2015, de

http://revistas.ucm.es/index.php/NOMA/article/viewFile/48 $\underline{339 / 45538}$

D'Amato, F. (2015): "In-store music in Italy". Forum Italicum: A Journal of Italian Studies. (August 49), 2, 567-580; recuperado el 21 de noviembre de 2015, de http://intlfoi.sagepub.com/content/49/2/567.abstract

DOI: $10.1177 / 0014585815581811$.

Gallego Pérez, J. (2010): Podcasting. Nuevos modelos de distribución para los contenidos sonoros. Barcelona: UOC.

Gómez-Borrero, P. (2014): “Audiencias”. En: García Santamaría, J.V. (ed.), El negocio de la prensa digital. Madrid: UNIR.

Magretta, J. (2002): "Why business models matter". Harvard Business Review, 80, 86-92.

Martínez-Costa, M.P. (2015): "Radio y nuevas narrativas: de la crossradio a la transradio". En: Oliveira, M. y Ribeiro, F. (Eds.) (2015). Radio, sound and Internet. Proceedings of Net Station International Conference, 168-187. Recuperado el 20 de noviembre de 2015, de www.lasics.uminho.pt/ojs/index.php/cecs.../2092

Peinado, F. y Rodríguez Barba, M.D. (2011): "Nuevos modelos de negocio para la Radio" En MA Ortiz Sobrino \& N López Vidales (Eds). Radio 3.0 Una nueva radio para una nueva era. Madrid: Fragua Libros, 161-162, 
Peinado, F. y Fernández Sande, M.A. (2012): “La Empresa

Radiofónica Actual". En JI Gallego \& MT García Leiva

(Coords.). Sintonizando el futuro. Radio y producción sonora en el siglo XXI. Madrid: IORTVE

Piñeiro-Otero, T. (2012): "Repositorios sonoros y recomendación de contenidos. El caso iVoox". El profesional de la información, 21 (2), 206-209. Recuperado el 21 de noviembre de 2015, de http:/ /www.elprofesionaldelainformacion.com/contenidos/20 12/marzo/13.html

Piñeiro-Otero, T. (2015): "Del Jingle a las radios corporativas. Una aproximación al concepto de audiobranding". Prismasocial, 14, junio-noviembre. Nuevas Tendencias en la Comunicación Organizacional, 663-688. Recuperado el 19 de noviembre de 2015, de http://www.isdfundacion.org/publicaciones/revista/numeros/ 14/secciones/abierta/nbiblio 01 jingle radios.html

Roses Campos, S. (2010: "Cambio del modelo de negocio de los medios informativos". En Pérez-Ugena, A. y Coromina y César Herrero, J.: Materiales para la innovación educative en estructura de la comunicación. Madrid: Universitas, páginas 129-166.

Sánchez, F. (2010). "Radio corporativa: la radio del futuro". Panorama Audiovisual. Recuperado el 19 de noviembre de 2015, de http://www.panoramaaudiovisual.com/2010/09/28/radiocorporativa-la-radio-del-futuro/

Scolari, C. (2013): Narrativas transmedias: cuando todos los medios cuentan. Barcelona: Deusto.

Sellas Güell, T. (2011): El podcasting: la (r) evolución sonora. Barcelona: UOC.

Stake, R. (2007): Investigación con estudio de casos. Madrid: Morata.

Tamayo. M. \& Tamayo (1981): El proceso de la investigación cientifica: Fundamentos de investigación. México: Limusa 
Timmers, P. (1998): "Business Models for Electronic Markets".

Electronic Markets, 8 (2), 3-8. Recuperado el 20 de noviembre de 2015, de http:/ / laurinaitis.home.mruni.eu/wp-

content/uploads/2010/03/Businnes-Models-for-ElectronicMarkets.pdf

\section{Otros documentos}

Audio Branding Academy (ABA) (2015): Glosary. Recuperado el 20 de noviembre de 2015, de http:/ / audio-brandingacademy.org/aba/knowledge/glossary/

Hammersley, B. (2004): "Audible revolution. Online radio is booming thanks to iPods, cheap audio software and weblogs". The Guardian (12.02.04). Recuperado el 20 de noviembre de 2015, de http://www.theguardian.com/media/2004/feb/12/broadcastin g. digitalmedia

Kotler, P. (2012): Qué es marketing. Entrevista a Philip Kotler. Recuperado el 21 de noviembre de 2015, de https://www.youtube.com/watch?v=TCpNzWdoO3Y

StreamRadio.es (s.f.): "Nuestra empresa". Recuperado el 20 de noviembre de 2015, de http:/ / www.streamradio.es/es/nuestraempresa/

\section{Entrevista en profundidad:}

F. Sánchez. Director Comercial y Marketing. Realizada el día 17 de noviembre de 2015.

* Este trabajo pertenece a la labor investigadora del grupo Research and Learning of Media and Communications Management-MediaCom UCM-. 


\title{
Los museos y el uso de la narrativas transmedia en las redes sociales
}

\author{
David Cordón Benito \\ Universidad Internacional de La Rioja (UNIR)
}

\begin{abstract}
Forma de citar este libro: Cordón Benito, D. (2016): "Los Museos y el uso de las narrativas transmedia en las redes sociales", en García Santamaría, J.V. y Pérez Bahón, F. (coord.): Los medios digitales españoles: procesos de cambio e innovación. Cuadernos Artesanos de Comunicación, CAC104 La Laguna (Tenerife): Latina.
\end{abstract}

\section{Resumen}

En los últimos años los medios de comunicación social han concentrado una gran popularidad otorgada por la ciudadanía, lo que les ha conferido un estatus muy próximo a los medios de comunicación tradicionales pero con audiencias cada vez más amplias.

Los museos se han interesado por este nuevo tipo de medio de comunicación. Dado su marcado carácter social definitorio como instituciones al servicio de las comunidades en las que se asientan, han investigado el poder bidireccional de estas nuevas herramientas. Esto ha repercutido en la presencia 'on-line' de este tipo de organizaciones en diversas redes sociales. Twitter se caracteriza por ser la herramienta de microblogging más utilizada para establecer un diálogo constante y fluido entre los museos y sus stakeholders. Algunas 
de estas organizaciones han desarrollado iniciativas innovadoras creando narrativas específicas para este nuevo tipo de medio de comunicación.

En este capítulo se analiza el desarrollo de nuevas narrativas transmedia por parte de las instituciones museísticas para promover su conocimiento, el engagement y la participación ciudadana. El objetivo de este capítulo es analizar el uso que el Muso ThyssenBornemisza, en Madrid, realiza de Twitter como medio de comunicación para dar a conocer su colección e incentivar la participación de sus seguidores.

El artículo finaliza con una serie de conclusiones que pretenden justificar por qué los social media son utilizados cada vez más como herramientas dinámicas y con un poder de penetración notable para transmitir información de interés a los diferentes públicos. Este uso de las redes sociales por parte de las instituciones incrementa la transparencia de estas y su reputación entre la población.

Palabras clave: Redes sociales, narrativa, transmedia, museos.

\section{Introducción}

RACIAS al desarrollo de Internet y al interés de la población T por incrementar su participación en los procesos de toma de decisión de las instituciones, han aparecido diferentes herramientas que, aprovechando las particularidades del entorno digital, han Navarida, 2012; Guzmán et al, 2013).

De esta forma, los ciudadanos participan y dialogan con las organizaciones mientras descubren que su opinión es tenida en cuenta por las organizaciones para las decisiones relativas al futuro de estas corporaciones (Mancera Rueda y Pano Alamán, 2013). Así, las organizaciones incrementan su presencia en las redes sociales y desarrollando una comunicación mucho más cuidada e individualizada con sus stakeholders (Küster y Hernández (2013). Las organizaciones entienden la importancia de introducir los medias 
sociales como un canal más a través del cual enviar sus mensajes corporativos y contribuir así a su estrategia de comunicación, incrementando su visibilidad y revitalizando el engagement por parte de los públicos (Ros-Diego y Castelló-Martínez, 2012). Se multiplica, por tanto, la posibilidad del público de participar y esto causa un interés por las instituciones por disponer de perfiles que muestren su identidad en la web 2.0 (Woo y Gil de Zúñiga, 2014).

Manuel Castells (2009: 88) entiende la comunicación como un "intercambio de información" facilitado gracias a "la tecnología de la comunicación, las características de los emisores y los receptores de la información, sus códigos culturales de referencia, sus protocolos de comunicación y el alcance del proceso". De esta forma, los usuarios dan a conocer su opinión en lo que el propio Catells reconoce como "autocomunicación de masas", quedando de manifiesto el interés que "las prácticas comunicativas derivadas de la intersección entre la sociabilidad y comunicación en internet" despiertan entre los investigadores (Del Fresno, 2012: 100).

\subsection{Twitter: red social de referencia y nuevo medio de comunicación}

Twitter se ha convertido en una de las herramientas más utilizadas para desarrollar estrategias comunicativas en el entorno on-line. Algunos autores (Wu et al, 2011; Deltell, 2014; Woo y Gil de Zúñiga, 2014; Doval y Martínez, 2015) defienden su supremacía como red social de referencia debido, en primer lugar, a su poder de unificar audiencias y, en segundo lugar, a su capacidad como un amplificador y multiplicador de mensajes.

Su uso en grandes momentos de relevancia nacional o internacional y, por tanto, de gran seguimiento por parte de los medios de comunicación tradicionales como, por ejemplo, la victoria de Barack Obama, las primaveras árabes o las protestas ciudadanas del 15-M en España, han conducido a algunos autores a afirmar que Twitter es algo más que una simple red social, mostrando rasgos de un medio de comunicación más (Kwak et al, 2010). Tíscar (2011), por su parte, 
entiende que Twitter es un medio de comunicación más con unos rasgos claros que los diferencian de otros social media. Según la autora (Tíscar, 2011: 41):

"La herramienta abandona la reciprocidad de las redes sociales (...). En Twitter no es necesario ser amigo de nadie para interactuar con él. Al ser (...) un espacio público, los mensajes de los usuarios se pueden consultar libremente (...). Para facilitar una lectura más ágil y organizada a aquellas personas que resulten relevantes, conviene 'seguirlas'. (...) Twitter se convierte en un panel de lecturas personalizado por cada usuario en función de sus intereses".

El usuario, por tanto, acude a esos perfiles que emiten una serie de mensajes que resultan de su interés y que se enmarcan dentro de una temática acorde a sus gustos y preferencias. Mediante el envío de tweets ${ }^{28} \mathrm{y}$ su identificación con hashtags ${ }^{29}$, los usuarios pueden hacerse eco de diferentes informaciones enviadas por las organizaciones e, incluso, convertirlas en trending topics ${ }^{30}$ que revelarán un interés en esos temas por parte de los seguidores ganando en visibilidad (AguirreSala, 2013).

A pesar de que los autores citados anteriormente entiendan que Twitter presenta una serie de particularidades que lo caracterizan como medio de comunicación, lo cierto es que son aproximaciones poco numerosas y que, por tanto, no pueden considerarse lo suficientemente representativas. Sin embargo, y partiendo de la base

\footnotetext{
${ }^{28}$ Un Tweet es cada uno de los mensajes que envía un usuario de Twitter y que tiene una capacidad de 140 caracteres.

${ }^{29}$ Un hashtag es aquel tema relevante que se identifica dentro de un Tweet mediante el símbolo \# y el nombre que el usuario decida otorgarle y que, posteriormente, el resto utilizará para clasificar un tema específico sobre el que se provoque discusión.

${ }^{30}$ Un Trending Topic o TT son aquellos temas identificados por los usuarios como relevantes a través de un hashtag y que, contabilizando el número de ocasiones en los que se utilizan, destacan aquellos temas de mayor relevancia para la audiencia.
} 
del estudio de Daria Dayter (2014), Twitter sí que se diferencia del resto de medios sociales desde el punto de las narrativas transmedia. Scolari, Jiménez y Guerrero (2012) clarifican que la investigación sobre narrativas transmediáticas ha evolucionado desde se citase por primera vez (Jenkins, 2003). Scolari, Jiménez y Guerrero (2012: 138) definen este concepto de narrativa transmedia o storytelling como: "Relatos que se expanden a través de múltiples medios y plataformas con la complicidad de sus receptores (...) ahora prosumidores". Por tanto, Twitter entra en el juego de las narrativas transmedia dado el carácter activo de sus usuarios, quienes a través del seguimiento de otros usuarios, establecen nuevas conexiones sociales y diálogos online que van enriqueciendo con sus aportaciones. Como afirma Scolari (2013: 25) lo interesante de este tipo de narrativa es que el relato se expande gracias a las incorporaciones de nuevos personajes y situaciones.

En los últimos años, el crecimiento de Twitter debido a su inclusión como herramienta de social media por parte de las instituciones ha experimentado un incremento notable. Tal y como refleja el estudio 'Análisis de las tendencias de uso y participación de las redes sociales a nivel mundial en España ${ }^{31}$, desarrollado por OBS, Twitter cuenta con un total de 356 millones de usuarios activos, de los cuales, 206 millones son hombres y 150 millones mujeres. La franja de edad que más utiliza esta red social es aquella que oscila entre los 25 y los 34 años (127 millones de usuarios) seguida por aquellos públicos entre 16 y 24 años (110 millones de usuarios).

\footnotetext{
${ }^{31}$ Informe OBS Social 2015. Análisis de las tendencias de uso y participación de las redes sociales a nivel mundial en España, disponible en: http://cdn2.hubspot.net/hubfs/342810/O-

PM/Informes/Investigacin OBS. Social Media 2015.pdf?t=1447872402711\& utm source $=$ hs automation $\& u t m$ medium $=$ email\&utm content $=23065031 \&$ hsenc $=$ p2ANqtz-9QZb9cz0fSwTfNgIiuhBTY34kB3-1H-

VR9bRnwXwlghCnERvfzOX4tKnDOGyAthUMrVaf1oRpatidAoQPC4BAGI1KRw\&_hsmi=23065031 (Recuperado el 24/02/2016).
} 
Focalizándose más en nuestro país, el informe destaca que aproximadamente 17 millones de personas en nuestro país utiliza de manera activa las redes sociales cada mes. El mismo documento refleja que el perfil del usuario mayoritario (un 68\%) es multipantalla, es decir, que accede a sus perfiles en diversas redes sociales desde diferentes dispositivos, por lo que la conectividad no supone un problema grave.

\section{Metodología}

Twitter se sitúa en nuestro país como la segunda red social más utilizada $^{32}$ precedida por Facebook ${ }^{33}$ y seguida por Google $+{ }^{34}$, Youtube $^{35}$, Instagram ${ }^{36}$ y Pinterest ${ }^{37}$. Debido a este segundo puesto que ocupa en nuestro país, y a las particularidades que se han destacado anteriormente y que lo hacen poseer unas características propias que lo distinguen del resto de redes sociales, este paper ha decidido centrarse en el uso que los museos realizan de Twitter.

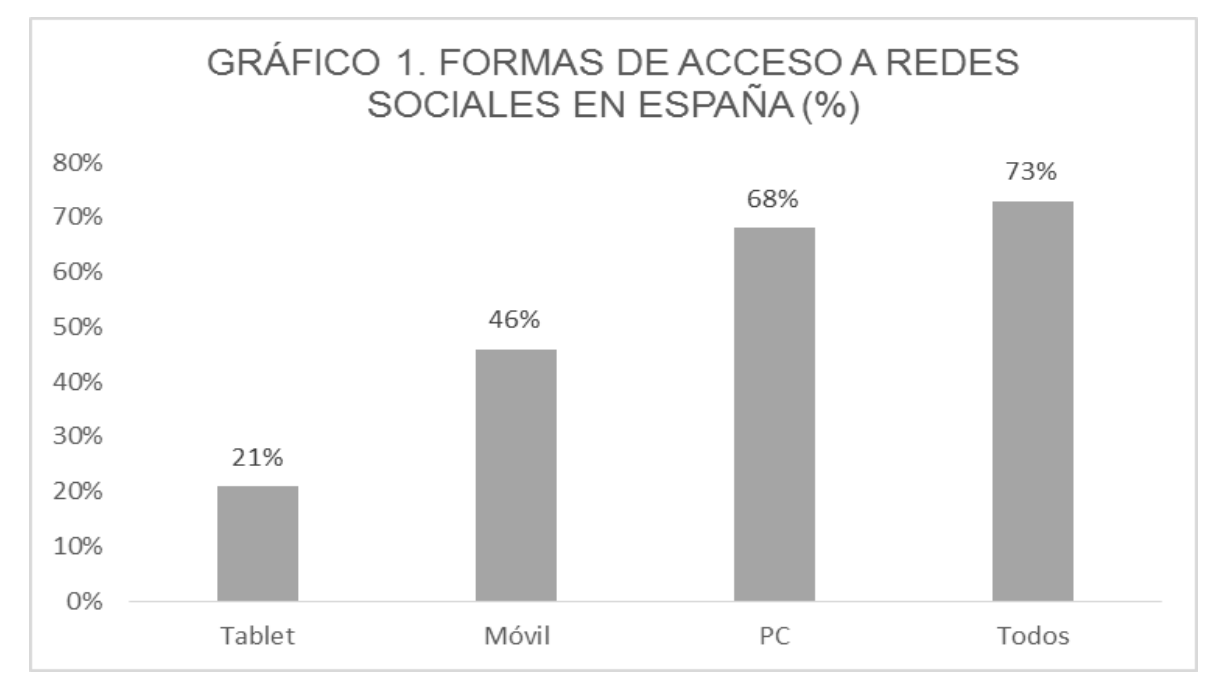

Fuente: Estudio Análisis de las tendencias de uso y participación de las redes sociales a nivel mundial en España (2015: 21).

${ }^{32}$ Ibídem.

${ }^{33}$ Disponible en: https://www.facebook.com/ (Recuperado el 24/02/2016).

${ }^{34}$ Disponible en: https://plus.google.com/ (Recuperado el 24/02/2016).

${ }^{35}$ Disponible en: https://www.youtube.com/ (Recuperado el 24/02/2016).

${ }^{36}$ Disponible en: https://www.instagram.com/ (Recuperado el 24/02/2016).

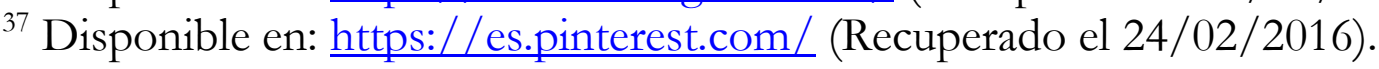


El objetivo principal es demostrar cómo Twitter puede servir de herramienta para los museos con el fin de crear contenido que ayude a la divulgación artística aprovechando las oportunidades que ofrece para el storytelling o las narrativas transmedia en el entorno digital.

Para ello, se analiza la iniciativa \#Thyssen140 desarrollada por el director artístico del Museo Thyssen-Bornemisza de Madrid, Guillermo Solana. Este experimento se puso en marcha en el año 2013 desde el perfil personal de Solana ${ }^{38}$ y ofreció un ejemplo de cómo los museos pueden desarrollar mensajes adaptados a la web 2.0 a través de los cuales incentivar a la participación de sus seguidores.

A través del hashtag \#Thyssen140, con el que clasificó todos los tweets que se enmarcaban dentro de esta iniciativa, Guillermo Solana se propuso utilizar el medio social Twitter para realizar una interpretación personal de la historia del arte que contenía el museo. Para el desarrollo del trabajo empírico se llevó a cabo una monitorización del perfil de Solana en Twitter. Se recogieron todos aquellos tweets clasificados con el hashtag \#Thyssen140, creado para esta iniciativa, lo que ofreció un total de 333 Tweets. El seguimiento al perfil de Solana se apoyó en el histórico que el propio Director Artístico del museo Thyssen-Bornemisza creó en el momento de desarrollar esta iniciativa a través de la herramienta web Storifi $3^{39}$. Además, como mecanismo de control se utilizó la obra bibliográfica \#Thyssen140, publicada por el Museo Thyssen-Bornemisza de Madrid a raíz de esta experiencia.

Esos datos cuantitativos recogidos se codificaron y descodificaron para facilitar su procesamiento. A continuación se analizaron, extrayéndose de los mismos una serie de resultados de carácter

\footnotetext{
${ }^{38}$ El nombre de usuario de Guillermo Solana en Twitter era @guillermosolana. Sin embargo, en el mes de septiembre del año 2015, el Director Artístico del Museo Thyssen-Bornemisza decidió cerrar su cuenta en esta red social atendiendo a razones de índole personal.

${ }^{39}$ Disponible en: https://storify.com/ (Recuperado el 24/02/2016).
} 
cualitativo, por lo que la metodología empleada para ese trabajo se consideró mixta.

En cuanto a la selección del Museo Thyssen-Bornemisza de Madrid, lo cierto es que su iniciativa \#Thyssen140 resultaba de gran interés, no sólo por el seguimiento que se le dio desde algunos medios de comunicación sino, además, por la novedad que supuso para los seguidores de esta institución museística madrileña la iniciativa anteriormente descrita.

Para reforzar esta elección con datos más objetivos se utiliza la publicación internacional considerada de referencia por parte de los profesionales del sector del arte y los museos 'The Art Newspaper', creada en el año 1996. Su periodicidad es mensual y la publica el grupo editorial Umberto Allemandi \& Co. Según su estudio: 'Visitor Figures: Exbibition \& Museum Attendance Survey', publicado todos los años y en el que se reflejan los museos y exposiciones más visitados de ese periodo, el Museo Thyssen-Bornemisza es el tercero más visitado de Madrid en los últimos 4 años.

\begin{tabular}{|c|c|c|c|c|}
\hline $\begin{array}{l}\text { Museo } \\
\text { /Año }\end{array}$ & Año 2011 & Año 2012 & Año 2013 & Año 2014 \\
\hline $\begin{array}{l}\text { Museo } \\
\text { Thyssen- } \\
\text { Bornemisza }\end{array}$ & 1.070 .390 & 1.255 .281 & 944.827 & 1.004 .470 \\
\hline
\end{tabular}

Tabla 1. Visitantes del museo Thyssen-Bornemisza de Madrid en los últimos años. Fuente: Elaboración propia a partir de la encuesta Visitor Figures: Exbibition \& Museum Attendance Survey, elaborada por The Art Newspaper.

De la tabla puede extraerse un descenso del número de visitantes entre los años 2012 y 2013 que, en el último periodo registrado y correspondiente a 2014, ha modificado su tendencia y comienza a incrementar y volver a situarse en cifras más cercanas a las de cuatro años atrás, es decir, a las del año 2011. 


\section{Discusión de los resultados}

La recolección de los datos para esta investigación obedece a una serie de variables que ayudan a la consecución del objetivo enunciado anteriormente. Por ello se decidió analizar: la cuenta emisora del tweet, la fecha de envío, la hora de inicio, la hora de fin, el número de tweets, si existe una mención a otra cuenta de Twitter, uso de otro hashtag además del propio de la experiencia, uso de enlaces web, número de los mismos en cada tweet, tipo de enlace y si se trata de un recurso propio o ajeno. Todas estas variables analizadas arrojan una serie de resultados representativos de la manera en que Guillermo Solana, como Director Artístico del museo Thyssen-Bornemisza, colabora en la difusión, creación de contenido y comunicación de la institución.

\subsection{Cuenta que emite los tweets}

La cuenta en Twitter a través de la cual se enviaron todos los tweets identificados a través del hashtag \#Thyssen140 y que formaron parte de la iniciativa fue la propia de Guillermo Solana. A través de su perfil @guillermosolana emitió todos y cada uno de los mensajes que narraban la historia del arte que contiene el museo. Esto pone de manifiesto la afirmación hecha por Claes y Deltell (2014: 597), donde explican que a pesar de poseer perfiles en redes sociales, los museos se encuentran "desorientados" en cuanto a su uso impidiendo "el establecimiento de un museo social pleno". No fue el perfil del museo aquel que incentivó este proyecto, sino el de uno de sus trabajadores que, a pesar de ser parte de la institución, difiere del perfil oficial que la organización mantiene en Twitter y, por tanto, se toma como un canal corporativo: @museothyssen.

Solana emitió estos mensajes ordenando la información en 11 lecciones a lo largo de los días que duró la iniciativa. Además, estableció una estructura narrativa cronológica, que facilitaba la comprensión de la historia a los seguidores de su perfil. 


\subsection{Momento del envío de las comunicaciones}

La iniciativa \#Thyssen140 se extendió entre los días 7 y 22 de mayo de 2013, y el recorrido histórico-artístico que abarcó partió desde 1290 y se extendió hasta 1982, es decir, 700 años de historia del arte, como especificaba el segundo tweet emitido por Guillermo Solana a sus seguidores.

Las horas de emisión de los mensajes comenzó durante todos los días entre las 17.59 y las 18.03 horas españolas. El propio Solana puntualizó a diversos medios de comunicación que su intención era iniciar sus sesiones a las 18.00 horas $^{40}$.

La hora de fin de cada una de estas 'lecciones', como el emisor de estos mensajes dio en llamar, se extendió desde las 18.21 horas en las que terminó la primera de ellas celebrada el 7 de mayo de 2013, hasta las 19:34 horas que se alargó la lección 6, la más extensa.

\subsection{Uso de enlaces a otras cuentas y empleo de hashtags}

En lo referente al uso de enlaces a otras cuentas y al uso de otros hashtags clasificatorios de los temas abordados, lo cierto es que los resultados no son numerosos.

Sólo se produce una única cita al perfil que el Museo Nacional del Prado, de Madrid, posee en Twitter (@museodelprado). El motivo obedece a la explicación del autor Francisco de Goya y Lucientes y se produce al hacer referencia a las obras firmadas por este pintor que posee el Museo Thyssen-Bornemisza. Concretamente, el tweet se envía el 15 de mayo de 2013, a las 18:03 horas, corresponde a la lección 7, ideada por Solana y dice lo siguiente (Museo Thyssen-Bornemisza, 2013: 122): "Con el debido respeto a nuestro vecino el Museo del Prado, que tiene lo mejor del pintor, el Thyssen posee 2 pequeños Goyas@museodelprado”. Sin embargo, la costumbre de citar a otros

\footnotetext{
${ }^{40}$ Disponible en:

http://cultura.elpais.com/cultura/2013/05/31/actualidad/1370004252 90059 3.html (Recuperado el 24/02/2016).
} 
museos cuyas obras expuestas se utilizan en las explicaciones dentro de \#Thyssen140 no se vuelve a repetir.

Respecto al uso de otros hashtags, no se efectúa durante toda la experiencia iniciada por Guillermo Solana. La única etiqueta clasificadora que se utiliza es la de \#Thyssen140, creada por el propio Director Artístico del museo con motivo de esta experiencia.

\subsection{Cuantificación de tweets enviados}

El número total de tweets publicados dentro de la iniciativa que se analiza en este paper y que vienen identificados por el hashtag \#Thyssen140 fue de un total de 333. Sin embargo, esos tweets se reducen a 308 si se tiene en cuenta el libro publicado por el museo debido a la popularidad de esta experiencia. En la edición de la obra se han eliminado los mensajes aclaratorios, de introducción, de inicio de lección y de corrección de alguna errata que el propio Guillermo Solana tuvo a consideración subsanar, tal y como puede comprobarse en el Storify ${ }^{41}$ desarrollado por el autor. Esto explica la reducción del número de mensajes que se llevaron a la versión impresa.

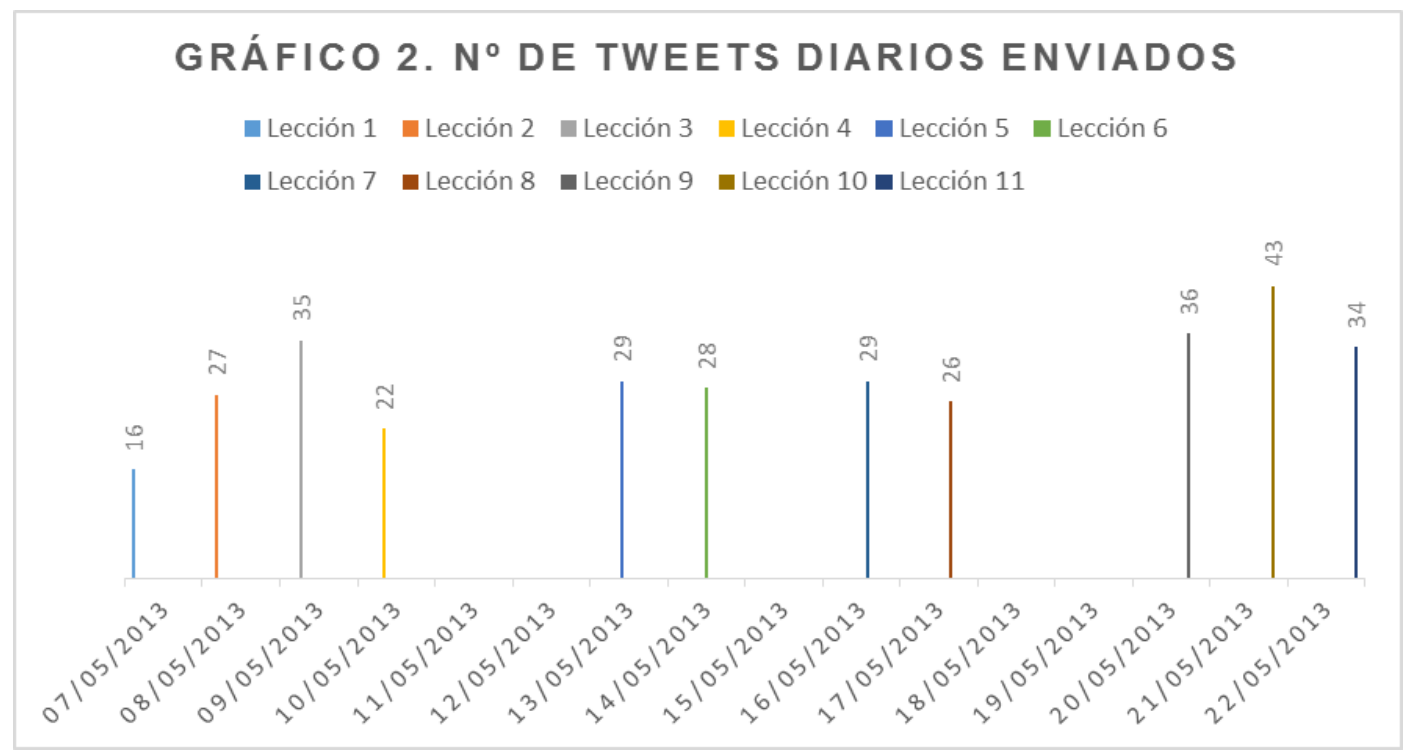

Fuente: Elaboración propia a partir de los datos recogidos en la investigación.

\footnotetext{
${ }^{41}$ Disponible en: https://storify.com/guillermosolana/thyssen140-porguillermo-solana-2 (Recuperado el 5/11/20105).
} 
Con respecto al número de tweets por lección no se siguió ninguna estructura predeterminada, por lo que no existe un criterio único con respecto a la cantidad de mensajes enviados cada día. La suma varía desde los 11 tweets de despedida de lección hasta los 42 enviados en la lección 10, que tuvo lugar el 21 de mayo de 2013. La media resultante es de 29.54 mensajes diarios enviados a los seguidores.

\subsection{Empleo de enlaces a webs y naturaleza de los mismos}

En lo referente al uso de enlaces webs, lo cierto es que se convierten en una dinámica constante durante toda la experiencia \#Thyssen140. El uso de estos enlaces es fundamental dentro de las narrativas transmedia y el storytelling que se deseaba poner en práctica durante esta iniciativa. Tal y como afirma De Ramón (2013: 128-129): "Los medios digitales $(. .$.$) han experimentado una clara evolución, desde$ una primera etapa basada en los códigos lingüísticos propios del estilo de redacción de los periódicos de papel, hasta llegar a la convicción de que la Red constituye un nuevo medio que exige su propio lenguaje". Esto justifica la evolución que se viene produciendo en las narrativas empleadas en los medios digitales y el interés de la academia en la investigación de las mismas.

Según Marañón (2012: 68): “Las Tecnologías de la Información y la Comunicación y los usos derivados de ellas en los mensajes de texto han provocado un cambio sustantivo en el lenguaje escrito". Y, precisamente, estas particularidades propias de las narrativas que se producen a través de los medios digitales son las que, a juicio de Dayter (2015) intensifican la colaboración, participación entre los usuarios y la interactividad.

En general, Guillermo Solana utiliza un total de 285 enlaces para enriquecer toda la información que narra a través de sus tweets. Se dividen en 278 enlaces en los que se emplean fotografías de las obras y 7 vídeos, que profundizan más en la temática específica de cada cuadro o del periodo histórico en el que se pintó. De las 278 fotografías, un total de 28 provienen de otros museos del mundo, pero se utilizan para contextualizar las explicaciones de Solana en 
\#Thyssen140. Por otro lado, los 7 vídeos empleados pertenecen al perfil que el museo mantiene en la web de vídeos Vimeo ${ }^{42}$, y en todos ellos Guillermo Solana es el narrador. Debe especificarse que, dado que algunos tweets pivotan sobre una misma obra artística, en ocasiones el enlace (en el caso de las fotografías) se repite, bien de manera total, bien de manera parcial (acudiendo a un detalle de la obra que analiza).

\section{Conclusiones}

Tras la discusión de los resultados obtenidos en el estudio, cabe presentar las conclusiones que se extraen de la investigación realizada y que se numeran a continuación.

Twitter es una herramienta que facilita las narrativas transmedia gracias a sus particularidades: la interactividad, la posibilidad de seguir perfiles sin necesidad de un permiso previo, el enlace a contenidos online que enriquecen la información o el envío de mensajes directos a través de la herramienta, son algunas de ellas.

A pesar de ser considerada por el público como una red social más, lo cierto es que cada vez son más los autores que destacan sus particularidades y diferencias con respecto a las mismas. Estos investigadores subrayan la importancia de Twitter como medio de comunicación aunque todavía se hace necesaria una mayor investigación a este respecto.

La iniciativa \#Thyssen140 supuso una novedad con respecto al tipo de comunicación on-line que venían haciendo los museos españoles. El contenido de los tweets enviados no se limitaba a un mero mensaje redactado en 140 caracteres, sino que supuso una nueva manera en la que los museos podían aprovechar las posibilidades de las narrativas transmedia. La experiencia fue apoyada por los seguidores de Guillermo Solana quienes participaron en el debate que generó cada

\footnotetext{
${ }^{42}$ Disponible en: https://vimeo.com/museothyssen (Recuperado el 24/02/2016).
} 
uno de los tweets, ampliaron la información, la enriquecieron y ayudaron a la propagación del experimento. Acercó la Historia del Arte al público general desarrollando una serie de mensajes sin tecnicismos ni construcciones gramaticales complejas, ejemplificando los temas que trataba y realizando una tarea de comunicación y divulgación de la colección a través de las redes sociales.

Si restar valor a la iniciativa desempeñada por Guillermo Solana, Director Artístico del Museo Thyssen-Bornemisza de Madrid, lo cierto es que hubiese sido conveniente que los mensajes enviados se generasen desde el propio perfil corporativo del museo en Twitter: @ museothyssen. La obra utilizada es parte del patrimonio cultural que posee el museo y, por tanto, los mensajes enviados deberían haber partido del mismo, ya que la referencia para el gran público es la institución en sí, y no uno de sus trabajadores.

Se hace necesario un mayor aprovechamiento de la herramienta y de todas las posibilidades que pone al alcance del usuario para optimizar mejor los recursos a su alcance.

El empleo de otros hashtags además del de \#Thyssen140 hubiese generado un mayor nivel de interactividad y de visibilidad de la estrategia. Hubiese ampliado el área de acción de la iniciativa al clasificarse con otras etiquetas del ámbito artístico o museístico.

Una estrategia para citar o mencionar cuentas o perfiles de otros museos nacionales o extranjeros a lo largo de la iniciativa, sin olvidar la realizada al Museo del Prado, hubiese podido establecer un nexo interinstitucional interesante por diversos motivos: en primer lugar, hubiese contribuido a una posible participación de la otra organización en la discusión pública on-line que generó \#Thyssen140, lo que hubiese enriquecido el debate. En segundo lugar, podría haber internacionalizado su alcance, ya que algunas de las obras citadas en el discurso transmedia pertenecen a otros museos con perfiles en Twitter. Y, en tercer lugar, la iniciativa hubiese ganado en visibilidad, ya que a través de la iniciativa de Guillermo Solana, otros museos nacionales o extranjeros y sus seguidores podrían haberse hecho eco 
del hashtag \#Thyssen140. De esta forma, el proyecto hubiese ganado en visibilidad.

\section{Bibliografía}

Aguirre Sala, J. F. (2013): "Nuevos alcances de la participación ciudadana a través de las redes sociales" en Culturales, época II, vol. I, núm. 2, julio-diciembre, páginas 119 a 150; recuperado el 24/2/2016 de: dialnet.unirioja.es/descarga/articulo/4725429.pdf.

Bryson, L. (1949): The communication of ideas. Oxford, England: Harper.

Castells, M. (2009): Comunicación y poder. Madrid: Alianza Editorial.

Claes, F., Deltell, L. (2014): "Museos sociales. Perfiles museísticos en Twitter y Facebook 2012-2013". El profesional de la información, Vol. 23, Núm. 6, noviembre-diciembre, pp. 594 -602; recuperado el 24 de febrero de 2016 de:

https://florenciaclaes.files.wordpress.com/2013/08/perfilesmusec3adsticos-claes-deltell.pdf

Congosto, M. L. y Aragón, P. (2012): "Twitter, del sondeo a la sonda" en Más poder local. Ejemplar dedicado a: Redes Sociales y Gobernanza, páginas 050 a 056. Recuperado el 24 de febrero de 2016 de: http://dialnet.unirioja.es/servlet/articulo? $\operatorname{codigo}=4013889$

Dayter, D. (2015): "Small stories and extended narratives on Twitter" en Discourse, Context \& Media.

De Ramón. M. (2013): “Un nuevo lenguaje para los medios periodísticos digitales. La necesidad de adaptarse al continuum informativo. Primeras experiencias en España”, en Revista de Comunicación de la SEECI, Nov., Año XV (32); pp. 127-140; Recuperado el 24 de febrero de 2016 de: Del Fresno, M. (2012): "Comprendiendo los social media y mass media: un modelo para el estudio de la comunicación interpersonal colectiva en tiempos de Internet", en Nueva Época. Sept-Nov. No 11, pp. 99-109; recuperado el 24/2/2016 de: dialnet.unirioja.es/descarga/articulo/4331247.pdf

Delltell, L. (2014): “Audiencia social versus audiencia creativa: caso de estudio Twitter", en Estudios sobre el mensaje periodístico, Vol. 20, Núm. 1, páginas de 033 a 047; recuperado el 24/2/2016 de: http://revistas.ucm.es/index.php/ESMP/article/view/45217 
Doval, M. y Martínez, B. (2012): "La audiencia activa en Twitter: análisis de la retirada de un artículo de opinión en ElMundo", en Estudios sobre el Mensaje Periodístico, Vol. 18, No 1, pp. 55- 071; recuperado el 24/2/ 2016: revistas.ucm.es/index.php/esmp/article/download/39354/37901

Guzmán, D., Del Moral, M. y González, F, y Gil, H. (2013): “Impacto de Twitter en la comunicación y promoción institucional de las universidades", en Pixel-Bit. Revista de Medios y Educación, No. 43, julio; páginas 139 a 153; recuperado el 24 de febrero de 2016 de: dx.doi.org/10.12795/pixelbit.2013.i43.10

Ibáñez-Cuenca, J.A. y Baraybar-Fernández, A. (2011): "Fuentes 2.0 y periodistas. Transformaciones en la comunicación museística" en El profesional de la información, v. 20, n. 6, páginas 634 a 638.

Jenkins, H. (2003): “Transmedia Storytelling”, en MIT Technology Review. Massachusetts: The MIT Press, January, recuperado el 5 de noviembre de 2015 de: http://www.technologyreview.com/news/401760/transmediastorytelling $/$

Küster, I, Hernández, A. (2013): "De la Web 2.0 a la Web 3.0: antecedentes y consecuencias de la actitud e intención de uso de las redes sociales en la web semántica", en Universia Business Review, núm. 37, 2013, pp. 104 -119; recuperado el 24/2/2016, de http:/ / www.redalyc.org/articulo.oa?id $=43325648006$ http://recyt.fecyt.es/index.php/EPI/article/view/epi.2011.nov.05

Kwak, H., Lee, C.; H Park y Moon, S. (2010): "What is Twitter a Social Network or a News Media?” Paper presentado en la International World Wide Web Conference Commitee (IW3C2), April 26-30, Raleigh, North Carolina, USA; recuperado el 24/2/2016 de: http://www.eecs.wsu.edu/ assefaw/CptS580-06/papers/2010www-twitter.pdf

Laswell, H. (1949): "The structure and function of Communication in society", en L Bryson (Ed) The communication of ideas. Oxford, England: Harper, pp. 37-51.

Mancera Rueda, A. y Pano Alamán, A. (2013): “Nuevas dinámicas discursivas en la comunicación política en Twitter", en Círculo de 
Lingüistica Aplicada a la Comunicación, No. 56, páginas 53 a 80; recuperado el 24 de febrero de 2016 de:

https://revistas.ucm.es/index.php/CLAC/article/download/43867 $\angle 41468$

Marañón, O. (2012): “The language as a reference for oral translation of speech to the digital environment: a multimedia and interactive space", en Revista de Comunicación Vivat Academia, Sept., Año XIV, N ${ }^{\circ}$ 120, pp. 65-79; recuperado el 24 de febrero de 2016 de:

www.vivatacademia.net/h/numeros/n120/PDFs/N120-4.pdf

Museo Thyssen-Bornemisza (2013): \#Thyssen140. Madrid:

Departamento de Publicaciones del Museo Thyssen-Bornemisza.

Purita, G. (2015): Estudio OBS Social 2015: Análisis de las tendencias de uso y participación en las redes sociales a nivel mundial en España; recuperado el 24 de febrero de 2016 de:

http://cdn2.hubspot.net/hubfs/342810/O-

$\mathrm{PM} /$ Informes/Investigacin OBS. Social Media 2015.pdf?t $=14478$

72402711\&utm source $=$ hs automation\&utm medium $=$ email\&utm content $=23065031 \&$ hsenc $=\mathrm{p} 2$ ANqtz-

9QZb9cz0fSwTfNgIiuhBTY34kB3-lH-

VR9bRnwXwlghCnERvfzOX4tKnDOGyA-

thUMrVaf1oRpatidAoQPC4BAGI1KRw\& hsmi=23065031

Ros-Diego, V. y Castelló-Martínez, A. (2012): “La Comunicación de las responsabilidad en los medios sociales" en Revista Latina de

Comunicación Social, Núm. 67; pp. 47-67; recuperado el 24/2/2016 de: http://www.revistalatinacs.org/067/art/947 UA/03 Araceli.html

Santiago, R. y Navarida, F. (2012): "La web 2.0, en escena" en Pixel-Bit. Revista de Medios y Educación, 41, página 19 a 30; recuperado el 24 de febrero de 2016 de:

http://acdc.sav.us.es/pixelbit/images/stories/a10 0064premaq.pdf

Scolari, C.A. (2011): Narrativas Transmedia: cuando todos los medios cuentan. Barcelona: Grupo Planeta.

Scolari, C.A., Jiménez, Guerrero, M. (2012): "Narrativas transmediáticas en España: cuatro ficciones en busca de un destino cross-media" en Comunicación y Sociedad, Vol. XXV, Núm. 1, páginas 137 a 163; 
recuperado el 24 de febrero de 2016 de:

http://dialnet.unirioja.es/servlet/articulo? codigo $=3954671$

The Art Newspapaer (2012): "Special Report. Visitor Figures 2011.

Exhibition \& Museum Attendance Survey", en The Art Newspaper, Section 2. $N^{\circ}$ 234, April.

The Art Newspapaer (2013): "Special Report. Visitor Figures 2012.

Exhibition \& Museum Attendance Survey", en The Art Newspaper, Section 2, Number 245, April.

The Art Newspapaer (2014): "Special Report. Visitor Figures 2013.

Exhibition \& Museum Attendance Survey", en The Art Newspaper, Section 2, Number 256, April.

The Art Newspapaer (2015): "Special Report. Visitor Figures 2014.

Exhibition \& Museum Attendance Survey", en The Art Newspaper, Section 2, Number 267, April.

Tíscar, L. (2011): "Competencia digital, nuevos medios, nuevos lenguajes, nuevos hablantes. Twitter y sus funciones comunicativas", en Revista Lenguajes y Textos, Núm. 34, diciembre, páginas 39 a 46; recuperado el 24 de febrero de 2016 de:

http:/ / dialnet.unirioja.es/servlet/articulo?codigo $=3900796 \mathrm{http}: / / \mathrm{w}$ ww.seeci.net/revista/index.php/seeci/article/viewFile/25/pdf 14

Woo Yoo, S. y Gil de Zúñiga, H. (2014): "Connecting blog, Twitter and Facebook use with gaps in Knowledge and participation", en Comunicación y Sociedad, Vol. 27 (4), páginas 33 a 48; recuperado el 24 de febrero de 2016 de: http://www.unav.es/fcom/communicationsociety/es/resumen.php?art id=511

Wu, S., Mason, W.A.,Hofman, J.M. y Watts, C.J. (2011): "Who says what to whom on Twitter". Paper presentado en la International World Wide Web Conference Commitee (IW3C2), March 28 - April 1, Hyderabad, India; recuperado el 24 de febrero de 2016 de: https://iriss.stanford.edu/sites/all/files/dsi/Duncan $\% 20$ Study $\% 20$ 1.pdf 


\title{
Las comunicaciones de marca digitales: hacia un modelo experiencial transmedia
}

\author{
María Galmés Cerezo \\ Universidad Internacional de La Rioja
}

\begin{abstract}
Forma de citar: Galmés, M. (2016): "Las comunicaciones de marca digitales: hacia un modelo experiencial transmedia", en García Santamaría, J.V. y Pérez Bahón (coord.): Los medios digitales españoles: procesos de cambio e innovación. Cuadernos Artesanos de Comunicación, CAC104. La Laguna (Tenerife): Latina.
\end{abstract}

Resumen: Los consumidores actuales buscan experiencias significativas en sus relaciones con las marcas. Los medios digitales brindan una oportunidad para crear un experiencias significativas y relevantes para los consumidores actuales. Hay marcas que han visto una oportunidad en las comunicaciones digitales para mejorar las relaciones con los usuarios. La innovación en este campo se dirige hacia un modelo experiencial transmedia. En este capítulo se revisa el caso de los Doodles como una apuesta experiencial innovadora de Google, que, a su vez, otros medios digitales están aprovechando para relacionarse con los usuarios a través de comunicaciones "líquidas" y contenidos "esparcibles". Se analiza este caso con el objeto de revisar como son estas experiencias y cómo se involucran en ella diferentes medios y soportes digitales. Se aporta un marco conceptual a partir de los modelos de "Experiencia del consumidor" de Bernd H. Schmitt, y de "Narrativa Transmedia" de Carlos Scolari. A modo de hipótesis se parte de la premisa de que los Doodles, son una propuesta de comunicación experiencial en la que se involucran 
otros medios de comunicación digitales creando experiencias transmedia significativas para los usuarios. Este tipo de propuestas ayudan a las marcas a mejorar la relación con sus clientes.

Palabras clave: experiencias digitales; comunicaciones experienciales; narrativa transmedia; contenidos líquidos; experiencias de marca.

\section{Introducción}

L AS empresas de medios digitales tienen una oportunidad al poder proponer experiencias de marca a sus clientes. Las marcas, en general, se enfrentan a un cambio de paradigma en la relación con sus clientes. Los clientes buscan un tipo de relación basada en experiencias de marca significativas, ya sea en las comunicaciones o durante el consumo. En el caso del consumo mediático, las audiencias digitales también están interesadas en propuestas experienciales. no distinguen fronteras entre los diferentes medios y soportes con los que interactúan.

Los Doodles son un ejemplo de ello. Google, a través de su logotipo cambiantes que conmemora un acontecimiento, ha creado una propuesta de comunicación experiencial. La experiencia que comienza en un Doodle no finaliza en el propio buscador. Hay otros medios de comunicación digitales que entran en esta propuesta experiencial, al aparecer en el buscador de Google, a través de su estrategia de posicionamiento, generando contenidos significativos para los usuarios que hacen que continúen su experiencia transmedia a través de ellos. Es decir, los medios de comunicación digital deben aprovechar la convergencia de los media (multimedialidad), la participación activa (interactividad) y las estructuras no secuenciales (hipertextualidad) para proponer experiencias significativas a sus usuarios.

Schmitt plantea que las experiencias están formadas por "Módulos Experienciales (MEE)", y que los "Proveedores Experienciales (ExPro)" son herramientas para darle forma. Scolari, por su parte, 
desarrolla un marco teórico de la narrativa transmedia y propone el desarrollo de "experiencias transmedia".

Los responsables de la comunicación de marca de Google están apostando por acciones experienciales que les permitan compartir experiencias significativas con sus clientes. Este planteamiento, que nació en el año 1998 casi de forma casual, se ha convertido en una nueva forma de relación entre Google y sus usuarios para compartir emociones, sensaciones, pensamientos y actuaciones. Además están planteados como una ocasión para que sean también compartidas entre las propias redes de los usuarios. Por ello, los Doodles de Google suscitaron nuestro interés y se han seleccionado como objeto de análisis de comunicación experiencial.

Con el análisis realizado se ha podido observar que las experiencias que dan comienzo en los Doodles se hacen líquidas y continúan en otros soportes. Se ha detectado que en España varios periódicos digitales, se esfuerzan por estar presentes en estas propuestas de comunicación experiencial transmedia. Medios de comunicación como La Voz de Galicia, Abc o El País, se posicionan en el buscador de Google, de tal forma que cada vez que un usuario quiere ampliar la información sobre un Doodle, estos periódicos aparecen en los primeros puestos. De esta forma consiguen que el usuario pueda continuar su experiencia transmedia en el propio periódico.

La investigación se ha centrado en analizar estas comunicaciones experienciales transmedia para determinar el papel que ocupan estos periódicos digitales españoles. El objetivo principal de este capítulo es entender cómo la digitalización de los medios de comunicación es una oportunidad para proponer a los usuarios comunicaciones experienciales transmedia significativas dentro del nuevo modelo de relación con los usuarios.

Se ha considerado que los Doodles de Google pueden ser utilizados como paradigma de experiencias de comunicación transmedia que permite analizar los "Módulos Experienciales" que lo componen y revisar los "Proveedores de Experiencias". Así mismo se explora la 
implicación de la prensa digital española en estas comunicaciones innovadoras.

\section{Experiencias de marca}

Actualmente, el concepto "experiencia de marca" se utiliza de forma incipiente en el ámbito profesional. A nivel académico existen algunos autores que han investigado sobre ello. Pero quizá sean los consumidores -como plantea Lenderman (2008: 276)- los que están forzando a las marcas a formar una corriente profesional basada en el diseño de experiencias. De hecho, cada vez hay más empresas que están tratando de planificar comunicaciones experienciales. Los pioneros del marketing experiencial consideran que estamos asistiendo a un cambio de filosofía de las marcas hacia este enfoque.

En lo que respecta a las aportaciones académicas se ha considerado que Toffler (1971) vislumbró el comienzo de esta nueva corriente. Y en sus inicios destacan varios trabajos: Jensen, 1999; Oee Sullivan y Spangler, 1999; Pine y Gilmore, 1999; Petkus, 2004. Estos autores empiezan a utilizan conceptos como "Industria Experiencial" (O’Sullivan y Spangler, 1999), o "Economía de la Experiencia" (Pine y Gilmore, 1999), o "Dream society" (Jensen, 1999). Poco a poco esta nueva corriente va tomando forma y profundiza en cómo las experiencias de marca juegan un papel fundamental a la hora de apelar y satisfacer a las personas de un modo emocional y también racional. (Jackson,2005 en Berridge, 2007: 118). En el 2004 Eric Hauser, Max Lenderman, y otros profesionales del marketing, escribieron el manifiesto IXMA ${ }^{43}$. Estos expertos reivindicaban que los consumidores necesitan un nuevo tipo de relaciones con las marcas, que "deslumbren sus sentidos, lleguen a sus corazones y estimulen sus mentes"; en definitiva, que supongan una experiencia (Lenderman 2008: 39).

Schmitt (2006) ha desarrollado un marco conceptual para planificar y gestionar las experiencias de los clientes. Este marco se centra en dos

\footnotetext{
${ }^{43}$ http://www.experientialforum.com/index.php.
} 
conceptos fundamentales: Los MEE (Módulos Experienciales Estratégicos) y los Expros (Proveedores de Experiencias). Las experiencias "son sucesos privados que se producen como respuesta a una estimulación” (Schmitt, 2006: 81). Los diseñadores pueden buscar estímulos que den como resultado experiencias de los clientes y para ello deben seleccionar unos proveedores de experiencias concretos. Schmitt (2006: 81).

Los expertos en comunicaciones de marketing van asumiendo que los consumidores ya no están dispuestos a dejarse convencer por campañas de publicidad que se basan en mensajes propuestos para controlar y estimular su impulso de compra. La comunicación experiencial está preparada para esta nueva realidad. (Lenderman 2008: 39).

Schmitt sienta las bases para poder avanzar en el diseño de las experiencias de marca. Para ello plantea un modelo basado en "La Matriz Experiencial" que combina Módulos Experienciales Estratégicos (MEEs) y Proveedores de Experiencias (Expros) (Schmitt, 2006: 258). La idea de que la mente se divide en partes funcionales especializadas sirve para entender los MEE. Las experiencias pueden diseccionarse en diversos módulos o secciones, cada uno con sus estructuras y procesos. Brakus, Schmitt y Zarantonello (2009) analizan un gran número de aportaciones relativas a las experiencias. A partir de dicha revisión dividen la experiencia en cinco tipos de módulos experienciales: sensaciones, sentimientos, pensamientos, actuaciones y relaciones.

Para llegar a definir estos Módulos Experienciales se revisaron propuestas realizadas desde diversos ámbitos: desde el marketing y el comportamiento del consumidor, desde el campo de la filosofía y desde la ciencia cognitiva. Entre las aportaciones filosóficas a la idea de experiencia destacan las investigaciones realizadas por el filósofo John Dewey que analizó la experiencia como una interconexión entre los humanos y su entorno (Dewey 1922, 1925). Dewey argumentó que el conocimiento (clasificación, análisis y razonamiento de las cosas) es sólo una parte del entendimiento del mundo. Planteó, que a 
las experiencias intelectuales (resultando del conocimiento) había que añadirles otras experiencias de percepción (a través de los sentidos), de emoción y de acción. Además, consideraba que los seres humanos están fundamentalmente conectados con otras personas y que estas conexiones también forman parte de la experiencia.

También se puede destacar la clasificación realizada por Dubé y LeBel (2003) a partir de los planteamientos de Dewey. Los autores distinguen varias "dimensiones placenteras de la experiencia" Estas son: intelectual, emocional, social y sensorial o física.

Desde la ciencia cognitiva destacan las investigaciones de los "módulos mentales" que realiza Fodor. Considera que cada "modulo mental" responde a específicas entradas sensoriales y permite resolver una determinada clase de problemas (Fodor 1998).

Asimismo, dentro del campo de la ciencia cognitiva son importantes las investigaciones de Pinker (1997) que se pueden relacionar con las dimensiones de la experiencia de Dewey. Pinker identificó cuatro "módulos mentales": percepción sensorial; sentimientos y emociones; creatividad y razonamiento, y relaciones sociales. Y aunque Pinker no distingue un módulo concreto de acciones, él considera, en conjunto, las experiencias y las acciones y comportamientos motrices como parte del "modulo motor-sensorial".

Desde el campo del Marketing es destacable el trabajo de Pine y Gilmore (1999) que estudia las experiencias en el comercio minorista y en los eventos. Los autores distinguen los siguientes tipos de experiencias: estéticas (que incluye aspectos visuales, sonoros, olfativos y táctiles), educacionales, de entretenimiento y escapistas. Por lo que se va confirmando la necesidad de conceptualizar las dimensiones de la experiencia en esta dirección: sensorial/estética; intelectual/educacional; y emocional/de entretenimiento. Finalmente, en esta misma dirección pero ampliada, está la propuesta de Schmitt (1999) de las cinco dimensiones de la experiencia de marca (MEEs): sensaciones, emociones, pensamientos, acciones y relaciones. 
Se puede observar, por tanto, una gran coincidencia entre las clasificaciones de las experiencias recogidas de diversos campos de conocimiento y concluir que las cinco dimensiones de la experiencia que plantea Schmitt en sus MEEs, están estrechamente relacionadas con la clasificación de Dewey, con la idea de las experiencias placenteras de Dubé y Le Bel y con los módulos mentales de Pinker (Brakus, Schmitt y Zarantonello, 2009). Schmitt (2006) define un marco conceptual para desarrollar y gestionar las experiencias de marca que se centra en los Módulos Experienciales Estratégicos y en los Proveedores de Experiencias. Los profesionales de marketing podrán definir qué tipo de experiencias deben proporcionar para conseguir una determinada actitud y relación con la marca. Esta experiencia podrá estar basada en un único MEE, podrá ser un "híbrido experiencial" o podrá ser una "experiencia holística".

El MEE de sensaciones crea experiencias sensoriales a través de los cinco sentidos. El MEE de emociones trata de crear experiencias afectivas hacia la marca. El MEE de pensamientos apela al intelecto y tratará de crear experiencias cognitivas que resuelvan problemas y que atraigan a los clientes creativamente. El MEE de actuaciones propone generar experiencias físicas, interacciones y estilos de vida. El MEE de relaciones apela a las relaciones sociales y trata de generar relaciones optimas con su yo ideal y con otras personas. Pueden apelar a la necesidad de ser percibidos de forma positiva, a la necesidad de pertenencia grupal.

Las estrategias experienciales en la mayoría de los casos emplean "Híbridos Experienciales" que combinan dos o más MEE. Aún más, Schmitt considera que se deben crear experiencias completas que combinen los cinco Módulos: "Lo ideal sería que los profesionales del marketing se esforzaran estratégicamente para crear experiencias integradas holísticamente que posean, al mismo tiempo, cualidades de sensaciones, sentimientos, pensamientos, actuaciones y relaciones" (Schmitt, 2006: 82-90). 


\section{Contenidos transmedia}

Jenkins utiliza por primera vez el concepto "transmedia" en el año 2003, en una aportación a su trabajo en el MIT (Massachusetts Institute of Technology. Proponía un cambio de modelo hacia la de convergencia de medios, y planteaba la necesidad de que los contenidos fluyeran a través de múltiples canales (Jenkins, 2003). En este nuevo modelo cada medio tiene su papel en la construcción de una historia. Scolari habla de "una nueva forma de narrativa que se construye a través de diferentes sistemas de significación (verbal, icónico, audiovisual, interactivo, etc.)" (Scolari, 2013).

Hay otras ideas cercanas al concepto transmedia, como el término "cross-media" que Boumans utiliza para hacer referencia a contenidos que utilizan más de un medio para materializarse, que parten de una producción integrada y que son accesibles a través de diferentes dispositivos (Boumans, 2004). Por su parte Ytrebreg hace referencia a "plataformas múltiples" en relación al diseño digital y a la necesidad de utilizar diferentes medios (textuales, audiviosuales,..) y distintas plataformas (chats, blogs, redes sociales, ...).

Otro de los conceptos afines es "convergencia mediática". Salaverría considera que "Los medios deben enfrentarse al reto de la convergencia y eso exige grandes dosis de planificación, creatividad y apuesta por los profesionales" (Salaverría 2003).

Scolari (2013) destaca la necesidad de que las empresas de medios superen el paradigma "mono-media" para empezar a pensar en formato transmedia. Plantea que el paradigma de la narrativa transmedia se puede resumir en dos ideas clave: la construcción de la historia a través de diferentes espacios mediáticos y sistemas de significación y la participación de la audiencia como productora y transmisora de contenidos.

En este sentido Marshal (2004) hace referencia a la "relación transformativa" entre el usuario del medio y el medio. Plantea la capacidad de la audiencia de transformar la forma y el flujo de los 
contenidos. Esta relación transformativa es básica para entender el concepto de interactividad. La interactividad da un gran poder al usuario, aunque la sensación que pueda tener de control y poder textual tiene uno límites marcados por el diseño de dicho entorno. Para que el usuario pueda participar en la transmisión o producción de contenidos debe aprender y amoldarse a la interfaz, aprendiendo la lógica de un software o el funcionamiento de una aplicación. Actualmente estos procesos de adaptación tecnológica prácticamente son actos reflejos y se han neutralizado y prácticamente no se perciben (Scolari, 2008).

La tecnología digital ha provocado que entremos en el nuevo modelo en el que el usuario colabora en la producción y transmisión de contenidos y en la jerarquización de la información. Por ello, el modelo transmedia se concreta en que cada usuario puede tener una experiencia de comunicación diferente ya que a través de la interactuación puede manejar (con mayor o menor margen de acción) los contenidos. Además, se debería reflexionar sobre la idea de buscar un nuevo término para referirse la audiencia, ya que, como su papel ha evolucionado hacia comunidades de prosumidores en red.

Para generar experiencias transmedia satisfactorias se deben determinar las diferentes extensiones mediáticas para potenciar las ventajas específicas de cada espacio mediático. Cada medio o plataforma tiene mayores posibilidades para un tipo de experiencias: por ejemplo las redes sociales ayudan a las experiencias relacionales, los buscadores a las experiencias intelectuales, y una aplicación digital sería idónea para general experiencias más interactivas.

En el diseño de las narrativas transmedia se debe planificar dónde deben ir los usuarios. Debe existir una estructura planificada -más o menos compleja- lo suficientemente profunda para que el cliente pueda explorarla. Esta estructura debe incluir espacios en blanco que puedan ser completados o expandidos por los propios usuarios.

Para diseñar la experiencia transmedia se necesita un profundo conocimiento de las audiencias. Para ello hay que investigar sus 
perfiles sociodemográficos, psicográficos, de consumo de medios y tecnológicos. Además, es necesario localizar a los fans y a los influencers, teniendo en cuanta el papel activo de las audiencias en la generación o transmisión de contenidos.

Hay dos ideas clave en las comunicaciones transmedia, la motivación y la gestión. En estas comunicaciones se debe incluir una "llamada a la acción" en la que el usuario, a golpe de vista, tenga claro el beneficio que obtendrá por participar, y a su vez explicar claramente cómo participar de forma adecuada a su nivel de competencia tecnológica. Es igualmente importante determinar el control que se debe dar al usuario sobre la historia, y el compromiso que está dispuesta a adquirir.

En el modelo transmedia "la historia comienza en un medio pero fluye de un espacio mediático a otro como si el relato fuera líquido". Además "el objetivo de un relato periodístico transmedia es informar de la mejor manera posible a los lectores" (Sam Ford, 2007). Esto se debe hacer a partir de una adecuada combinación de medios y plataformas, ya que las conexiones entre estos espacios mediáticos son cada vez más reales.

Según Jenkins (2003) el periodismo desde la mirada transmedia, "tiene que generar un espacio para la participación activa". Considera que debe tomar muchas formas (cartas a la dirección, inteligencia colectiva para resolver problemas, newsgaming, periodismo ciudadano, y que se deben tener en cuenta todas las nuevas oportunidades que ofrece el cambio de paradigma mediático. "Esto no cambia la misión tradicional del periodismo, más bien es una realización de esa misión en un mundo que espera más oportunidades para el compromiso y la participación” (Jenkins, 2003).

Maloney (2011) resume los principios fundamentales del periodismo transmedia en tres ideas clave: la "expansión" considerada a partir de la motivación a la viralización de contenidos, la "exploración" consistente en activar la curiosidad para que la audiencia siga explorando, la "continuidad" y que hace referencia a la necesidad de 
mantener un hilo conductor a través de su expansión en la forma y en el tono aprovechando la fortaleza de cada espacio mediático, y la "sinceridad" referida al valor que aportan los diferentes puntos de vista de cada espacio mediático.

\section{Estudio del caso Doodles de Google}

Para realizar el estudio del caso se han revisado los Doodles aparecidos en el mes de octubre en el buscador de España de Google. Cada Doodle se ha diseccionado en los diferentes módulos experienciales (MEEs).

Se han observado los diferentes sistemas de significación (verbal, icónico, audiovisual e interactivo) que se utilizan (Scolari, 2013). Además, se ha analizado cómo intervienen en cada experiencia periódicos y revistas digitales que aparecían en las primeras posiciones de la búsqueda (extensión) de cada Doodle.

Cada uno de ellos se concibe como una unidad de análisis, ya que cada uno de ellos parte de un diseño que ofrece a los usuarios la oportunidad de tener una experiencia de comunicación transmedia.

Los Doodles aparecidos en el buscador de España entre el 1 de octubre y el 15 de noviembre de 2015 fueron:

- 9 de octubre: 605 aniversario del Reloj Astronómico de Praga

- 31 octubre: Copa Mundial de los Dulces Halloween 2015

- 2 de noviembre: $200 .^{\circ}$ aniversario del nacimiento de George Boole

- 6 de noviembre: 201. ${ }^{\circ}$ aniversario del nacimiento de Adolphe Sax

- 9 de noviembre: $101^{\circ}$ aniversario del nacimiento de Hedy Lamarr

\subsection{Experiencias transmedia}

\subsubsection{Sistemas de significación}

Verbal: En general en el propio Doodle no suele haber grandes textos. Siempre se incluye el nombre de la Marca Google. Únicamente se incluyen otros textos en el Doodle "Festival mundial de caramelos 
Halloween 2015" se incluyen varios textos para motivar a jugar, y el del aniversario del nacimiento de Hedy Lamarr en el que su nombre aparece varias veces. Sin embargo en los diarios digitales el sistema de significación verbal suele ser el principal, con grandes textos que desarrollan la mayor parte del contenido de la comunicación.

Icónico: Los Doodles incorporan muchos símbolos necesarios para que el usuario interactúe con el propio Doodle. Pero los diarios también incluyen símbolos que igualmente son interpretados inmediatamente por el usuario. La experiencia transmedia utiliza símbolos para compartir en redes sociales, símbolos para que el usuario pueda empezar-parar un video, o por ejemplo una lupa para que el usuario sepa que puede ampliar la información o un triángulo en medio de la pantalla para que interprete que la imagen es un video.

Audiovisual: El sistema de significación audiovisual está siempre presente en los Doodles. Como mínimo, incluyen una imagen que suele ser una ilustración contextualizada en un momento y en una historia. Hay dos en los que este sistema de significación tiene más protagonismo: el Doodle de Heydi Lamarr que utiliza un video montado con ilustraciones y música para contar su historia, y el de Halloween, que incluye ilustraciones animadas, música y otros sonidos de efectos. La experiencia líquida que continua en los diarios se enriquece con fotografías, ilustraciones y videos con imágenes filmadas y sonido.

Interactivo: Todos ellos tienen algo de interactividad, por lo que este sistema de significación está siempre presente. Por una parte esta presencia se basa en la posibilidad de ampliar la información enlazando con el buscador y entrando en otros medios digitales que hacen una propuesta de contenido. Y por otra parte, todos los doodles estimulan a compartirlos en diferentes redes sociales. En el caso del de Halloween la interactividad es todavía mucho más rica ya que se invita al usuario a jugar y se le dan todas la herramientas para que interactúe fácilmente mientras se divierte consiguiendo caramelos. Por su parte el Doodle de Heydy Lamarr ofrece la posibilidad de comenzar-parar-retrodecer o adelantar el video y marcar el propio 
ritmo de la historia. Cuando el usuario interactúa continuando la experiencia de comunicación transmedia en un diario, puede seguir interactuando abriendo videos, enlazando con ampliaciones de la información, o ampliando las imágenes.

\subsubsection{Canales}

Los Doodles se desarrollan en la página de inicio del buscador de Google en España. Cuando el usuario pincha en el Doodle o en el símbolo de ampliar información, enlaza con la página del buscador en la que aparecen las diferentes propuestas de extensiones mediáticas, como Wikipedia, o periódicos y revistas digitales. En los cinco analizados se han observado los diarios y revistas digitales que han aparecido en los tres primeros puestos. Estos han sido: La Voz Galicia, Abc, El País, El Mundo y Hola. La Voz de Galicia es el único periódico digital que ha estado en los primeros puestos del buscador todos los días. Además, ha aparecido los cinco días en el primer puesto. Es importante decir que Google publica el Doodle en el buscador hacia las 11 de la noche del día anterior, y esto permite a los periódicos elaborar la noticia y conseguir posicionarla adecuadamente a partir de una estrategia de posicionamiento orgánico.

\subsection{Módulos experienciales de los Doodles}

Módulo de Sensaciones: De los Doodles analizados esté módulo experiencial tiene espacial fuerza en el Doodle del $101^{\circ}$ aniversario del nacimiento de Hedy Lamarr, ya que incluye un montaje audiovisual a base de espectaculares ilustraciones animadas con el estilo visual de ese momento histórico y con la estética del mundo del cine del momento. Además incorpora una música ad-hoc. El Doodle de la Copa Mundial de los Dulces Halloween 2015 también tiene potencial para el estímulo sensorialmente gracias a las ilustraciones animadas, los efectos sonoros, así como la música que incorpora. En tercer lugar el Doodle del doscientos aniversario del nacimiento de George Boole, también ofrece alguna posibilidad a la experiencia sensorial ya que los colores cambiantes de las letras del logotipo pueden estimular visualmente. Los Doodles del 605 aniversario del Reloj Astronómico 
de Praga, y del $201^{\circ}$ aniversario del nacimiento de Adolphe Sax tienen un menor potencial sensorial ya que solo incorporan una imagen sin movimiento ni sonido.

Módulo de Emociones: Este módulo experiencial es difícil de observar, ya que no es posible conocer como va a sentir cada usuario en cada experiencia transmedia. Pero hay Doodles potencialmente mas emocionales ya que utilizan un mayor número de figuras retóricas e imágenes con mayor carga emocional. Este es el caso del Doodle de aniversario del nacimiento de Hedy Lamarr, o el del aniversario del nacimiento de Adolphe Sax.

Módulo de Actuaciones: En todos los Doodles está presente el módulo de actuaciones ya que todos ellos invitan al usuario a compartirlos en varias redes sociales: twitter, facebook, Google Plus, y por email. Además el usuario también puede ampliar la información. En el caso del Doodle de la Copa Mundial de los Dulces Halloween 2015 la interacción va mucho más allá y el usuario puede participar en un concurso mundial consiguiendo caramelos a través de un juego. En el Doodle de aniversario del nacimiento de Hedy Lamarr también hay algo más de experiencia interactiva al poder manejar el video decidiendo si se quiere parar, avanzar volver a 1 principio, etc.

Módulo de Pensamientos: Respecto al MEE de pensamientos o intelectual, está presente en casi todos los Doodles. En el que menos intensidad tiene es en el de la Copa Mundial de los Dulces. En el resto de los Doodles siempre se trata de despertar el interés sobre el acontecimiento que se conmemora, por ejemplo sobre quiénes fueron George Boole, Adolphe Sax o Hedy Lamarr y qué hicieron de especial. El que más información incorpora en el propio Doodle es el del aniversario del nacimiento de Hady Lamarr. Lo más interesante de los Doodles en relación a este módulo es que invitan siempre a una experiencia intelectual transmedia al enlazar de forma directa con los espacios digitales que mejor amplíen la información.

Módulo de Relaciones: Los Doodles siempre hacen una propuesta en la que este módulo está presente y lo que aportan es una forma fácil de 
compartirlo con sus redes. Sin embargo, las posibilidades relacionales de las comunicaciones digitales pueden ir más allá invitando a los usuarios ha hacer cosas de forma colectiva $\mathrm{O}$ a intercambiar información. En el caso del Doodle de la Copa Mundial de los Dulces se ofrece un paso más en este sentido, ya que al compartir en redes la información se invita a participar en un equipo concreto para poder ganar de forma colectiva.

\subsection{Análisis de la experiencia transmedia}

Las experiencias en el periódico digital La Voz de Galicia: En este medio digital la experiencia de comunicación transmedia se enriquece en todos los casos analizados. En especial la propuesta sensorial es muy interesante ya que incluye videos altamente sensoriales con imágenes y audios potentes y de gran calidad. Por supuesto, y al igual que el resto de los periódicos, siempre existe la posibilidad de mejorar la experiencia intelectual con un amplio contenido textual y con videos informativos de calidad. Los enlaces que se hacen en el texto suelen estar realizados a contenidos de calidad en general en formato textual. Además los titulares que se utilizan son relevantes y suelen intrigar. El módulo de actuaciones también se amplía porque el usuario puede seguir enlazando con diferentes contenidos y puede manipular los videos y ampliar las imágenes. El módulo de relaciones se enriqueces porque ofrece la posibilidad de comentar.

Las experiencias en el periódico digital $A b c$. Cuando $A b c$ aparece en los primeros puestos suele destacar porque su propuesta emocional es mas fuerte que en otros periódicos digitales. Los títulos que utiliza como "Muerte, lujuria, avaricia y vanidad, todo junto en el reloj astronómico de Praga" suelen estar junto a una imagen con alto contenido emocional que se superpone de forma retórica. También suele enriquecer la propuesta intelectual con un amplío contenidos textual y ofrece la posibilidad de seguir ampliándolo con enlaces en el cuerpo de texto y algunos enlaces redactados para crear intriga como "doce secretos de Praga que probablemente no conoces." 
El módulo de actuaciones tiene la misma dimensión que en el resto de los medios: ampliación de información, manipulación de videos, y ampliación de fotografías. El módulo de sensaciones no suele ser especialmente fuerte en el $A b c$, salvo en el caso de Hoy Cinema en el que se incluye un video de gran calidad y potencial sensorial. En este caso, además gran parte del contenido informativo se desarrolla a través de este video y hace mucho más atractiva la experiencia que en los otros casos de $A b c$ en los que el cuerpo de texto resulta demasiado largo. El módulo de relaciones se enriquece en el momento en que el usuario puede hacer un comentario y compartir sus ideas con otros usuarios.

Las experiencias en el periódico digital El Pais: En los tres casos en los que El País se ha colocado en los primeros puestos, su propuesta transmedia enriquece la experiencia en su módulo de pensamientos. Suele utilizar un video en primer plano pero cuando el usuario pincha aparece publicidad que no puede saltarse y está obligado a ver. También se incluyen algunas imágenes y aparecen en el cuerpo de texto enlaces a otras extensiones mediáticas. Hay un apartado de "mas información" en el que los enlaces son contenidos del propio periódico que guarda algún tipo de relación. El módulo de actuaciones, al igual que en el resto de los periódicos digitales se representa en la posibilidad de ampliar información y marcar el ritmo de los videos.

La experiencia en la revista digital Hola: La propuesta sensorial no es especialmente fuerte en el único caso analizado. Sin embargo el Módulo Emocional tiene mas fuerza porque se relaciona Halloween con las celebrities. Utiliza un titular connotativo "Piratas, calabazas y hasta un 'teletubbie': ¡Las 'celebrities' ya están listas para Halloween”, junto a imágenes de famosas disfrazadas de Halloween. El módulo de actuaciones no se enriquece ya que no hay ninguna posibilidad de interactuar con el contenido. El módulo de relaciones se enriquece al poder hacer un comentario, pero no parece que estimule a ello ya que nos aparece ningún comentario. 
La experiencia en el periódico digital El Mundo: La experiencia en el único caso analizado de El Mundo no enriquece nada más que el MEE intelectual con un texto que amplia información sobre el significado de Halloween. Se hace una alusión directa al Doodle. Los módulos de actuaciones y de relaciones no enriquecen la experiencia de esta unidad de análisis.

\section{Los Doodles de Google: Experiencias Transmedia}

Los Doodles son comunicaciones experienciales digitales que comienzan en el buscador pero que continúan en otros medios digitales. Por ello, hay periódicos digitales españoles, que de forma recurrente, a través de su estrategia de posicionamiento natural en el buscador de Google, se posicionan en los primeros puestos cuando hay un Doodle. Esta acción se desarrolla para poder conseguir usuarios que lleguen a ellos a través de una experiencia transmedia que ha comenzado en el Doodle.

Se observa una gran diferencia entre las propuestas de los medios digitales que solo quieren conseguir visitas aprovechando las búsquedas que genera cada Doodle, y los que quieren ofrecer una oportunidad para enriquecer las experiencias transmedia de sus clientes.

Las empresas que operan en entornos digitales, pueden diseñar comunicaciones experienciales transmedia, o incluso pueden tener una estrategia para introducirse en experienciales de comunicación diseñadas por otros medios. Pero son los usuarios los que deciden cómo será su experiencia. Por ello el medio digital tiene que conseguir motivarle a continuar la experiencia en su espacio mediático, y para ello debe hacer una propuesta interesante $y$ significativa para el usuario.

Los periódicos digitales pueden enriquecer la experiencia transmedia en cualquiera de sus módulos experienciales. Pueden incluir material audiovisual que eleve la estimulación sensorial. Pueden ampliar de forma atractiva los contenidos que ayuden al usuario a aprender algo nuevo o que despierten su curiosidad. De esta forma se enriquecerá la 
experiencia intelectual. Además es posible ampliar el módulo experiencial de actuaciones invitando a los usuarios a realizar alguna actividad para mejorar su experiencia, como enlazar con otros contenidos, manipular un video o incluso jugar. Respecto al módulo de Relaciones hemos detectado que tanto en los Doodles, como en las propuestas de los periódicos digitales se está desaprovechando la posibilidad de mejorar la experiencia y de fidelizar a los clientes. Las experiencias transmedia se caracterizan por la participación de los usuarios en la producción y la difusión de los contenidos. Las experiencias que se han analizado estimulan a las audiencias a compartir los contenidos, pero en ninguno de los casos invitan a participar en la producción colectiva de nuevos contenidos.

Por ello se concluye que en el caso de los Doodles, los periódicos digitales están enriqueciendo la experiencia mejorando en todos los casos el Módulo intelectual y el de actuaciones, en algunos el sensorial y el emocional, pero el módulo relacional en ningún caso invita a los usuarios a producir un contenido colectivo y potenciar así su papel de prosumidor.

\section{Bibliografía}

Berridge, G. (2007): Events Design and Experience. Oxford: Elsevier Buterworf-Heinemann.

Boumans, J. (2004): “Cross-media E-Content Report”. Series of EContent Reports ACTeN.

Carù, A. y Cova, B. (2003): "Revisiting Consumption Experience", en Marketing Theory, vol.3, $\mathrm{n}^{\circ}$ 2. P. 273.

Dubé, L. y LeBel, L. (2003): "The Content and Structure of Laypeople's Concept of Pleasure", Cognition and Emotion, 17 (2), pp. 263-95.

Fodor, J. (1998): In Critical Condition: Polemic Essays on Cognitive Science and the Philosophy of Mind. Cambridge: Bradford Books/MIT Press. 
Ford, S. (2007): “Transmedia Journalism: A story-Based Approach to convergence" en Weblog Archives MIT, Abril del 2007. Recuperado el 15/11(2015 de www.convergenceculture.org/weblog/2007/04/transmedia jou rnalism a storyb.php

Galmés, M. y Victoria, J.S. (2010): “Experiencia y eventos. La creación de experiencia de marca a partir de la organización de eventos. El caso español". AD Research. Vol. 5. ESIC, pp. 64-78.

Gennette, G. (1997): Paratext Tresholds of interpretation. London: Cambridge University Press.

Jenkins, H. (2003): “Transmedia Storytelling”. MIT Technology Review. Massachusetts: The MIT Press. Recuperado de http://www.technologyreview.com/articles/wo jenkins011503 .aspSchmitt, B. H., Brakus, J. y Zarantonello. L. (2009): “Brand Experience: What is It? How do We Measure It? And Does It Affect Loyalty?". Journal of Marketing, Vol. 73, No. 3, Columbia

Lenderman, M. (2008): Marketing Experiencial. La Revolución de las Marcas. Madrid: ESIC.

Locke, C., Levine, R., Searls, D. y Weinberger, D. (1999): The Cluetrain Manifesto: The End of Business as Usual. Kindle Edition.

Maloney, K. (2011): Porting Transmedia Storytelling to Journalism. Tesis Doctoral, University of Denver.

Marshall, D. (2004): New Media Cultures. Oxford University Press. New York.

Masterman, G. y Wood, E. (2008): “Event Marketing: Measuring an experience". Venice: $7^{\text {th }}$ International Marketing Trends Congress - Jan $17^{\text {th }} / 19^{\text {th }}$. O ${ }^{\text {ee }}$ Sullivan, E. y Spanfler, K. (1999): Experience Marketing: Strategies for the New Millenium. Ed. Venture.

Petkus, E. (2004): "Enhancing the application of experiential marketing in the arts", en International Journal of Nonprofit and Voluntary Sector Marketing, no 9 (1), pp. 49-56. 
Pine, J. y Gilmore, J. (1999): The Experience Economy. Cambridge: Harvard Business School Press.

Pinker, S. (1997): How the Mind Works. New York: Norton.

Salaverría, R. (2003): “Convergencia de los medios". Chasqui Revista Latinoamericana de Comunicación $\mathrm{n}^{\circ}$ 81. Centro Internacional de Estudios Superiores de Comunicación para América Latina. Quito.

Scolari, C.A. (2008): Hipermediaciones: elementos para una teoría de la comunicación digital interactiva. Editorial Gedisa.

Scolari, C.A. (2013):"Narrativas Transmedia: Cuando todos los medios cuentan”, Austral Comunicación, vol. 2, no 2, páginas. 247-249.

Schmitt, B.H. (2006): Experiential marketing: cómo conseguir que los clientes identifiquen en su marca sensaciones, sentimientos...relaciones. Barcelona: Deusto.

Ytreberg, E. (2009): "Extended liveness and eventfulness in multiplatform reality formats", New Media \& Society, 2009, vol. 11, n 4, pp. 467-485.

Wohlfeil, M. y Whelan, S. (2005): "Event Marketing: When Brands Become Real Lived". En Experiences. Proceedings of Irish Academy of Management Conference, Galway-Mayo Institute of Technology. 


\section{A \\ Coordinación}

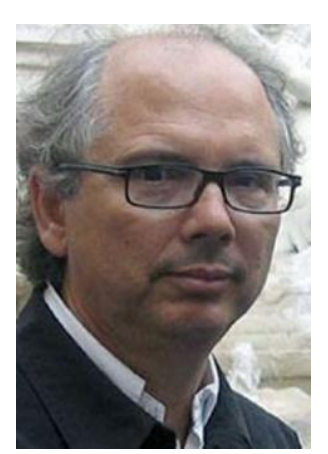

\section{José Vicente García Santamaría}

Profesor del Departamento de Periodismo y Comunicación Audiovisual de la Universidad Carlos III de Madrid, donde coordina la asignatura de Estructura, y es profesor del Máster de Comunicación Institucional y Política. Licenciado en Periodismo y en Comunicación Audiovisual por la Universidad Complutense y doctor en Ciencias de la Comunicación por la Universidad Rey Juan Carlos. Director de investigación del Instituto para la Innovación Periodística (2IP). Es miembro del equipo de investigación PASEET de la Universidad Carlos III y del grupo de investigación del proyecto del Plan Nacional I+D CS0201452283-C2-1-P, financiado por el $\mathrm{M}^{\mathrm{o}}$ de Economía y Competitividad (MINECO).

Ha ampliado estudios de dirección empresarial en el IESE. Cuenta con una dilatada experiencia profesional como consultor en marketing y comunicación y ha trabajado también en la Dirección de Comunicación de BBVA. Profesor visitante en el Instituto Francés de Prensa (Universidad Paris II) y en la LUMSA (Roma) y profesor investigador en la Universidad de Sheffield (Reino Unido).

Sus más recientes publicaciones son: El negocio de la prensa digital (cord.) (UNIR, 2014) La exbibición cinematográfica española, cincuenta años de cambio (Editorial Cátedra, 2015) y Grupos multimedia en España: análisis y estrategias (Editorial UOC, 2016). Cuenta también con treinta artículos académicos en revistas de impacto y alrededor de veinte capítulos de libro. 


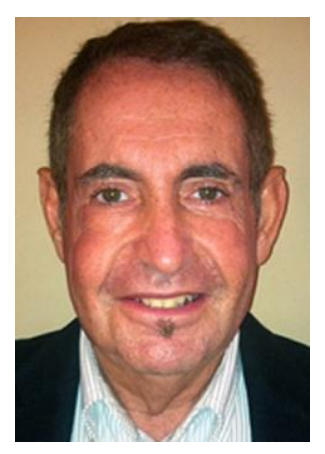

\section{Félix Pérez Bahón}

Doctor en Periodismo por la Universidad Complutense, ha trabajado durante 35 años en medios impresos españoles de distinto tipo. Es profesor asociado en la Universidad Carlos III de Madrid desde 2004. También ha impartido clases en el Centro Villanueva, vinculado a la Universidad Complutense. Investigador del Instituto para la Innovación Periodística 2IP y del UNIR Research, con registros independientes.

Forma parte del Grupo de Investigación y Análisis de Internet en el Periodismo (GIAIP), de la Universidad Complutense, y también del Grupo Big Data, Redes Sociales y Periodismo de Datos, de la Universidad Carlos III. Responsable del área de 'Tendencias en Periodismo', en la revista profesional de la Asociación de la Prensa de Madrid (APM) 'Cuaderno de Periodistas'.

\section{Autores}

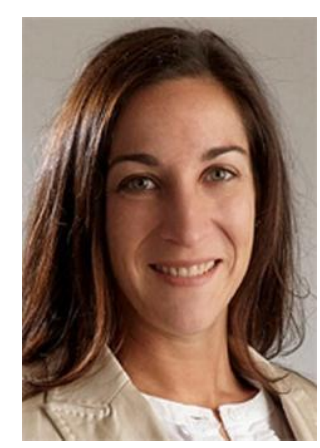

\section{Gema Alcolea Díaz}

Doctora en Ciencias de la Información (Universidad Complutense de Madrid), Segundo Premio Nacional de Fin de Carrera de Educación Universitaria y Premio Extraordinario de Licenciatura. Profesora en el departamento de Ciencias de la Comunicación y Sociología de la Universidad Rey Juan Carlos. También lo ha sido del departamento de Comunicación Audiovisual del CES Felipe II de Aranjuez (UCM). Miembro del grupo de investigación en Estructura, Historia y Contenidos de la Comunicación (GREHCCO) de la Universidad de Sevilla. Participa en el proyecto de $\mathrm{I}+\mathrm{D}+\mathrm{i}$ "Cultura audiovisual y representaciones de género en España: mensajes, consumo y apropiación juvenil en la ficción televisiva y los videojuegos". 
Coordinadora de Prácticas de Comunicación Audiovisual (CES Felipe II). Autora de libros de investigación (entre otros La televisión digital en España o Una semana sin televisión en el siglo XXI), coautora en obras colectivas (como Preparing for the future: studies in communication sciences in the EHEA o La dinámica periodística. Perspectiva, contexto, método y técnicas) y de artículos de investigación en revistas como Telos y Estudios sobre el Mensaje Periodístico, dentro del área de la Empresa Informativa, donde es especialista.

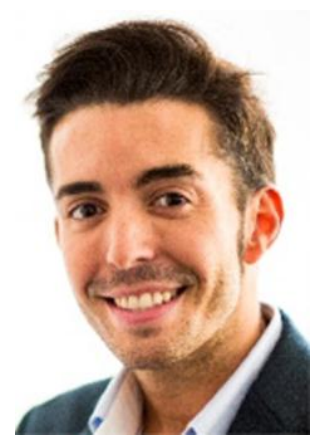

\section{David Cordón Benito}

Licenciado en Periodismo y Doctor Internacional en Periodismo por la Universidad de Navarra. Master of Arts (MA) in Museum Studies por la University of Leicester (Reino Unido). Ha trabajado como profesor de Comunicación Institucional, Relaciones con los Medios y Teoría y Técnica de las Relaciones Públicas.

Ha colaborado en diversos medios de comunicación como Diario La Rioja y Onda Cero. Además, ha desarrollado gran parte de su labor profesional en Gabinetes de Comunicación de diversas instituciones como la Cámara Oficial de Comercio e Industria de La Rioja y el Victoria and Albert Museum de Londres (V\&A).

Es miembro de varios grupos $\mathrm{I}+\mathrm{D}+\mathrm{i}$ financiados por el Gobierno de España. Actualmente dirige el Grado de Comunicación de la Universidad Internacional de La Rioja (UNIR), y sus líneas de investigación se centran en la comunicación institucional aplicada a museos y la función de las relaciones públicas en las comunidades.

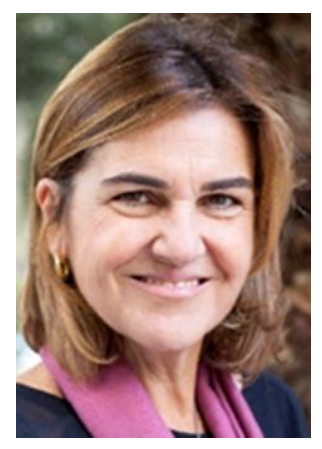

\section{María Galmés Cerezo}

Doctora en Ciencias de la Comunicación por la Universidad de Málaga. Titulo Superior de Marketing en Internet por la Escuela Superior de Gestión Comercial y Marketing ESIC. Profesora asociada en varias universidades en Grados y Másters de comunicación y publicidad. Coordinadora académica del master universitario en marketing digital y comercio electrónico 
de la Universidad Internacional de La Rioja. Ha publicado varios artículos en revistas científicas indexadas y ha asistido como ponente a varios congresos internacionales. Su principal línea de investigación es la comunicación experiencial de las marcas. Forma parte del grupo de investigación Grupo PROCOMM Comunicación Multimedia, Marketing Experiencial y Publicidad, de la Universidad Internacional de La Rioja.

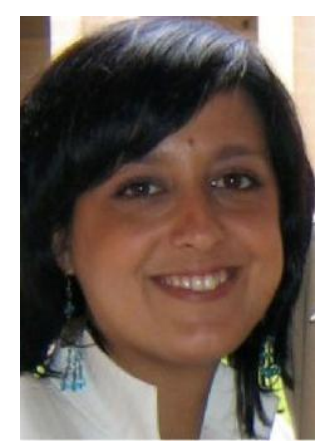

\section{Lidia Maestro Espínola}

Licenciada en Publicidad y Relaciones Públicas y doctora en Ciencias de la Comunicación por la Universidad Rey Juan Carlos de Madrid, Máster en cine, Televisión y medios interactivos y MBA por la EOI.

Es profesora del grado de Comunicación, grado de Marketing y Máster en la Universidad Internacional de La Rioja (UNIR). Actualmente dirige el grado de Marketing y Comercio Internacional y el Máster de Publicidad Integrada: Estrategia y Creatividad de la Universidad Internacional de La Rioja. Su trayectoria y producción científica se vincula al estudio de la economía de los medios y, específicamente, en sus estrategias como soportes publicitarios. Ha publicado artículos en revistas nacionales e internacionales, así como diversos capítulos de libro. Forma parte del grupo de Investigación del Instituto para la Innovación Periodística.

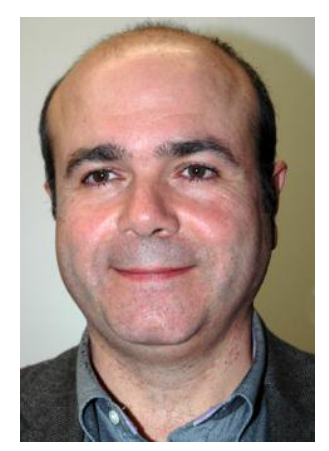

\section{Fernando Peinado-Miguel}

Profesor Titular de Universidad en el Departamento de Periodismo IV (Empresa Informativa) en la UCM. Imparte docencia en Grado y Posgrado de Periodismo. Investigador Principal del grupo complutense de investigación "Research and Learning of Media and Communications Management" (MediaCom UCM). Ha coordinado los contenidos del proyecto MEDIA Prensa, en el programa de Recursos Educativos en Línea del Ministerio de Educación, Cultura y Deporte. Miembro del claustro 
docente del Master de RNE-UCM. Miembro de diferentes colectivos profesionales y académicos como la AE-IC, ECREA, ProCom, APMD.

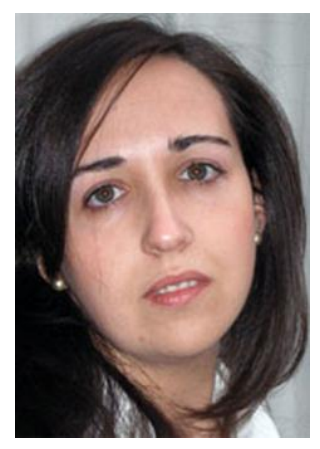

\section{María José Pérez Serrano}

Licenciada en Periodismo, doctora en Ciencias de la Información por la Universidad Complutense de Madrid, Premio Extraordinario de Doctorado 20062007 y MBA con la especialidad de Gestión Financiera. Es profesora del Departamento de Periodismo IV (Empresa Informativa) de la Universidad Complutense de Madrid y miembro del grupo de investigación Research and Learning of Media and Communications Management (MediaCom UCM). Ha pertenecido, entre otros, al cuerpo docente de la Universidad San Jorge, de la Universidad Pontificia de Salamanca y del Instituto de Postgrado y Formación Continua de la Universidad Pontificia de Comillas (ICADE).

Su trayectoria y producción científica se vincula al estudio de la Empresa Informativa y, específicamente, a la concentración de medios de comunicación y su influencia en el pluralismo. Entre sus publicaciones destacan el libro La concentración de medios en España. Análisis de casos relevantes en radio prensa y televisión, así como artículos de investigación en revistas académicas nacionales e internacionales, capítulos y comunicaciones en congresos en los ámbitos científicos antes citados.

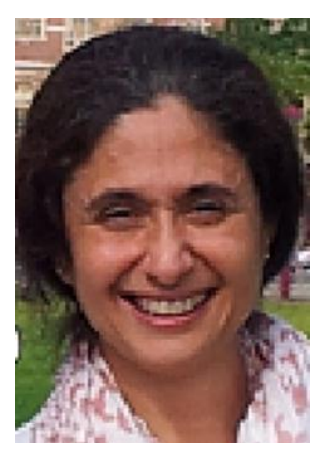

\section{Dolores Rodríguez Barba}

Doctora en Ciencias de la Información por la UCM. Docente en el Grado y Master de Periodismo con especialidad en Organización y Gestión de Empresas de Comunicación. Su trayectoria profesional se ha desarrollado en TVE en las áreas de producción y coordinación internacional. Después, pasó a formar parte de diferentes proyectos radiofónicos, hasta la creación de Europa FM, del Grupo AtresMedia, donde fue responsable de la Secretaría General Técnica de la Cadena. Como investigadora, forma parte del Grupo MediaCom UCM. Ha participado en varios proyectos $\mathrm{I}+\mathrm{D}+\mathrm{i}$; publicado en diferentes 
revistas científicas de impacto como El Profesional de la Información, Revista Latina de Comunicación Social, Razón y Palabra, Icono 14 o Mediterránea; y dirigido varias tesis doctorales referidas al desempeño profesional, tanto en prensa, como en radio y televisión con diferentes enfoques: desde la perspectiva de género, las situaciones de crisis o la gestión de contenidos. Fue co-autora del Informe Anual de la Profesión Periodística de la Asociación de la Prensa de Madrid desde el año 2006 hasta 2011; de "Nuevos Modelos de Negocio para la Radio" en Radio 3.0, una nueva radio para una nueva era; de la Guía de Publicaciones gratuitas en Madrid (Madrid Emprende, 2009); coeditora y autora de La Radio y la Televisión en la Europa digital (Madrid: UCM, 2005); y autora de diferentes artículos sobre innovación educativa, empresas periodísticas, radio, televisión y perfiles profesionales en comunicación en diversas revistas científicas de impacto reconocido. Es miembro de la AE-IC, miembro de la ECREA y miembro fundadora de OCENDI.

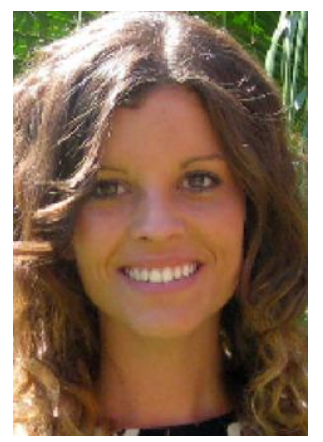

\section{Miriam Rodríguez Pallarés}

Doctora en Periodismo por la UCM, Master en Periodismo por la misma universidad y Diplomada en Biblioteconomía y Documentación (USAL). Miembro del grupo de investigación MediaCom UCM y, desde el año 2010, Colaboradora Honorífica del Departamento de Periodismo IV (Empresa Informativa) de la Facultad de Ciencias de la Información de la UCM. Imparte docencia en la USJ y en la UNIR. Actualmente, su producción científica se desarrolla en el ámbito de la gestión de activos intangibles (contenidos y conocimiento) en el entorno de los medios de comunicación de masas, además, está involucrada en proyectos de investigación vinculados al estudio del contexto metodológico, didáctico y profesional en el campo de las Ciencias de la Comunicación, así como al análisis del salto digital desarrollado por los medios de comunicación y las estrategias de campañas políticas en España. 


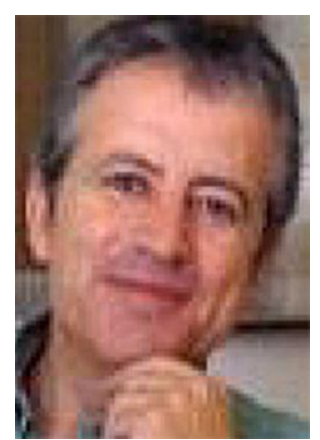

\section{Juan Yunquera Nieto}

Profesor de Periodismo de la Universidad Carlos III de Madrid desde el año 2001. Licenciado en Ciencias de la Información (Periodismo) por la Universidad Complutense de Madrid. Se doctoró en la Universidad Carlos III en Investigación en Medios de Comunicación con la tesis cum laude "Desarrollo de las publicaciones digitales y nuevos soportes informativos: Historia y evolución de las revistas y diarios digitales en España”.

Pertenece al Grupo de Investigación PASEET. Sus principales líneas de investigación son el periodismo, el diseño editorial, las publicaciones digitales, las tecnologías aplicadas a los nuevos soportes informativos y la publicidad. Autor del libro: Revistas y diarios digitales en España. Historia de una evolución. (UOCPress, 2016)

Ha desarrollado su carrera profesional en diferentes medios de comunicación: Radio Televisión Española (RTVE), Grupo Zeta (Revista Tiempo, Director de Arte), InfoLibre y colaborado en diversos medios impresos como director de arte y asesor editorial. Durante varios años ha sido el Director de Arte y Redactor Jefe de la revista "online" Digital 3, editada por el Vicerrectorado de Comunicación de la UC3M. 